$$
\begin{gathered}
\text { UNIVERSIDADE DE SÃO PAULO } \\
\text { INSTITUTO DE ASTRONOMIA E GEOFISICA } \\
\text { MESTRADO PROFISSIONAL EM ENSINO DE ASTRONOMIA }
\end{gathered}
$$

KARLINE ALVES BRANDÃO

PROPOSTA DE APRENDIZAGEM PARA O ENSINO DE ASTRONOMIA E QUÍMICA UTILIZANDO O JOGO COMO FERRAMENTA DIDÁTICA

SÃO PAULO 
KARLINE ALVES BRANDÃO

\title{
PROPOSTA DE APRENDIZAGEM PARA O ENSINO DE ASTRONOMIA E QUÍMICA UTILIZANDO O JOGO COMO FERRAMENTA DIDÁTICA
}

\author{
Dissertação apresentada ao Instituto de Astronomia, \\ Geofísica e Ciências Atmosféricas da Universidade de \\ São Paulo como requisito parcial para obtenção do \\ título de Mestre em Ensino de Astronomia. \\ Orientador: Prof. Dr. Amâncio Cesar Santos Friaça \\ Versão Corrigida. $\mathbf{O}$ original encontra-se disponível na \\ Unidade.
}

\section{SÃO PAULO}


"O número de átomos em uma única molécula de DNA é comparável ao número de estrelas em galáxias. Cada um de nós é um pequeno universo"

Neil de Grasse Tyson. 


\section{AGRADECIMENTOS}

Aos meus familiares.

Meu irmão João Kleber por ter ajudado a consertar algumas cartas no programa de computador.

Minha mãe Maria Das Dores por ter me incentivado.

Meu noivo Cicero Brandão por ter tido paciência e compreensão.

Minha filha por ter ajudado com alguns programas de design.

Aos amigos do Planetário e Cine dome de Santo André, Johannes Kepler que me ajudaram.

A professora Rachel Zuchi Faria, por ter me incentivado a fazer o mestrado.

Aos funcionários da escola Hans Grudzinski que me receberam tão bem, os professores que me ajudaram e pelos alunos que realizarão a experiência de jogar com tanto entusiasmo.

Em especial ao professor Amâncio que me ajudou com a sua orientação no momento que mais precisei.

Aos meus amigos Douglas Bezerra, Jessica Resterich e Giovana Mota que estiveram ao meu lado todo esse tempo.

"Diante da vastidão do tempo e da imensidão do universo, é um imenso prazer para mim dividir um planeta e uma época com você."

Carl Sagan 


\section{RESUMO}

A origem dos elementos químicos é um tema que praticamente não é abordado no ensino da química. Por ser um assunto de grande relevância, deveria ser melhor explorado, facilitando assim a compreensão da tabela periódica. Com base nisso, confeccionamos e aplicamos um jogo envolvendo Química e Astronomia para alunos iniciantes do ensino médio da rede estadual de São Paulo, mostrando como surgiram os elementos organizados na tabela periódica por Mendeleev. É de extrema importância que os alunos tenham conhecimento dos elementos químicos e de onde eles foram formados para que alcancem um entendimento mais amplo dentro do estudo de química. A existência e as propriedades dos elementos químicos já constituem parte corrente do currículo da educação básica, mas questionamentos sobre a origem dos elementos químicos - onde surgiram e como foram formados - em geral não estão presentes no ambiente escolar. A proposta desse projeto é trabalhar transdisciplinarmente com Química e Astronomia, enfatizando a origem dos elementos químicos. Para que o objetivo seja alcançado, utilizamos como ferramenta pedagógica os jogos didáticos, que constituem um instrumento facilitador de aprendizagem permitindo que os alunos desenvolvam não só conhecimentos, mas também habilidades e atitudes. $O$ uso do jogo como ferramenta permite alcançar um aprendizado mais significativo. Assim, os jogos didáticos são fortes aliados no processo de ensino e aprendizagem dentro de uma perspectiva de educação necessária para o mundo atual, altamente conectado e em rápida transformação, resumida nos Quatro Pilares da Educação de Jacques Delors: aprender a conhecer, aprender a fazer, aprender a viver com os outros e aprender a ser.

Palavras-Chave: Ferramentas de aprendizagem, Jogos didáticos, Ensino de Ciências, Ensino de astronomia, Ensino de química, Transdisciplinaridade. 


\begin{abstract}
The origin of chemical elements is a topic that is hardly addressed in teaching of chemistry. As it is a very relevant subject, it should be better explored, thus facilitating the understanding of the periodic table. Based on this, we designed and applied a game involving chemistry and astronomy for junior high school students of the state of São Paulo, showing how the elements organized in the periodic table by Mendeleev emerged. It is extremely important that students have knowledge of the chemical elements and where they have been formed in order to reach a broader understanding within the study of chemistry. The existence and properties of chemical elements are already part of the basic education curriculum, but questions about the origin of chemical elements - where they have originated and how they were formed - are not usually present in the school environment. The purpose of this project is to work transdisciplinarily with chemistry and astronomy, emphasizing the origin of the chemical elements. In order that this goal be achieved, we use didactic games as a pedagogical tool, which are a facilitator of learning, allowing students to develop not only knowledge but also skills and attitudes. The use of the game as a didactic tool allows to acquire a more significant learning. Thus, didactic games are strong allies in the teaching and learning process within a perspective of education necessary for the current, highly connected and rapidly changing world, summarized in the Four Pillars of Learning by Jacques Delors: learning to know, learning to do, learning to live together and learning to be.
\end{abstract}

Keywords: Learning tools, Didactic games, Science teaching, Astronomy teaching, Chemistry teaching, Transdisciplinarity. 


\section{LISTA DE TABELAS}

TABELA 1- NÚMERO DE PROFESSORES POR TIPO DE ESCOLA.........................66

TABELA 2- NÚMERO DE PROFESSORES POR NÍVEL ESCOLAR..........................66

TABELA 3-RESPOSTAS DOS PROFESSORES DO $1^{\circ}$ ANO DO ENSINO

FUNDAMENTAL

TABELA 4- RESPOSTAS DOS PROFESSORES DO $2^{\circ}$ ANO DO ENSINO FUNDAMENTAL

TABELA 5- RESPOSTAS DOS PROFESSORES DO $3^{\circ}$ ANO DO ENSINO

FUNDAMENTAL

TABELA 6- RESPOSTAS DOS PROFESSORES DO $4^{\circ}$ ANO DO ENSINO

FUNDAMENTAL

TABELA 7- RESPOSTAS DOS PROFESSORES DO $5^{\circ}$ ANO DO ENSINO

FUNDAMENTAL

TABELA 8- RESPOSTAS DOS PROFESSORES DO $6^{\circ}$ ANO DO ENSINO FUNDAMENTAL

TABELA 9- RESPOSTAS DOS PROFESSORES DO $7^{\circ}$ ANO DO ENSINO

FUNDAMENTAL

TABELA 10- RESPOSTAS DOS PROFESSORES DO $8^{\circ}$ ANO DO ENSINO

FUNDAMENTAL

TABELA11- RESPOSTAS DOS PROFESSORES DO $1^{\circ}$ ANO DO ENSINO

MÉDIO.

TABELA 12- RESPOSTAS DOS PROFESSORES DO $2^{\circ}$ ANO DO ENSINO

MÉDIO.

TABELA 13- RESPOSTAS DOS PROFESSORES DO $3^{\circ}$ ANO DO ENSINO

MÉDIO.

TABELA 14- CONCLUSÃO TOTAL DAS RESPOSTAS DOS

PROFESSORES.

TABELA 15- RESPOSTAS DOS ALUNOS DO $9^{\circ}$ ANO DO ENSINO FUNDAMENTAL (PRÉ JOGO) 84

TABELA 16- RESPOSTAS DOS ALUNOS DO $9^{\circ}$ ANO DO ENSINO FUNDAMENTAL (PÓS JOGO) 
TABELA 17- RESPOSTAS DOS ALUNOS DO $1^{\circ}$ ANO DO ENSINO MÉDIO (PRÉ JOGO)

TABELA 18- RESPOSTAS DOS ALUNOS DO $1^{\circ}$ ANO DO ENSINO MÉDIO (PÓS JOGO) 


\section{LISTA DE FIGURAS}

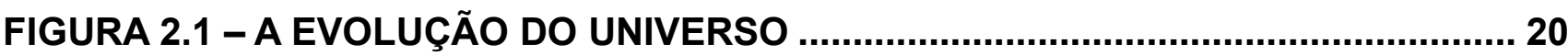

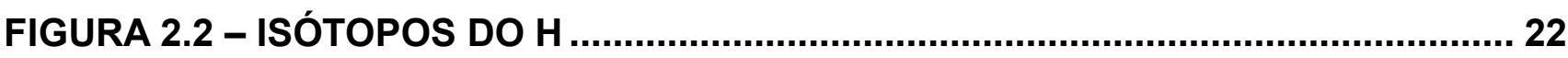

FIGURA 2.3 - ABUNDÂNCIAS DOS ELEMENTOS QUÍMICOS ..................................... 23

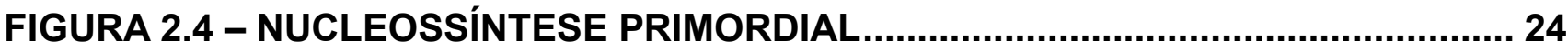

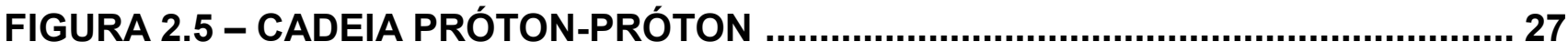

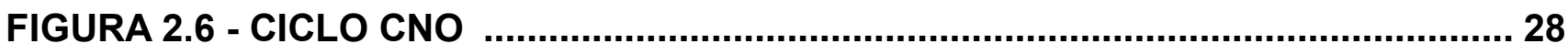

FIGURA 2.7 - REAÇÃO TRIPLO-ALFA

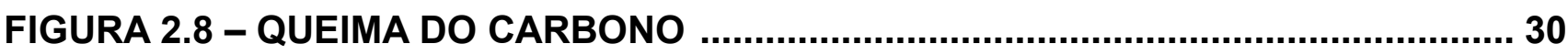

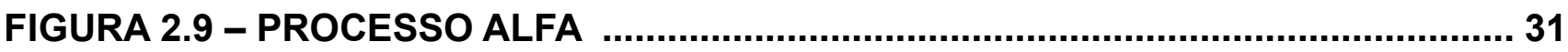

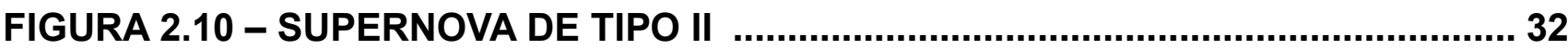

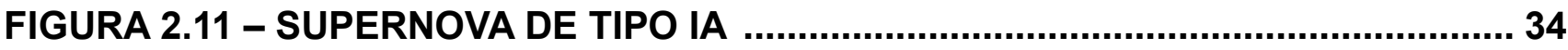

FIGURA 2.12 - ELEMENTOS DEVIDOS AOS PROCESSOS S E R …............................. 36

FIGURA 2.13 - EVOLUÇÃO ESTELAR ……................................................................ 39

FIGURA 2.14 - ESPALAÇÃO POR RAIOS CÓSMICOS …...........................................43

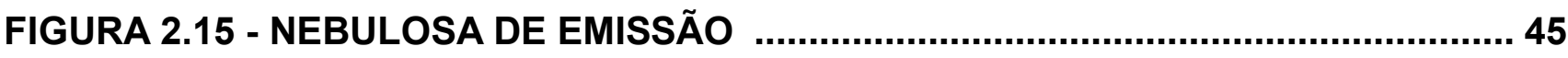

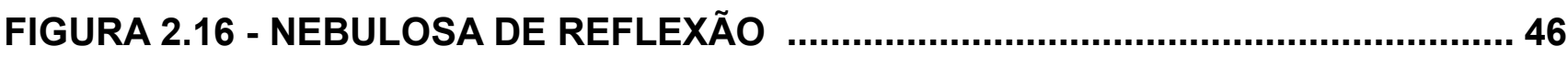

FIGURA 2.17 - NEBULOSA DE ABSORÇÃO OU ESCURA …….................................. 46

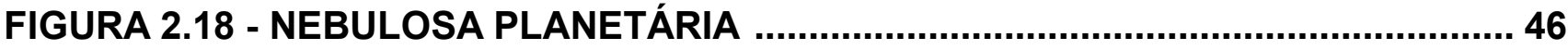

FIGURA 2.19 - REMANESCENTE DE SUPERNOVA ….............................................. 47

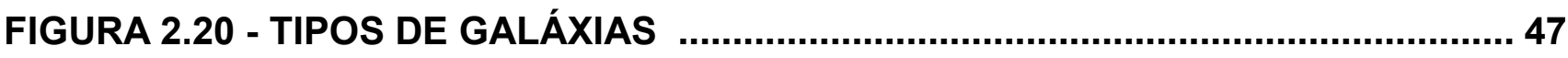

FIGURA 3.1 - TABELA PERIÓDICA DO ASTRÔNOMO ........................................... 51

FIGURA 3.2 - TABELA PERIÓDICA DO BIÓLOGO ................................................. 51

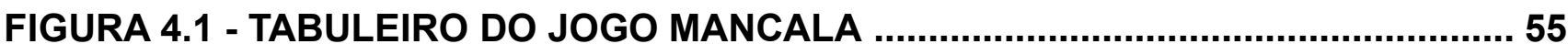

FIGURA 4.2 -TABULEIRO DO JOGO SENET ............................................................ 56

FIGURA 4.3 - GTTP (GALILEO TEACHER TRAINING PROGRAM) ..............................62

FIGURA 4.4 - OBA (OLIMPÍADA BRASILEIRA DE ASTRONOMIA E ASTRONÁUTICA) 63

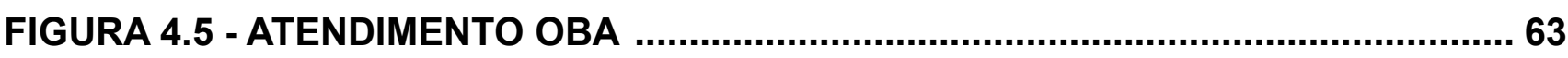




\section{LISTA DE GRÁFICOS}

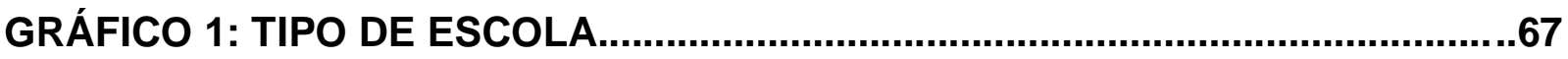

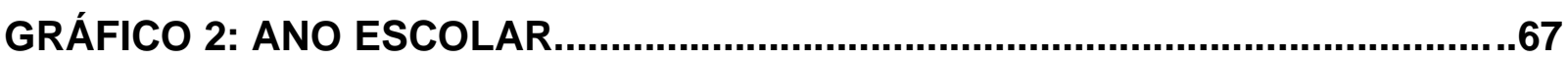

QUESTIONÁRIO 1 ANO DO ENSINO FUNDAMENTAL

GRÁFICO 3: VOCÊ TEVE ALGUMA DIFICULDADE EM APLICAR O JOGO?........68 QUESTIONÁRIO 2 ANO DO ENSINO FUNDAMENTAL

GRÁFICO 4: VOCÊ TEVE ALGUMA DIFICULDADE EM APLICAR O JOGO?........70

QUESTIONÁRIO 3 ANO DO ENSINO FUNDAMENTAL

GRÁFICO 5: VOCÊ TEVE ALGUMA DIFICULDADE EM APLICAR O JOGO?........71

QUESTIONÁRIO 4 ANO DO ENSINO FUNDAMENTAL

GRÁFICO 6: VOCÊ TEVE ALGUMA DIFICULDADE EM APLICAR O JOGO?........73

QUESTIONÁRIO 5\% ANO DO ENSINO FUNDAMENTAL

GRÁFICO 7: VOCÊ TEVE ALGUMA DIFICULDADE EM APLICAR O JOGO?........75

QUESTIONÁRIO 6 ANO DO ENSINO FUNDAMENTAL

GRÁFICO 8: VOCÊ TEVE ALGUMA DIFICULDADE EM APLICAR O JOGO?.........76

QUESTIONÁRIO 7 ANO DO ENSINO FUNDAMENTAL

QUESTIONÁRIO DIAGNÓSTICO (PRÉ-JOGO) 9 ANO DO ENSINO FUNDAMENTAL

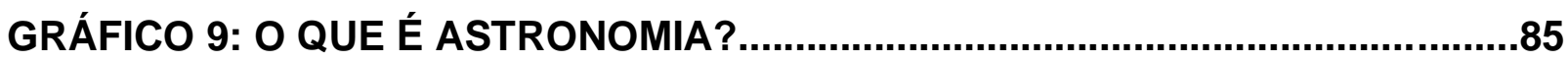

GRÁFICO 10: ONDE SURGIU A MAIORIA DOS ELEMENTOS QUÍMICOS?...........85

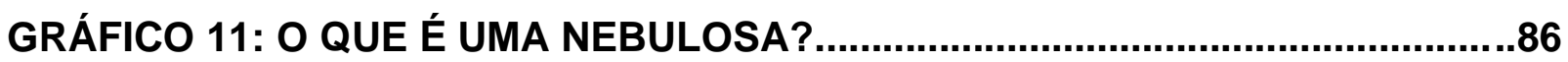

GRÁFICO 12: VOCÊ JÁ TEVE AULA COM JOGOS?............................................86

GRÁFICO 13: O QUE VOCÊ ACHA DE JOGOS COMO MEIO DE

APRENDIZADO?.

QUESTIONÁRIO DIAGNÓSTICO (PÓS-JOGO) 9 ANO DO ENSINO FUNDAMENTAL

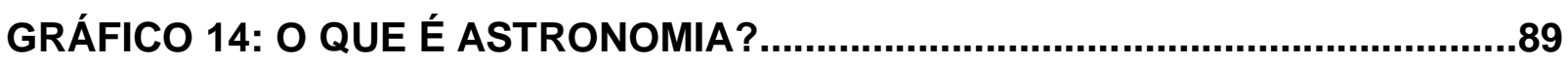

GRÁFICO 15: ONDE SURGIU A MAIORIA DOS ELEMENTOS QUÍMICOS?...........89

GRÁFICO 16: O QUE É UMA NEBULOSA? ........................................................ 90

GRÁFICO 17: VOCÊ GOSTOU DO JOGO “DE ONDE EU VIM"? ............................90 
GRÁFICO 18: O QUE VOCÊ ACHOU DO JOGO COMO MEIO DE APRENDIZADO?.

QUESTIONÁRIO DIAGNÓSTICO (PRÉ-JOGO) 1 ANO DO ENSINO MÉDIO GRÁFICO 19: O QUE É ASTRONOMIA? .94 GRÁFICO 20: ONDE SURGIU A MAIORIA DOS ELEMENTOS QUÍMICOS?...........94 GRÁFICO 21: O QUE É UMA NEBULOSA? .....................................................95 GRÁFICO 22: VOCÊ JÁ TEVE AULA COM JOGOS? ...........................................95 GRÁFICO 23: O QUE VOCÊ ACHA DE JOGOS COMO MEIO DE APRENDIZADO?. .96

QUESTIONÁRIO DIAGNÓSTICO (PÓS-JOGO) 1 ANO DO ENSINO MÉDIO GRÁFICO 24: O QUE É ASTRONOMIA? .98

GRÁFICO 25: ONDE SURGIU A MAIORIA DOS ELEMENTOS QUÍMICOS? .98

GRÁFICO 26: O QUE É UMA NEBULOSA? .99

GRÁFICO 27: VOCÊ GOSTOU DO JOGO "DE ONDE EU VIM"? 99 GRÁFICO 28: O QUE VOCÊ ACHOU DO JOGO COMO MEIO DE APRENDIZADO? 


\section{SUMÁRIO}

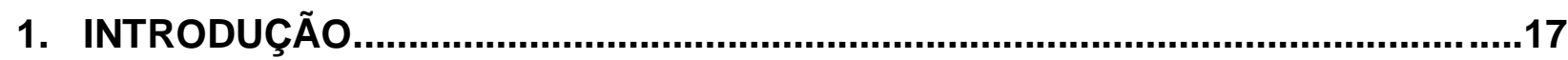

2. ORIGEM DOS ELEMENTOS E EVOLUÇÃO ESTELAR....................................20

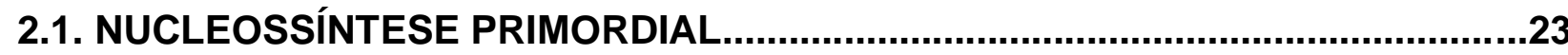

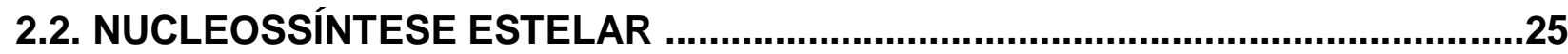

2.2.1 SEQUÊNCIA PRINCIPAL: FUSÃO DE HIDROGÊNIO EM HÉLIO....................... 26

2.2.2 TRIPLO-ALFA: FUSÃO DE HÉLIO EM CARBONO.......................................... 28

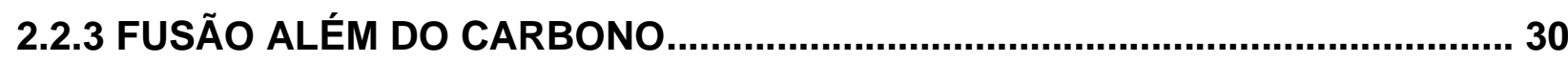

2.2.4 NUCLEOSSÍNTESE EXPLOSIVA: SUPERNOVAS TIPO II E IA ....................... 31

2.2.5 NUCLEOSSÍNTESE ALÉM DO FERRO: PROCESSO-S E PROCESSO-R ...... 34

2.2.6 NUCLEOSSÍNTESE EM FUSÕES DE ESTRELAS DE NÊUTRONS................... 37

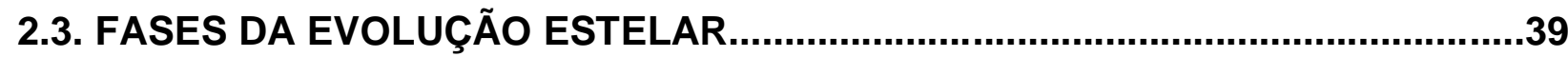

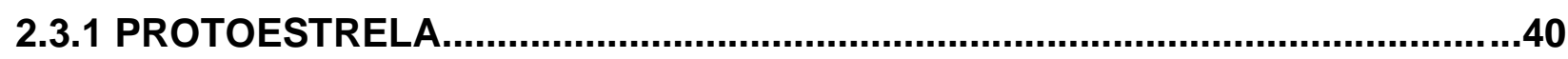

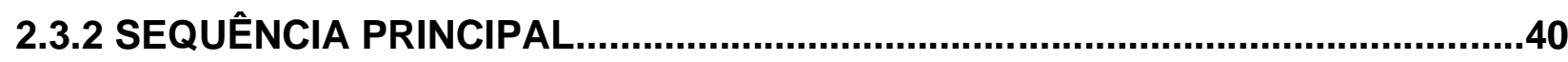

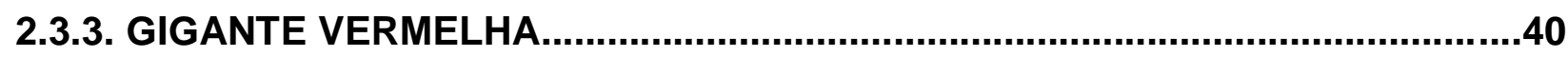

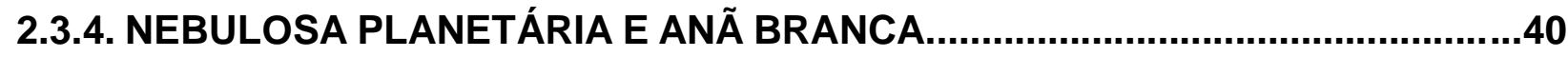

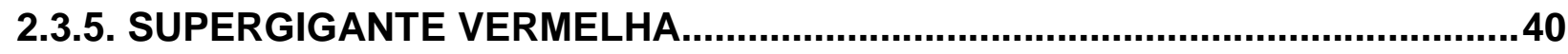

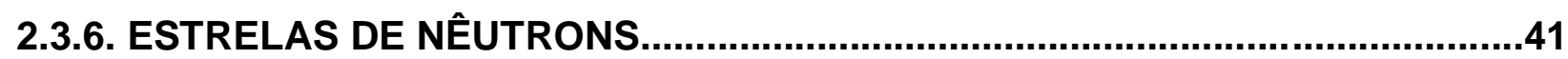

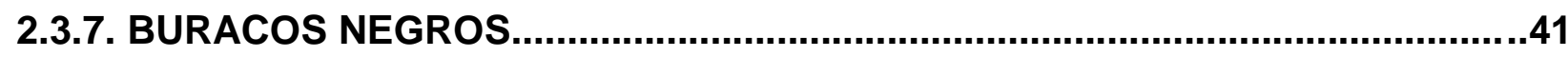

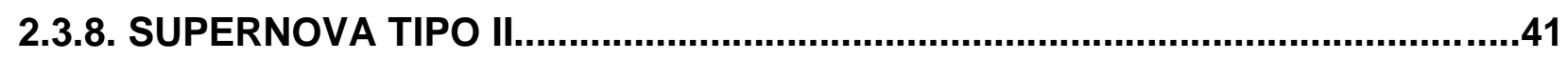

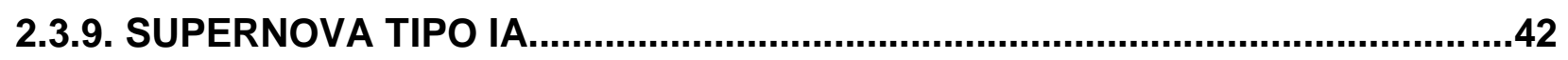

2.4. ESPALAÇÃO

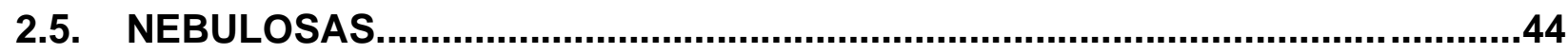

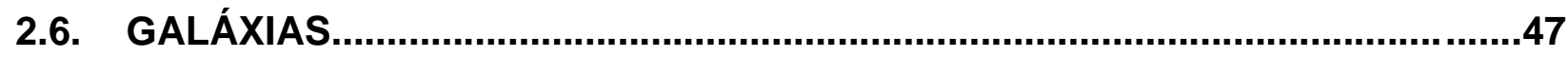

3. O PORQUÊ APRENDER SOBRE OS ELEMENTOS QUÍMICOS...........................49

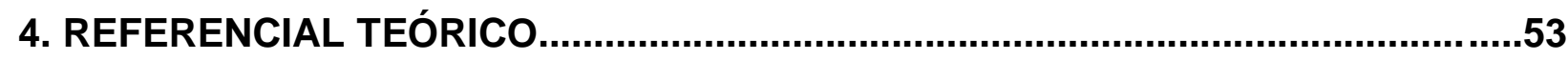

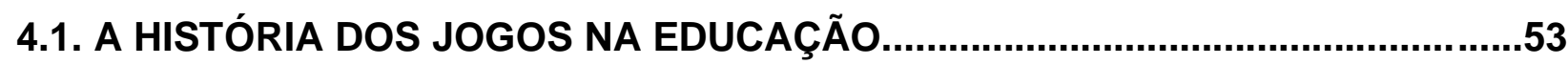

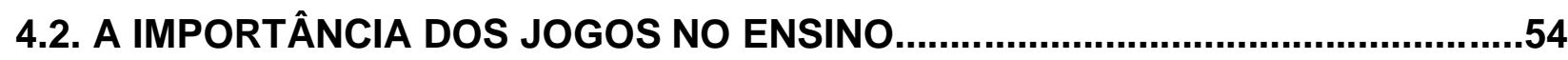

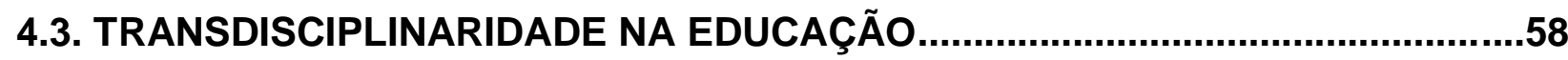

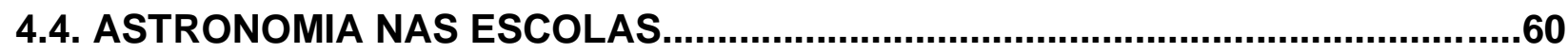

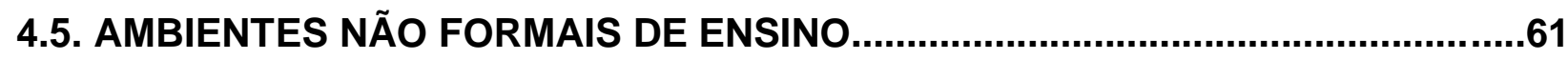


5. DADOS, ANÁLISE E DISCUSSÃO...........................................................64

5.1. QUESTIONÁRIO DIAGNÓSTICO PARA PROFESSORES.................................66

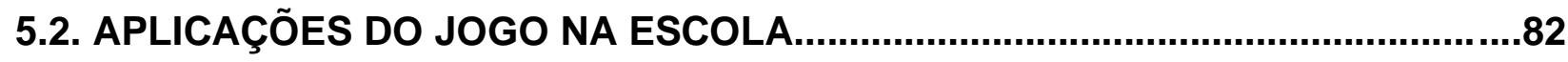

5.3. QUESTIONÁRIO DIAGNÓSTICO PARA ALUNOS DO 9 ANO FUNDAMENTAL E 10 ANO DO ENSINO MÉDIO..............................................................................84

5.4. CONCLUSÃO DOS RESULTADOS DO 9 ANO DO ENSINO

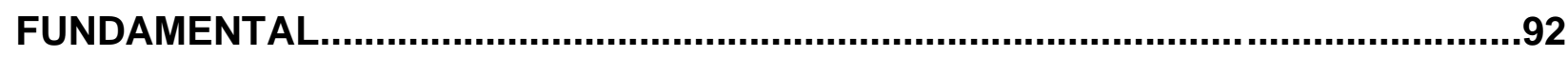

5.5 CONCLUSÃO DOS RESULTADOS DO 1ㅇ ANO DO ENSINO MÉDIO..................102

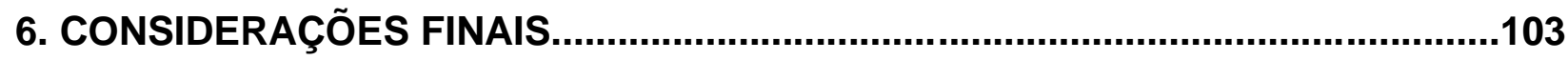

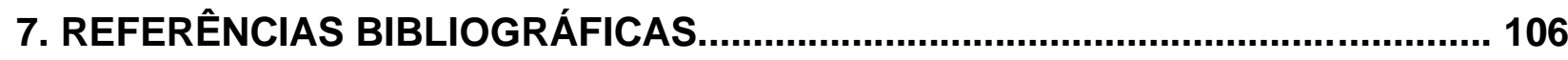

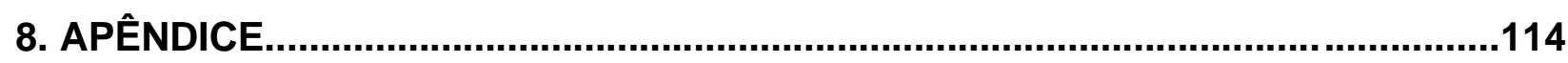


"A escrita talvez seja a maior das invenções humanas, ligando pessoas, cidadãos de épocas distantes, que nunca se conheceram. Livros rompem correntes do tempo, prova de que humanos podem fazer mágica".

Carl Sagan 


\section{INTRODUÇÃO}

Os professores têm encontrado dificuldades para ensinar, pois nos dias de hoje os alunos são pouco motivados a aprender com métodos tradicionais como giz e lousa. Por esse motivo, os professores estão desenvolvendo outros meios de fazer com que o interesse desses alunos volte e o aprendizado se torne mais ameno.

Cada professor tem seu jeito de tentar atrair a atenção dos alunos, usando desde técnicas convencionais a inovadoras. Alguns dos métodos são as músicas empregando uma paródia da matéria, aula prática com experimentos, vídeos com algo relacionado àquele tema específico da matéria e jogos didáticos.

O objetivo desta pesquisa é utilizar um jogo de tabuleiro e cartas no ensino de química, inicialmente para alunos do $9^{\circ}$ ano e $1^{\circ}$ ano do ensino médio. Trata-se de um jogo onde é apresentada a tabela periódica de uma maneira diferente, pois além de conhecer as características, curiosidades e propriedades dos elementos, ainda mostra suas aplicações e o sítio astronômico onde surgiram esses elementos, fazendo assim com que os alunos já comecem a associar os elementos ao seu dia a dia. Isso facilitará seu entendimento tanto de Química quanto de Astronomia.

Tive o meu primeiro contato mais a fundo com a astronomia na Sabina Escola Parque do Conhecimento quando comecei a trabalhar como monitora. Nessa instituição, as aulas são ministradas de forma lúdica, é utilizada a visualização e exploração do espaço, e as crianças conseguem aprender brincando até mesmo assuntos um pouco mais complexos como Física, Química, Biologia, e até mesmo Astronomia. No Planetário Johannes Kepler abordam-se diversos temas, desde evolução estelar até astronáutica.

As escolas do município de Santo André têm um roteiro conforme a faixa etária de cada sala de aula. Do $1^{\circ}$ ao $2^{\circ}$ ano do ensino fundamental, os alunos exploram um pouco sobre a formação do sistema Sol-Terra-Lua, os movimentos de rotação e translação, as estações do ano e eclipses. Com o equipamento Telúrio, conseguem explorar o Sol cenográfico, e os planetas em escala, finalizando com uma sessão de Planetário lúdica conforme o ano escolar. Os alunos de $3^{\circ}$ e $4^{\circ}$ ano exploram a cultura indígena com os instrumentos do Núcleo de Observação do Céu, no qual eles podem aprender sobre a Rosa dos Ventos, o Relógio de Sol Analemático, Telescópios e o Observatório indígena, finalizando com a sessão de planetário voltada 
ao tema indígena. Já os $5^{\circ}$ e $6^{\circ}$ anos têm aulas mais voltadas a evolução estelar e astronáutica. Os jovens adultos (EJA) também têm vez, e quando esses alunos chegam no planetário ficam deslumbrados e exploram tudo.

O Planetário Johannes Kepler disponibiliza cursos gratuitos tanto para crianças com o curso Cientista Mirim, quanto para professores com os cursos do GTTP (Galileo Teacher Training Program) e para o público geral com os cursos de férias, que são realizados nos meses de janeiro e julho, quando a Sabina e o Planetário Johannes Kepler oferecem diversas atividades e oficinas para o público. As oficinas são extremamente fáceis de fazer e muitos professores aproveitam esse período de férias para aprender e ampliar o conhecimento em sala de aula com os alunos.

A falta de interesse dos alunos nos dias de hoje deve ser atribuída não só ao professor, mas também aos processos de ensino. Muitas vezes, por falta de tempo ou de materiais não se tem a oportunidade de ter uma didática diferenciada.

Segundo Cunha (2012), o interesse daquele que aprende passou a ser a força motora do processo de aprendizagem, e o professor, o gerador de situações estimuladoras para aprendizagem. Jogando, o indivíduo se depara com o desejo de vencer que provoca uma sensação agradável, pois as competições e os desafios são situações que mexem com nossos impulsos mais básicos. Assim, o método de ensino deve explorar diversas formas para que o aprendizado se torne uma coisa agradável, e não só um aprender por aprender.

No estudo da química, o conhecimento da Tabela Periódica é central. Um passo importante no ensino de química, é aprender a interpretar a Tabela Periódica: as divisões nela existentes, o porquê de cada elemento estar localizado em determinado período ou família e quais elementos são naturais e quais são sintéticos. Todas essas questões podem ser esclarecidas com uma pausada exploração da Tabela Periódica (ALVES, 2016). Por essa razão, o presente trabalho se propõe a ensinar química junto com astronomia de uma maneira lúdica, na qual os alunos se interessem a aprender.

No Currículo do Estado de São Paulo (SÃO PAULO, 2010), a tabela periódica é apresentada aos alunos no $1^{\circ}$ ano do ensino médio. É nesse momento que se inicia a compreensão da importância desse assunto no mundo que nos cerca. A tabela periódica permite saber que todas as substâncias são compostas por um pequeno número de elementos químicos. Assim se enfatiza como a enorme 
diversidade do nosso mundo tem uma base relativamente simples. Esse fato tem grandes implicações para a educação ambiental, pois fundamenta o conceito de reciclagem, que é um dos "três Rs" da sustentabilidade (reduzir, reutilizar e reciclar). A reciclagem, em seu limite, consiste em reconduzir todos os resíduos que a humanidade produz, alguns deles nocivos, aos elementos químicos fundamentais e depois recombiná-los em substâncias úteis, trabalháveis e assimiláveis. Por outro lado, há uma conexão cósmica. Os elementos químicos têm uma origem, e essa origem é astronômica. Eles foram formados no Big Bang, nas estrelas ou no meio interestelar. Há um ciclo dos elementos não só no planeta Terra, onde há uma forte influência da humanidade, mas também no cosmos, onde os elementos se originaram. A apropriação do tema da tabela periódica e da origem dos elementos constitui parte importante da alfabetização cientifica, que permite que haja no futuro adultos críticos e atuantes na sociedade. $O$ jogo que foi desenvolvido, e que é produto central deste trabalho, permite interpretar a tabela periódica em termos tanto das implicações de nossas ações no ambiente que nos cerca como de nossa posição no Universo. 


\section{ORIGEM DOS ELEMENTOS E EVOLUÇÃO ESTELAR}

Um dos temas mais apaixonantes do conhecimento é o estudo da evolução do Universo e de tudo que ele contém. Estima-se que a idade do Universo seja, aproximadamente, 13,7 bilhões de anos. O momento zero do Universo marca o início de sua expansão, o Big Bang. A expansão do Universo foi descoberta graças ao trabalho de Edwin Hubble e Milton Humason usando o telescópio de 2,5m do Observatório de Monte Wilson. Em 1929, eles verificaram que as suas medidas de velocidades radiais das galáxias implicavam que as galáxias estavam se afastando, com a velocidade de recessão $(v)$ proporcional a sua distância $(D)$, ou seja, seguindo a relação $v=H_{0} D$, que veio a ser conhecida como a lei de Hubble (onde $H_{0}$ é a constante de Hubble). Foi então revelada a expansão do Universo. A expansão do Universo implica que no passado ele passou diversas fases, caracterizadas por densidades e temperaturas cada vez maiores a medida em que se aproximava do instante zero da evolução do Universo, a singularidade.

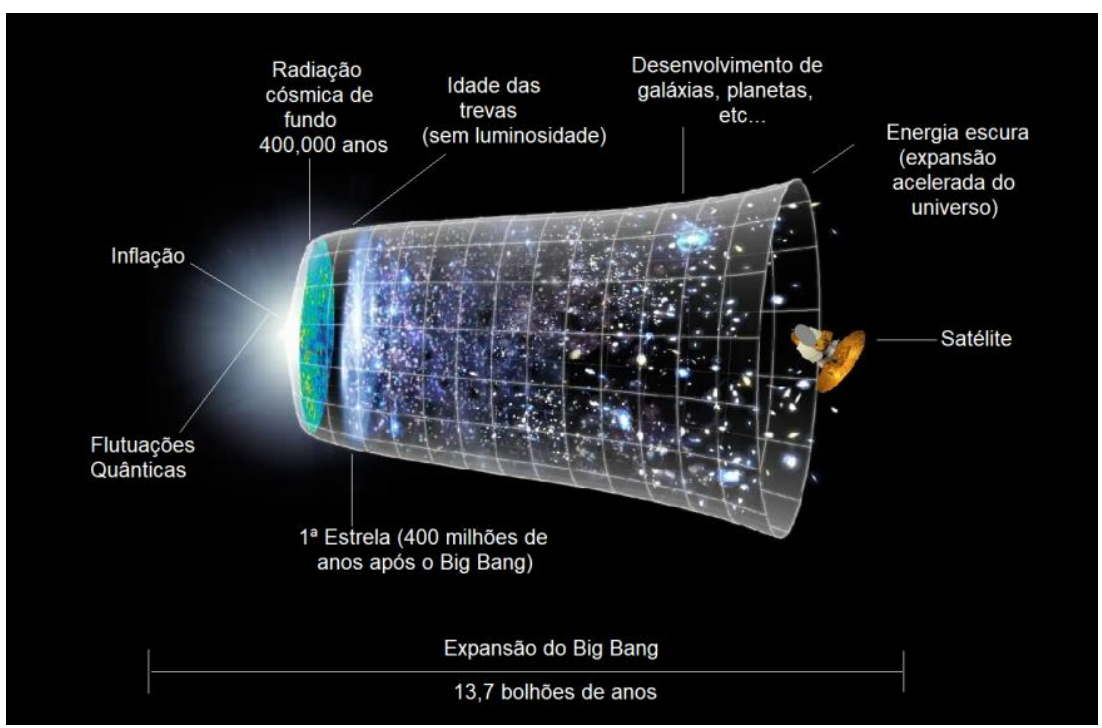

Fonte: https://universoracionalista.org/antes-do-big-bang/

Figura 2.1 - A evolução do Universo. Destacando diferentes épocas.

A cosmologia se pergunta sobre as origens do que observamos no universo. Uma de suas questões é sobre a origem dos elementos químicos. Mas, o que é um elemento químico? 
Um elemento é definido pelos prótons, partículas de carga positiva que compõem os núcleos atômicos. Nos núcleos atômicos também há os nêutrons, sem carga. Prótons e nêutrons são denominados de "núcleons", ou "bárions".

Átomos são constituídos pelo núcleo atômico, de carga positiva, circundado por elétrons, de carga negativa. Dentro do núcleo atômico, os prótons e nêutrons interagem atrativamente pela força nuclear que é tão intensa que supera a repulsão eletromagnética entre os prótons.

A energia de ligação dos elétrons aos núcleos atômicos é da ordem de eletronvolts. Por isso, a força nuclear é chamada de interação forte. Um eletronvolt (ev) é a energia que um eletron ganha ao atravessar um pontencial de $1 \mathrm{~V} ; 1 \mathrm{eV}=$ 1.602×10-19 J. Já as energias do núcleo atômico são da ordem de vários Mev. Esse é o motivo da imensa energia de uma bomba atômica (mais propriamente bomba nuclear) ou de um reator nuclear.

Átomos de mesmo elemento, que é dado pelo número de prótons, mas que diferem na quantidade de nêutrons, são chamados isótopos. O termo nuclídeo é usado para designar determinado isótopo de um elemento químico, cujo núcleo tem "Z" prótons e "N" nêutrons, num total de "A" núcleons (com A = Z + N). (TERUYA e DUARTE, 2012).

Em relação à notação, $Z$ (número de prótons) é chamado de número atômico e $\mathrm{A}$ (número de prótons e nêutrons) de número de massa.

Cada elemento é designado por um símbolo que pode ser uma letra maiúscula ou duas letras, a primeira maiúscula e a segunda, minúscula, por exemplo, "H" para o hidrogênio, e "He", para o hélio. A notação para designar os nuclídeos é dada pelo símbolo do elemento com um subscrito à esquerda e em cima do símbolo do elemento. Por exemplo, ${ }^{4} \mathrm{He}$ (lê-se "hélio 4"), o isótopo mais comum do hélio.

Alguns isótopos são estáveis e outros instáveis, ou radioativos. Mesmo o elemento mais simples, o hidrogênio apresenta isótopos. Todos os isótopos do $\mathrm{H}$ têm um 1 próton, mas só 2 isótopos são estáveis, o prótio, ${ }^{1} \mathrm{H}$, que na verdade é só um próton, e que é o hidrogênio comum, e o deutério, ${ }^{2} \mathrm{H}$, que tem um próton e um nêutron no núcleo. Já o isótopo trítio, um próton e dois nêutrons, ${ }^{3} \mathrm{H}$, é instável e decai por decaimento $\beta$ com uma meia vida de 12,32 anos. Nesse processo um dos nêutrons se convertem em próton emitindo um elétron e um neutrino e $0{ }^{3} \mathrm{H}$ se transforma em ${ }^{3} \mathrm{He}$. 


\section{Isótopos do Hidrogênio}
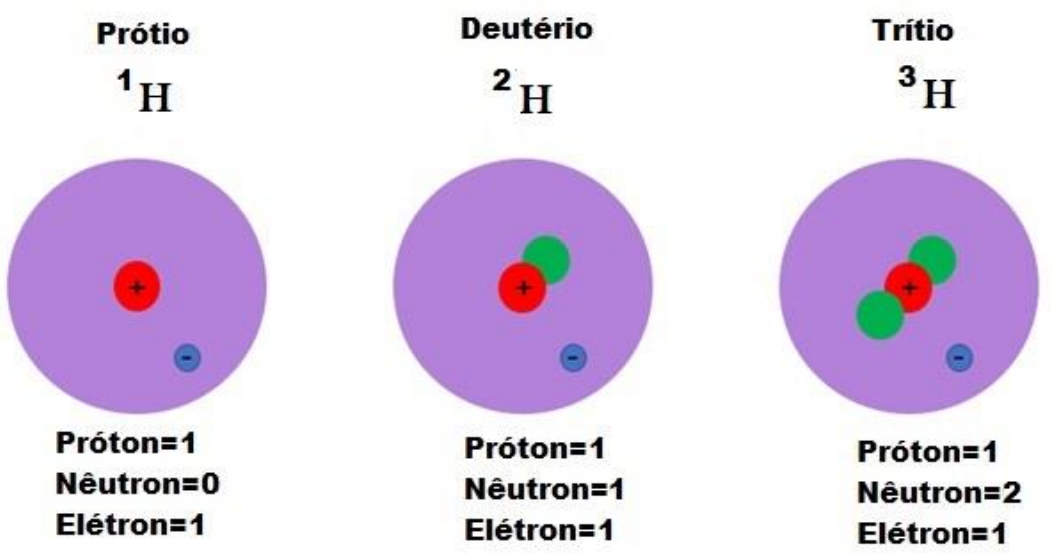

Fonte: a autora

Figura 2.2 - Isótopos do H. ${ }^{1} \mathrm{H}$, hidrogênio comum (prótio); ${ }^{2} \mathrm{H}$, deutério; ${ }^{3} \mathrm{H}$, trítio.

Outro exemplo de isótopos é dado pelo carbono. Como elemento, o C é definido pelo número de prótons, 6 , e apresenta dois isótopos estáveis, que diferem pelo número de nêutrons: $0{ }^{12} \mathrm{C}$, com 6 nêutrons, mais abundante ( $98,9 \%$ do total) e o ${ }^{13} \mathrm{C}$, com 7 nêutrons (os restantes $1,1 \%$ ). Já o tão falado ${ }^{14} \mathrm{C}$ (carbono 14 ) é um isótopo radioativo, que decai com o tempo como uma meia vida de 5730 anos. Ele é produzido pela interação de raios cósmicos com a atmosfera terrestre, onde se encontra em diminutas quantidades. As razões isotópicas (razões entre isótopos de um elemento) nos dão pistas sobre a história pela qual passaram ao formar as várias substâncias do presente. Neste trabalho, usaremos as abundâncias dos elementos e as razões isotópicas no Sistema Solar (ASPLUND et al. 2009), muitas vezes chamadas de abundâncias cósmicas.

A distribuição das abundâncias dos elementos em vários contextos nos fornece indícios sobre a origem dos elementos químicos e de seus isótopos (Figura 2.2). Como foram sintetizados os elementos químicos? Considera-se normalmente três fontes de nucleossíntese: primordial, estelar e por raios cósmicos. 


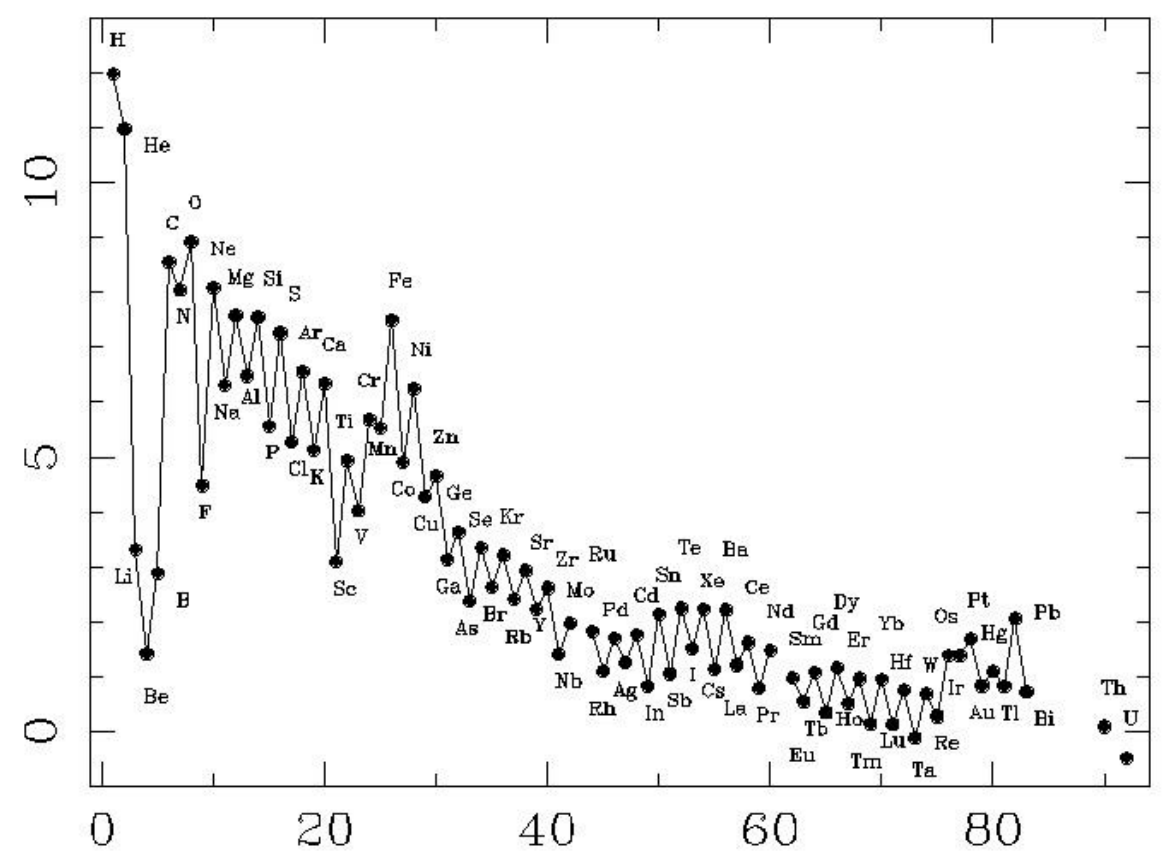

Fonte: http://www.physics.unlv.edu/ jeffery/astro/atomic/cowley_001.html

Figura 2.3 - Abundâncias dos elementos químicos no Sistema Solar. Na abcissa está o número atômico e na ordenada, a abundância do número de átomos em relação ao hidrogênio, medida numa escala logarítmica $\log \left(\mathrm{N} / \mathrm{N}_{\mathrm{H}}\right)+12$ (assim $\circ \mathrm{H}$ vale 12). Observe as lacunas devidas aos elementos radioativos artificiais tecnécio $(Z=43)$ e promécio $(Z=61)$.

\subsection{Nucleossíntese primordial}

Uma das questões mais importantes em astronomia é sobre a origem dos elementos químicos. Os estudos de cosmologia revelaram que os elementos mais leves como o Hidrogênio, Hélio e Lítio, foram fabricados no Big Bang. Devido à expansão do Universo, se olharmos para o passado, estamos dando rewind na expansão, e o Universo vai estar mais denso, vai também estar mais quente. Quando o Universo tem entre 10 e 1000 segundos de idade, a temperatura e a densidade são tão altas que são sintetizados elementos através da fusão nuclear com os prótons e nêutrons que já existiam antes desse período. Esse processo vai o até número de massa 7: ${ }^{1} \mathrm{H}$ (hidrogênio), ${ }^{2} \mathrm{H}$ (deutério, ou hidrogênio pesado, também indicado pelo símbolo D), ${ }^{4} \mathrm{He}$ (hélio) ${ }^{3} \mathrm{He}$ (hélio 3 , o isótopo mais leve do hélio) e ${ }^{7} \mathrm{Li}$ (lítio 7, o isótopo mais pesado do lítio). É o que se chama de Nucleossíntese Primordial, ou BBN (Big Bang Nucleosynthesis). A nucleossíntese primordial não vai além do número de massa 8 , pois o isótopo ${ }^{8}$ Be é uma ressonância de vida muito curta. Ademais, 0 Universo está em expansão muito rápida durante a era da nucleossíntese primordial 
e sua temperatura e densidade despencando tanto que as reações de fusão nuclear logo não são mais possíveis. $A$ isso se soma o fato de que nêutrons livres são radioativamente instáveis. Se o nêutron não estiver ligado um núcleos com prótons, ele sofre um decaimento $\beta$ em um próton, um elétron e um antineutrino com meiavida de 10 minutos e 10 segundos.

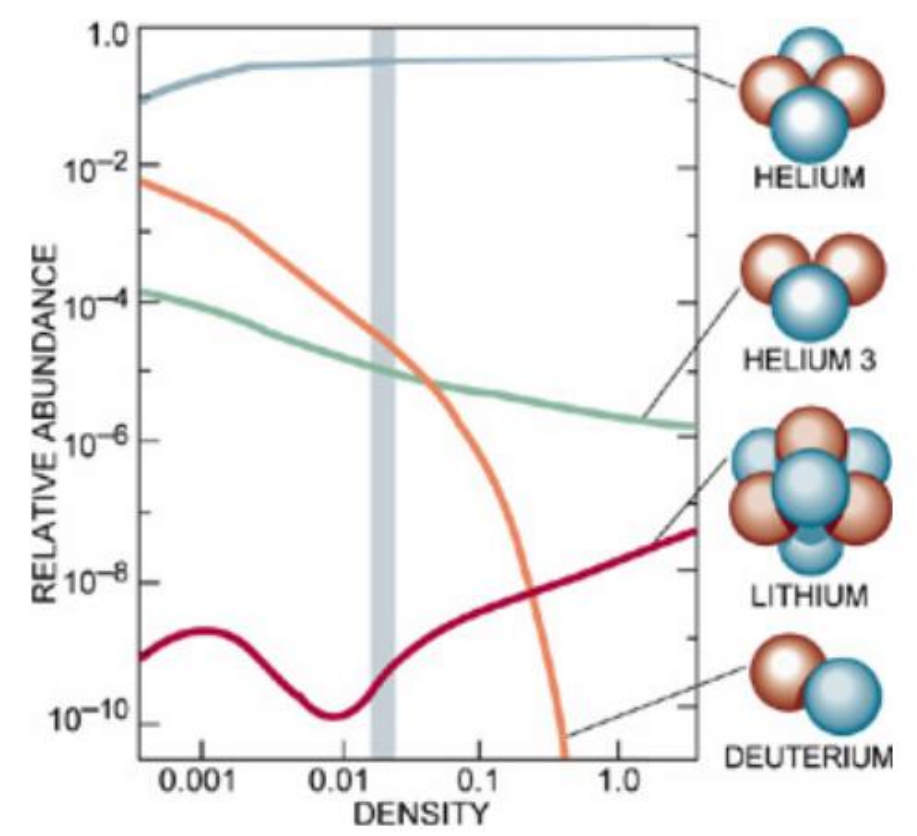

Fonte: http://w.astro.berkeley.edu/ mwhite/darkmatter/bbn.html

Figura 2.4 - Nucleossíntese primordial. Abundâncias de elementos leves em função da razão entre a densidade de bárions (prótons e nêutrons) e a densidade de fótons.

O conceito de nucleossíntese primordial aparece no artigo aßy (ALPHER et al. 1948) para explicar a origem dos elementos químicos em geral. Porém esse primeiro trabalho se apoiava em uma física nuclear ainda muito rudimentar e posteriormente se verificou que a BBN podia dar conta apenas das abundâncias do hélio (explica cerca de $90 \%$ da abundância cósmica desse elemento) e de uns poucos elementos leves.

As abundâncias desses elementos dependem fortemente da razão de densidades de fótons e de bárions. Esse parâmetro foi obtido com grande precisão a partir das flutuações da radiação de fundo cósmica pelo satélite Planck (ADE et al. 2016), permitindo Coc e Vangioni (2017) determinarem as abundâncias primordiais $(\mathrm{N} / \mathrm{NH})=8.267 \times 10^{-2}\left({ }^{4} \mathrm{He}\right), 2.45 \times 10^{-5}(\mathrm{D}), 1.05 \times 10^{-5}\left({ }^{3} \mathrm{He}\right)$ e $5,61 \times 10^{-10}\left({ }^{7} \mathrm{Li}\right)$. 
O que acontece com esses elementos depois da BBN? O deutério é um isótopo muito frágil. Ele só pode ser destruído após a BBN durante a evolução estelar. Depois da BBN, ${ }^{4} \mathrm{He}$ é produzido por estrelas, acrescentando às abundâncias cósmicas desse elemento cerca de $10 \%$. Já o ${ }^{3} \mathrm{He}$ é tanto produzido como destruído em estrelas. $\mathrm{O}^{7} \mathrm{Li}$ tem uma história mais complicada. É produzido durante o processo de espalação devido às colisões de raios cósmicos com átomos do meio interstelar e pode ser produzido nas estrelas (estrelas AGB e novas) e destruído (no interior das estrelas).

\subsection{Nucleossíntese estelar}

O processo de nucleossíntese que havia ocorrido durante o Big Bang se deu por fusão nuclear. Fusão nuclear é a união de núcleos atômicos, que formarão um núcleo maior. Esse processo cessa quando o universo tinha cerca de 1000 segundos de idade, e volta a acontecer quando o ele tem 100 milhões de anos e surgem as estrelas. Agora se formam novos elementos químicos no interior da estrela. É o que chamamos de Nucleossíntese Estelar.

Todos os elementos do carbono em diante se formam por nucleossíntese estelar. Em astrofísica se chama de metais todos os elementos mais pesados do que o Hélio, e de metalicidade a proporção do total de metais em relação ao hidrogênio. A nomenclatura é meio incômoda porque inclui elementos como o oxigênio e os gases nobres, mas é útil devido ao fato que reflete a contribuição das estrelas aos elementos do universo, já que elas são a única origem de elementos mais pesados (os metais).

A nucleossíntese estelar depende da massa estelar $M^{\star}$. A nossa estrela, o Sol é uma referência, daí se tem como unidade de massa para as estrelas, a massa solar $\left(\mathrm{M}_{\odot}=1,989 \times 10^{30} \mathrm{~kg}\right)$. Os elementos químicos sintetizados no interior de uma estrela são ejetados no final do sua vida que ocorre de um modo dramático.

As estrelas de massa intermediária $\left(0,8\right.$ a $\left.8 \mathrm{M}_{\odot}\right)$ terminam sua vida como Nebulosa Planetária e deixam como resto uma anã branca. A "morte" de estrelas de alta massa (> $8 \mathrm{M}_{\odot}$ ) é catastrófica: explodem como Supernova e deixam como resto uma estrela de nêutrons, se $\mathrm{M}^{*}<\sim 25 \mathrm{M}_{\odot}$, ou um buraco negro, caso contrário. 
O tempo de vida de uma estrela cai rapidamente com a massa da estrela. Estrelas com menos de 0,8 $\mathrm{M}_{\odot}$ têm um tempo de vida maior do que a idade do Universo, e assim não chegaram ao final de sua vida e, portanto, não ejetaram os elementos que poderiam ter sintetizado. Por isso, o limite inferior 0,8 $\mathrm{M}_{\odot}$ acima.

$\mathrm{O}$ artigo fundamental da nucleossíntese estelar é conhecido como $\mathrm{B}^{2} \mathrm{FH}$ (título "Síntese dos Elementos nas Estrelas"), devido às iniciais de seus autores: Margaret Burbidge, Geoffrey Burbidge, William A. Fowler e Fred Hoyle (BURBIDGE et al. 1957).

\subsubsection{Sequência Principal: Fusão de Hidrogênio em Hélio}

Fusão do $\mathrm{H}$ em He é também chamada de queima de hidrogênio. As estrelas têm uma massa mínima para realizarem a queima de hidrogênio: $0,08 M_{\odot}$. Objetos com massa inferior a essa nunca realizam a fusão nuclear de hidrogênio em hélio e são chamados de anãs marrons.

A formação de uma estrela começa nas regiões mais densas das nuvens moleculares gigantes, que são o nascedouro de todo um grande conjunto de estrelas. Nessas regiões, concentrações ainda mais densas se colapsam sob a ação de sua própria gravidade, aquecendo-se e formando a protoestrela. Quando a estrela adquire um equilíbrio hidrostático, ela entra na pré-sequência principal. Após alguns milhões de anos, a temperatura da estrela atinge um valor alto o suficiente para ocorrer a fusão nuclear de hidrogênio em hélio. Neste momento, a estrela entra na fase da Sequência Principal. No interior da estrela ocorre um processo de autorregulação entre a energia produzida pelas reações nucleares e a atração gravitacional que mantém a estrela estável.

São chamadas de sequência principal, porque definem uma faixa no Diagrama HR (Hertzsprung-Russell), onde estão a maioria das estrelas. O Diagrama HR é um gráfico da luminosidade versus a temperatura de estrelas, e a sequência principal é aproximadamente uma diagonal entre o canto de baixa temperatura e luminosidade até o canto de alta temperatura e luminosidade do diagrama.

A sequência principal é caracterizada pelo fato da estrela realizar fusão nuclear transformando hidrogênio em hélio em seu núcleo. Esta etapa da vida da estrela é a mais longa da sua existência. Assim, o Sol ficará 10 bilhões de anos da 
Sequência Principal e só 1 bilhão de anos a mais em estágios de evolução mais avançados. O tempo de vida de uma estrela cai rapidamente com a massa da estrela. O Sol levará aproximadamente 10 bilhões de anos na sequência principal para consumir todo o hidrogênio na sua região central. Já o tempo de vida de uma estrela com 10 massas solares é cerca de 30 milhões de anos, pois o seu combustível é consumido mais rapidamente. $O$ tempo de vida da sequência principal depende com a massa aproximadamente de acordo com a relação $t * t_{\odot}=\left(M * / M_{\odot}\right)^{-2,5}$, onde $t_{\odot}=10$ bilhões de anos.

Se a estrela tem uma massa mais baixa, como o Sol, o processo de fusão nuclear dominante na sequência principal é a cadeia próton-próton (Figura 2.5). Em estrelas da sequência principal mais massivas $\left(M^{*}>1.4 M_{\odot}\right)$, é mais importante outro processo de fusão, o ciclo Carbono-Nitrogênio-Oxigênio (CNO).

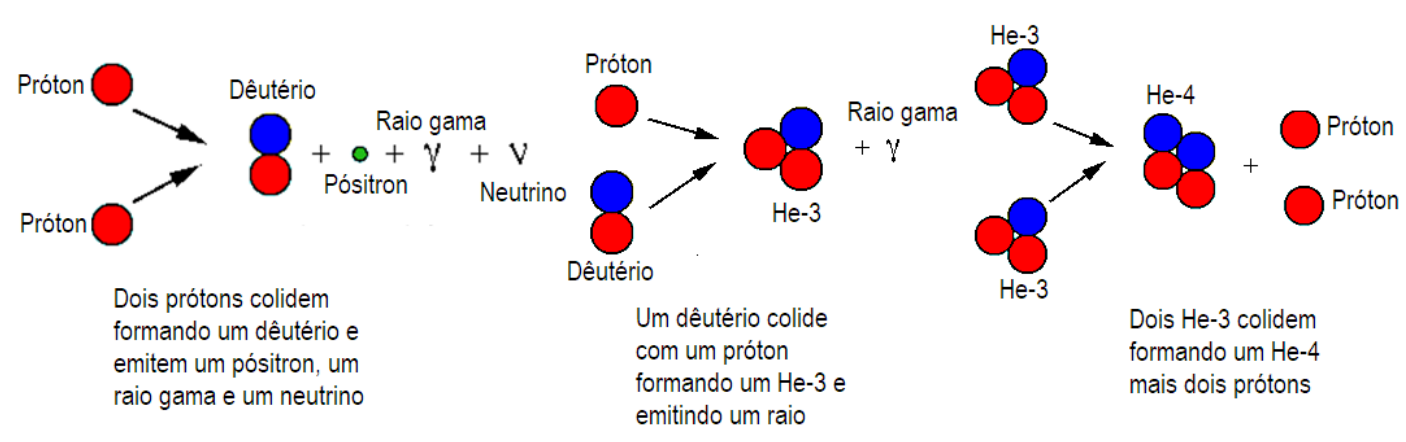

Fonte:https://cienciaempratica. .iles. wordpress.com/2016/08/protonproton.jpg $? w=493 \&$ h=278 Figura 2.5 - Cadeia próton-próton.

No ciclo CNO (Figura 2.6), ocorre a fusão de um próton com um núcleo de carbono, o que gera raios gama e um núcleo de ${ }^{13} \mathrm{~N} . \mathrm{O}{ }^{13} \mathrm{~N}$ é instável e decai para ${ }^{13} \mathrm{C}$ liberando um pósitron e um neutrino. O pósitron encontrará um elétron e se destruirão gerando raios gama. ${ }^{13} \mathrm{C}$ se funde com outro próton liberando ${ }^{14} \mathrm{~N}$ e raios gama. ${ }^{14} \mathrm{~N}$ se funde com um próton liberando ${ }^{15} \mathrm{O}$ e raios gama. ${ }^{15} \mathrm{O}$ é instável e decai para ${ }^{15} \mathrm{~N}$ liberando um pósitron e um neutrino. $O$ pósitron encontrará posteriormente um elétron e se aniquilarão gerando raios gama. ${ }^{15} \mathrm{~N}$ se funde com um próton formando $0{ }^{4} \mathrm{He} e$ ${ }^{12} \mathrm{C}$. E por fim $0{ }^{12} \mathrm{C}$ dará início a um novo processo de fusão. 


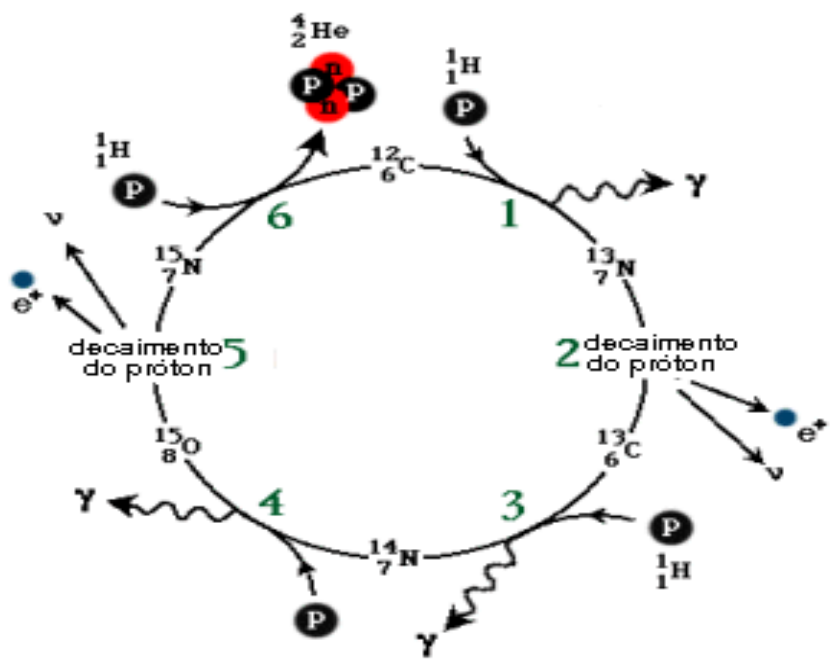

Fonte: https://cienciaempratica. files. wordpress.com/2016/08/protonproton.jpg?w=493\&h=278

Figura 2.6 - Ciclo CNO.

A queima de hidrogênio, quer na fase da sequência principal, quer em estágios mais avançados de evolução interestelar, enriquece o universo em hélio, que já havia sido produzido na maior parte no Big Bang. Os valores primordiais são 0.2484 em fração de massa, ou N/NH=8.267×10-2, em número (COC e VANGIONI, 2017). No proto Sistema Solar (ASPLUND et al. 2009), a abundância do He é 0.2703, em fração de massa $\left(\mathrm{N} / \mathrm{N}_{\mathrm{H}}=8.267 \times 10^{-2}\right)$. Assim, a queima de hidrogênio em estrelas incrementa em $12 \%$ as abundâncias do He no universo.

\subsubsection{Triplo-alfa: Fusão de Hélio em Carbono}

Quando o núcleo da estrela esgota o hidrogênio, convertido em hélio, ocorre uma queda de pressão que faz com que a mesma sofra uma contração. A partir daí a estrela sai da Sequência Principal, para posteriormente se tornar uma gigante vermelha, ou, se a estrela tiver mais de aproximadamente oito massas solares, entrar na região das supergigantes. Ao sair da sequência principal, seu núcleo tem praticamente só hélio e o hélio não está produzindo energia por fusão nuclear.

Como há perda do suporte por pressão, o núcleo começa a se contrair e a temperatura e a densidade no interior aumentam. Com o aumento da temperatura decorrente da contração, a região próxima ao núcleo atinge a temperatura necessária para realizar fusão de hidrogênio em hélio na parte mais externa da estrela. Essa fusão faz com que a luminosidade da estrela aumente fazendo com que as partes externas sofram o processo de expansão. Com a expansão a temperatura das regiões 
mais externas da estrela vai diminuindo e a estrela ganha um tom avermelhado, daí vem o nome gigante vermelha.

O núcleo da estrela, agora mais quente e mais comprimido, pode atingir a temperatura de $1 \times 10^{8} \mathrm{~K}$ e com essa temperatura passa a fundir hélio em carbono na chamada reação Triplo-Alfa.

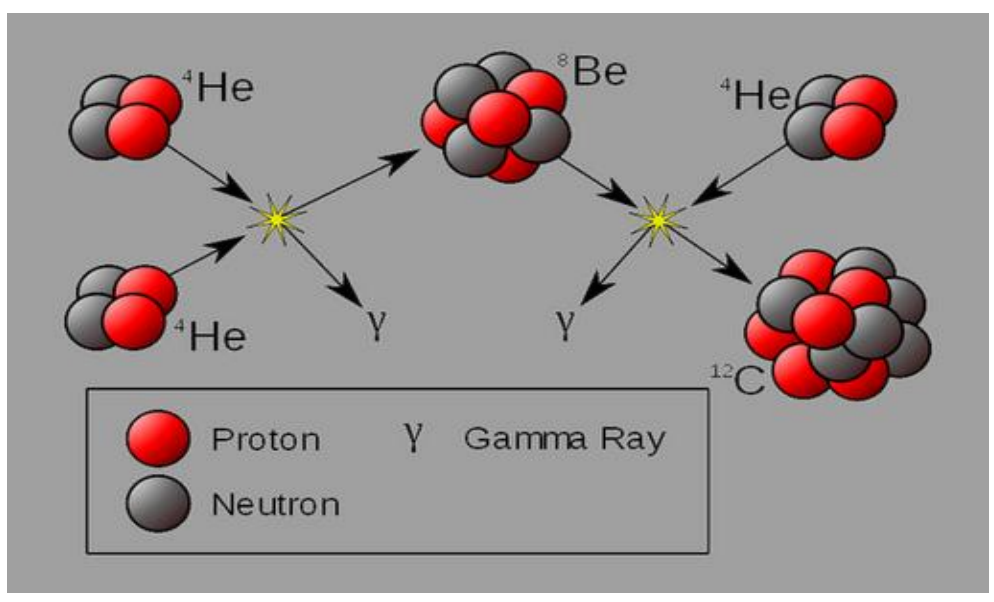

Fonte: https://people.highline.edu/iglozman/classes/astronotes/media/triple_alpha.jpg

Figura 2.7 - Reação triplo-alfa.

Do ponto de vista da nucleossíntese, a queima de hélio em carbono apresenta uma forma importante em estrelas de massa intermediária (0,8 a 8 massas solares). Essas estrelas, próximas do final da sua vida, passam pelo estágio de $A G B$ (de Asymptotic Giant Branch, "Ramo Assintótico das Gigantes", uma região do Diagrama HR). Observacionalmente, uma AGB aparecerá como uma gigante vermelha brilhante com uma luminosidade que de até milhares de vezes a do Sol. Sua estrutura é característica: um núcleo central inerte de carbono e oxigênio, uma camada onde o hélio está se fundindo em carbono, outra camada onde o hidrogênio está se fundindo em hélio, e um envelope extenso de material de composição semelhante às estrelas da sequência principal.

Nas AGBs ocorre a produção de nitrogênio $\left({ }^{14} \mathrm{~N}\right)$, principalmente de origem secundária (a partir de carbono e oxigênio pré-existentes), e de isótopos menos abundantes como ${ }^{13} \mathrm{C}$ e ${ }^{17} \mathrm{O}$, assim como a liberação de carbono primário (recémproduzido) e de algum oxigênio primário. Resulta que as estrelas de massa intermediária são as principais contribuidoras do C e $\mathrm{N}$ do Universo. 


\subsubsection{Fusão além do carbono}

Se a estrela tiver mais de $\sim 3 \mathrm{M}_{\odot}$, ocorre a queima de carbono no seu núcleo, sintetizando mais nuclídeos, que pode se dar tanto por queima C-C por processo alfa, que é captura de um núcleo de ${ }^{4} \mathrm{He}$ (uma partícula alfa) por um núcleo mais leve, como por queima $\mathrm{C}-\mathrm{C}$.

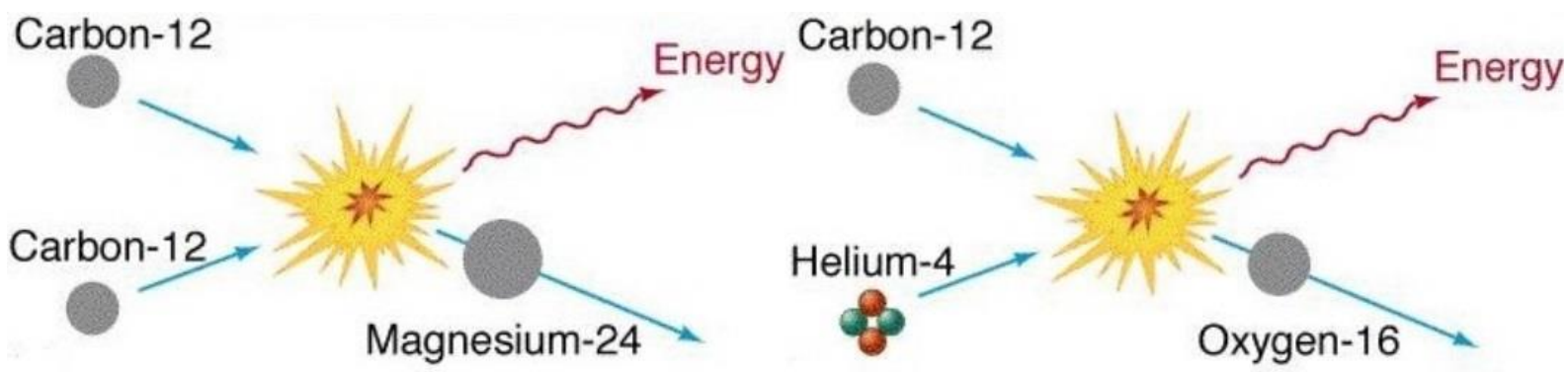

Fonte: http://physics.uoregon.edu

Figura 2.8 - Queima do carbono.

Se a estrela tem mais de $8 \mathrm{M}_{\odot}$, ou seja, é uma estrela de alta massa, que terminará como supernova, ocorre a queima de oxigênio no seu interior (MACIEL 2004), ou por queima O-O,

$$
\begin{aligned}
& { }^{16} \mathrm{O}+{ }^{16} \mathrm{O} \rightarrow{ }^{32} \mathrm{~S}+\mathrm{y} \\
& { }^{16} \mathrm{O}+{ }^{16} \mathrm{O} \rightarrow{ }^{31} \mathrm{~S}+\mathrm{n} \\
& { }^{16} \mathrm{O}+{ }^{16} \mathrm{O} \rightarrow{ }^{31} \mathrm{P}+\mathrm{p}
\end{aligned}
$$

ou, prosseguindo o processo alfa:

$$
\begin{aligned}
& { }^{16} \mathrm{O}+{ }^{4} \mathrm{He} \rightarrow{ }^{20} \mathrm{Ne}+\mathrm{y} \\
& { }^{20} \mathrm{Ne}+{ }^{4} \mathrm{He} \rightarrow{ }^{24} \mathrm{Mg}+\mathrm{Y} \\
& { }^{24} \mathrm{Mg}+{ }^{4} \mathrm{He} \rightarrow{ }^{28} \mathrm{Si}+\mathrm{Y} \\
& { }^{28} \mathrm{Si}+{ }^{4} \mathrm{He} \rightarrow{ }^{2} \mathrm{~S}+\mathrm{y}
\end{aligned}
$$

Cada uma dessas etapas ocorre com uma velocidade maior do que anterior. Após a queima do carbono, a fusão prossegue em várias camadas ao redor do núcleo, com elementos cada vez mais pesados queimando em cada camada mais interna. A estrutura da estrela se assemelha às cascas de uma cebola. Ao se chegar 
na etapa da queima do Silício, o processo é tão rápido que pode ocorrer em dias para uma estrela bem massiva. A estrela está a ponto de virar uma Supernova.

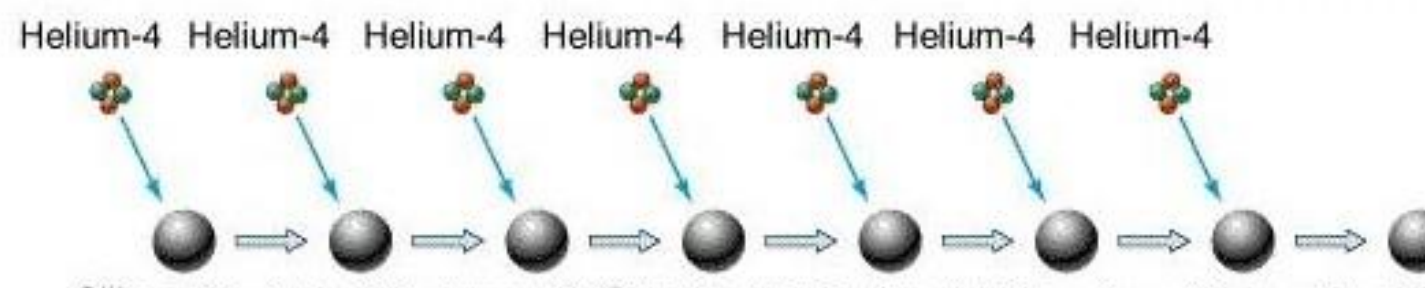

Silicon-28 Sulfur-32 Argon-36 Calcium-40 Titanium-44 Chromium-48 Iron-52 Nickel-56

Fonte: http://physics.uoregon.edu

Figura 2.9 - Processo alfa.

O processo alfa prossegue até o chamado "pico do ferro", em torno do ${ }^{56} \mathrm{Fe}$, que é o nuclídeo com maior energia de ligação por partículas de todos os núcleos atômicos. O nuclídeo mais pesado formado pelo processo alfa foi o ${ }^{56} \mathrm{Ni}$, que, porém, é instável, e sofre dois decaimentos $\beta$ gerando o ${ }^{56} \mathrm{Fe}$. O processo de fusão é inibido para elementos mais pesados do que o ferro, porque as reações de fusão se tornam endotérmicas, "roubando" energia do meio. O pico do ferro inclui esse elemento e seus vizinhos: $\mathrm{Cr}, \mathrm{Mn}, \mathrm{Fe}, \mathrm{Co}$ e $\mathrm{Ni}$. Considerando uma rede de reações nucleares ampla, abarca também o Ti, V, Cu e Zn.

O processo alfa é importante para o explicar o efeito par-ímpar nos elementos da Tabela Periódica além do carbono (Figura 2.3), pois os elementos de número atômico par têm uma abundância maior do que os elementos com $Z$ ímpar. Os elementos alfas, do oxigênio ao titânio, serão injetados em grande quantidade pelas Supernovas de tipo II, que são o resultado final da evolução de uma estrela massiva. Contudo, como esse tipo de supernova deixa como resto uma estrela de nêutrons ou buraco negro, parte dos elementos do pico do ferro são aprisionados neste resto compacto.

\subsubsection{Nucleossíntese Explosiva: Supernovas Tipo Il e la}

Há duas formas de nucleossíntese estelar: a nucleossíntese quiescente e a nucleossíntese explosiva. A nucleossíntese quiescente ocorre ao longo da vida de uma estrela, mesmo quando a estrela passa por mudanças dramáticas, como aquelas além da sequência principal, por exemplo, nas estrelas de massa intermediária, as 
fases de gigante vermelha e de AGB, após a qual uma estrela termina sua vida como uma nebulosa planetária. A escala de tempo para esses eventos é relativamente longa. Como veremos, a nucleossíntese quiescente pode contribuir para produzir elementos bastante pesados, como o Chumbo e Bismuto, devido ao estágio AGB de estrelas de massa intermediária.

Já a nucleossíntese explosiva ocorre em escalas de segundos, podendo ser caracterizada como uma explosão. São assim as explosões de supernovas quando uma estrela massiva está no seu estágio final de sua evolução ou em sistemas binários em que uma das estrelas é uma anã branca que está acretando massa da companheira até que supere a massa de Chandrasekhar (1,4 massa solar) e sofra um colapso. A supernova de uma estrela massiva (mais do que oito massas solares) é chamada de supernova de tipo II (SN II), enquanto que a supernova originária de um par binário é uma supernova de tipo la (SN la). Recentemente, um novo tipo de evento explosivo foi reconhecido, a fusão de duas estrelas de nêutrons. Cada um desses fenômenos explosivos contribuiu de um modo às abundâncias dos elementos químicos.

\section{Supernovas de tipo II}

Supernovas de tipo II, também conhecidas como supernovas de colapso do núcleo, são o final da evolução de uma estrela massiva que resulta em uma violenta explosão. Uma estrela deve ter pelo menos oito massas solares para que sofra este tipo de colapso.
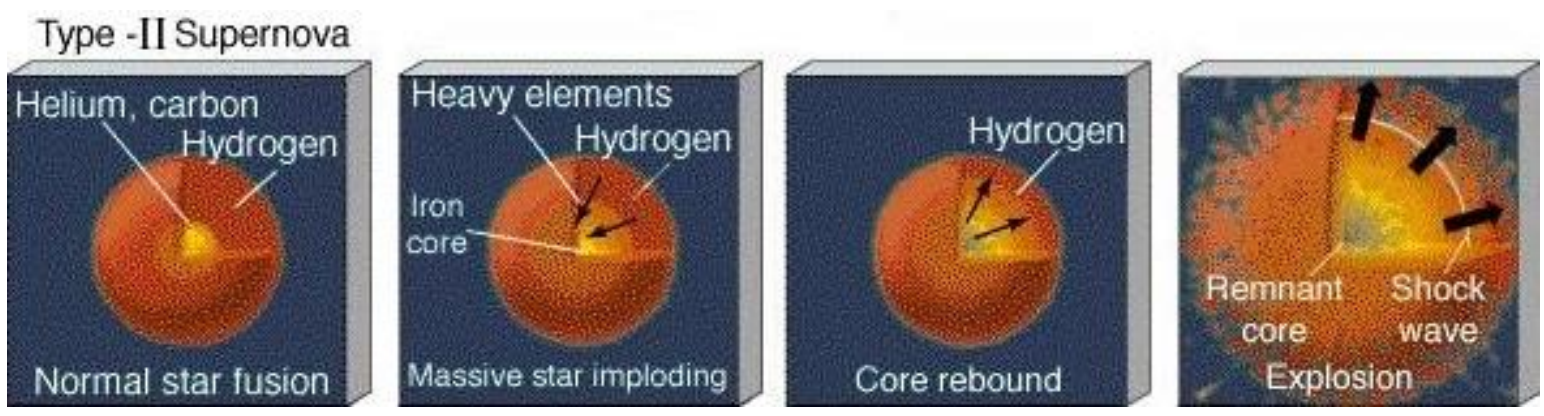

Fonte: http://physics.uoregon.edu

Figura 2.10 - Supernova de tipo II

Estrelas massivas geram energia através da fusão nuclear de elementos químicos cada vez mais pesados no seu núcleo até chegar ao ferro, e, em particular, 
o ${ }^{56} \mathrm{Fe}$. Com o passar do tempo, núcleos atômicos de massa cada vez maior são formados no núcleo da estrela, até que finalmente um núcleo composto por ferro é produzido. Quando a massa do núcleo de ferro chega a 1,4 massas solares acontece uma implosão. O nuclídeo ${ }^{56} \mathrm{Fe}$ é o mais fortemente ligado dos núcleos atômicos e se a nucleossíntese prosseguisse além do ferro, as reações nucleares passariam de exotérmicas para endotérmicas, o que sequestraria energia do meio, removendo o suporte de pressão contra o colapso gravitacional.

Em vez da fusão além do ferro, o que ocorre no núcleo da estrela é a fotodesintegração dos núcleos de ferro em partículas alfa (núcleos de ${ }^{4} \mathrm{He}$ ), e conjuntamente a fotodesintegração das partículas alfa em prótons e nêutrons. Todo esse processo é endotérmico e reduz a pressão que sustenta o núcleo contra a contração gravitacional e ele implode. A densidade do núcleo aumenta drasticamente até um ponto onde ocorre a neutronização, que é a captura de elétrons pelos prótons gerando nêutrons e neutrinos, conforme a reação $p+e \rightarrow n+v$. O núcleo atinge uma densidade em que é composto quase totalmente por nêutrons e a pressão de degenerescência dos nêutrons detém o colapso. A matéria em queda sofre um repique no núcleo ultradenso (densidade superior a cerca de um bilhão de toneladas por centímetro cúbico), forma-se uma onda de choque e a implosão é revertida em uma expansão do material que estava em queda. Mas só a onda de choque seria insuficiente para explicar as velocidades de até $10000 \mathrm{~km} / \mathrm{s}$ observadas nas explosões de supernovas de tipo II. Ocorre que a matéria em queda ficou tão densa que se tornou opaca a neutrinos, que têm uma interação extremamente fraca com a matéria comum. Neutrinos foram produzidos em quantidades copiosas durante a neutronização e, com a expansão das camadas em torno do núcleo, finalmente escapam gerando um "vento de neutrinos" que varre a matéria em torno do núcleo e expulsam todo o corpo externo da estrela em uma explosão com $10^{51}$ ergs em radiação eletromagnética e energia cinética (FRIAÇA et al. 2000, p.170-171)

As supernovas de tipo II deixam como resto ou uma estrela de nêutrons ou, se a massa da progenitora for acima de cerca de 25 massas solares, um buraco negro. As supernovas de tipo II têm uma contribuição significativa ao conteúdo de carbono e ferro do Universo, mas a sua principal contribuição é às abundâncias cósmicas dos elementos alfa, que são aqueles obtidos por sucessivas adições de um núcleo de hélio (partícula alfa) a um núcleo de ${ }^{12} \mathrm{C}:{ }^{16} \mathrm{O},{ }^{20} \mathrm{Ne},{ }^{24} \mathrm{Mg},{ }^{28} \mathrm{Si},{ }^{32} \mathrm{~S},{ }^{36} \mathrm{Ar},{ }^{40} \mathrm{Ca},{ }^{44} \mathrm{Ti}$. 


\section{Supernovas de tipo la}

Esse tipo de supernova é originário de um sistema binário de estrelas, cada uma de massa intermediária (entre 0.8 que 8 massas solares) que, se estivessem isoladas, cada uma morreria como nebulosa planetária, deixando como resto uma anã branca. No sistema que produz uma supernova de tipo la, as coisas acontecem de um modo diferente. A estrela mais massiva do par chega ao final da sua vida e deixa como produto uma anã branca. Após, a estrela menor deixa a sequência principal e se expande, tornando-se uma gigante vermelha. Se as duas estrelas estiverem próximas o suficiente, o envelope da estrela inicialmente menor preenche o lobo de Roche comum a ambas as estrelas e a anã branca começa a capturar sua massa. A massa é transferida da companheira na fase de gigante vermelha até a anã branca formando um disco de acresção ao seu redor. A matéria capturada pode então cair sobre a anã branca que irá começar a aumentar de massa. Caso a anã branca ultrapasse o limite de Chandrasekhar (por volta de 1,4 massa solar), haverá um colapso da anã branca, produzindo uma explosão de supernova do tipo la. As supernovas de tipo la não deixam resto. Elas são as principais contribuidoras as abundâncias cósmicas dos elementos do pico do ferro, Cr-Mn-Fe-Co-Ni, sendo também importantes para as abundâncias dos elementos do $\mathrm{S}$ ao $\mathrm{Zn}$.

\section{Type $\cdot$ I Supernova}
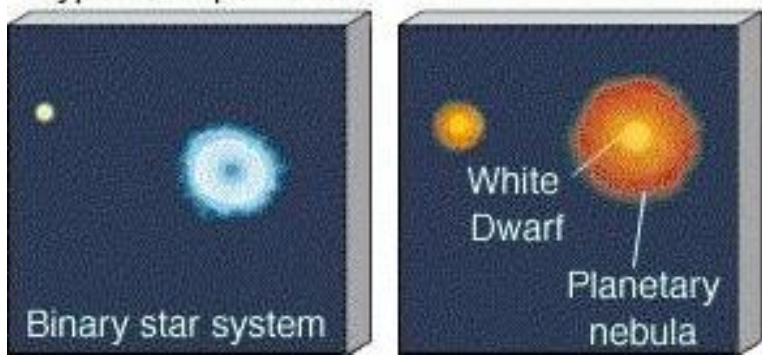
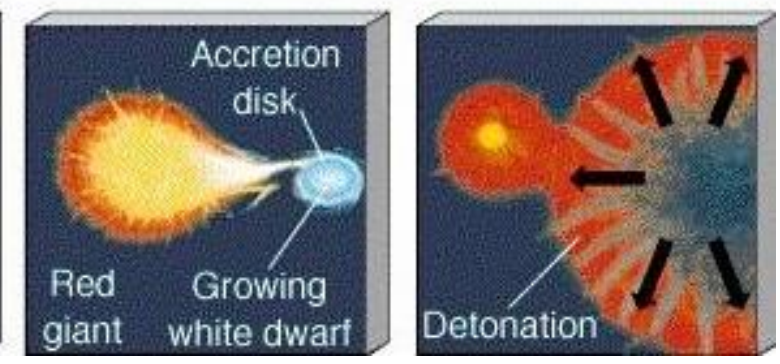

Fonte: http://physics.uoregon.edu

Figura 2.11 - Supernova de tipo la

\subsubsection{Nucleossíntese além do Ferro: Processo-s e Processo-r}

Além do pico do ferro, que, de um modo estendido, inclui o cobre e o zinco, há uma queda abrupta nas abundâncias dos elementos (ver Figura 2.3). A fusão nuclear de elementos mais pesados do que o ferro se torna endotérmica (exige energia). Assim outros processos se tornam necessários para a nucleossíntese 
estelar desses elementos. Nesse caso, o principal processo para a produção de elementos mais pesados é a captura de nêutrons, que pode ocorrer de dois modos, pelo processo-s (de slow "lento") e pelo processo-r (de "rápido"). Há também o processo- $p$, a captura de prótons, mas esse é bem menos importante, devido à repulsão entre o núcleo e o próton, ambos positivos (barreira Coulombiana), e que exige temperaturas muito altas (MACIEL, 2004).

O processo-s e o processo-r foram primeiro definidos em 1957 no monumental artigo B² FH (BURBIDGE et al. 1957). O processo-s é uma adição mais lenta de nêutrons a um "núcleo semente", como o ${ }^{56} \mathrm{Fe}$, até chegar um núcleo estável, que ocorre em fluxos de nêutrons mais baixos, e que envolve isótopos intermediários que podem ser instáveis, mas que devem ter uma meia vida maior do que séculos ou milênios. Já o processo-r ocorre em fluxos muito intensos de nêutrons e a adição de nêutrons é tão rápida que os núcleos intermediários podem ter meias vidas de fração de segundo. As densidades do número de nêutrons são muito diferentes nos processos s e r, típicamente $\mathrm{N}<\sim 10^{8} \mathrm{~cm}^{-3}$ para o processo-s, e $10^{24}-10^{28} \mathrm{~cm}^{-3}$ para 0 processo-r (SNEDEN et al. 2008).

Um exemplo famoso de isótopo do processo-s é dado por uma primeira detecção em 1952 do tecnécio na estrela R Gemini (MERRILL, 1952). O tecnécio ( ${ }^{99} \mathrm{Tc}$ ) é um elemento radioativo artificial que não é encontrado naturalmente na Terra. Sua meia vida de $2,11 \times 10^{5}$ anos ilustra as meias vidas "longas" dos isótopos intermediários do processo-s, mas é curta numa escala de tempo astronômica ou geológica. Sua presença na estrela demonstra que ele foi sintetizado in situ durante a evolução estelar quiescente.

No Sistema Solar, onde se pode medir com precisão as abundâncias dos isótopos estáveis ou de vida longa dos diversos elementos, não parece haver contribuição substancial às suas abundâncias de captura de nêutrons em regimes de densidade de nêutrons intermediários entre aqueles do processo s e r. (SNEDEN et al. 2008) Usando física nuclear fundamental, pode-se estimar a contribuição do processo-s e do processo-s à origem de cada nuclídeo. Alguns isótopos são produzidos apenas pelo processo-s (por exemplo, ${ }^{128} \mathrm{Xe}$ ), outros apenas pelo processo-r (por exemplo, ${ }^{134} \mathrm{Xe}$ e ${ }^{136} \mathrm{Xe}$ ), outros por uma mistura dos dois processos $\left({ }^{129} \mathrm{Xe}{ }^{130} \mathrm{Xe},{ }^{131} \mathrm{Xe} \mathrm{e} \mathrm{e}{ }^{132} \mathrm{Xe}\right)$ (Ver Figura 2.12). Para o mesmo elemento, os nuclídeos do processo-r são mais ricos em nêutrons do que os devidos ao processo-s. 


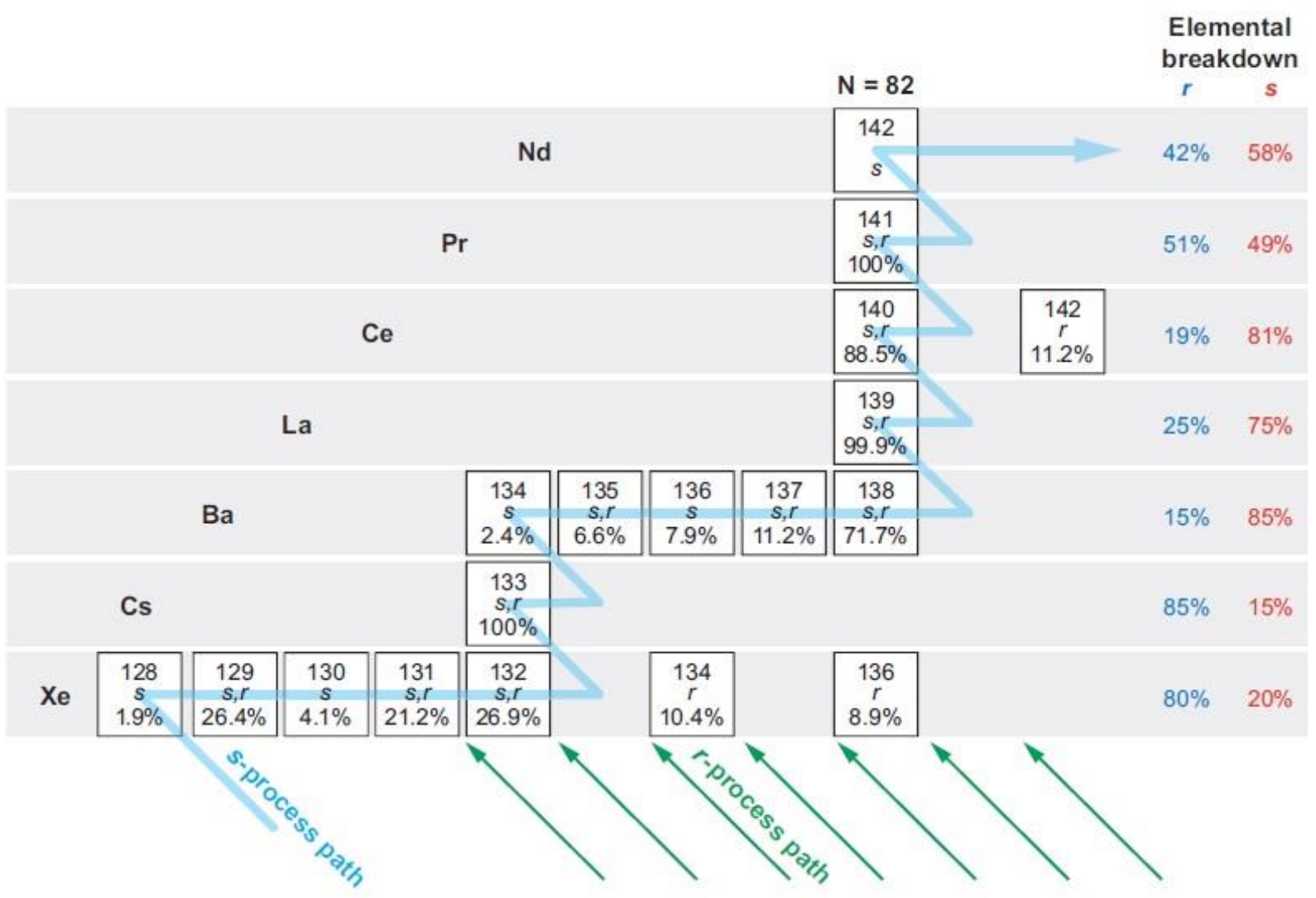

Fonte: SNEDEN et al. 2008.

Figura 2.12 - Elementos devidos aos processos s e r. Proporção de produção dos elementos de $\mathrm{Xe}$ a Nd pelos processos s e r no Sistema Solar (coluna da direita) e cadeias de produção de cada isótopo pelos processos. O processo s (linha azul claro) opera perto da estabilidade - as caixas pretas mostram núcleos estáveis - enquanto o processo $r$ é formado por núcleos muito ricos em nêutrons (instáveis) que sofrem decaimento $\beta$ (linhas verdes) até a estabilidade. Considera-se um único isótopo do $\mathrm{Nd}$ apenas para indicar as próximas etapas na cadeia do processo-s para os outros isótopos de $\mathrm{Nd}$.

Há três picos de abundância para o processo-r perto dos números de massa $\mathrm{A}=80$ (elementos $\mathrm{Se}, \mathrm{Br}$ e Kr), $\mathrm{A}=130$ (elementos Te, I e Xe) e $\mathrm{A}=195$ (elementos Os, Ir e Pt) (KRATZ et al. 2007). O processo-s também tem três picos de abundância, em A por volta de 90 (Sr, Y, Zr), 138 (Ba, La, Ce, Pr, Nd) e 208 (Pb e Bi). Os picos de abundância são devidos a isótopos com um número mágico de nêutrons (50, 82 ou 126) que dão configurações particularmente estáveis para os núcleos atômicos (TERUYA e DUARTE, 2012). Os picos de abundância do processo-s são cerca de 10 unidades de massa maiores do que os do processo-r porque os isótoposr são mais ricos em nêutrons.

Pode-se distinguir nos núcleos do processo-s do $\mathrm{Fe}$ ao $\mathrm{Bi}$, dois componentes, o componente fraco, responsável pelos nuclídeos até $A=\sim 90$, e 0 
componente principal, responsável pelos nuclídeos mais pesados até $A=208$ (Chumbo) e $A=209$ (Bismuto). Esses componentes corresponderiam a duas origens distintas, o fraco ao final da queima de hélio e carbono em estrelas massivas, elementos que são depois liberados quando a estrela explode como uma supernova de tipo II, e o principal ao estágio AGB de estrelas de massa intermediária. Antigamente imaginava-se a necessidade de um outro componente, o componente forte, para explicar a abundância do isótopo mais abundante do chumbo $\left({ }^{208} \mathrm{~Pb}\right)$ no Sistema Solar, mas posteriormente se verificou que bastava o componente principal ao se incluir estrelas AGB de baixa metalicidade (TRAVAGLIO et. al. 2001). A contribuição do componente fraco às abundâncias dos elementos-s despenca a partir do estrôncio (isótopo mais abundante ${ }^{88} \mathrm{Sr}$ ): $40 \%, 26 \%, 11 \%, 7 \%$ e $3 \%$ para $\mathrm{Kr}, \mathrm{Rb}$, Sr, Y e Zr, respectivamente (TRAVAGLIO et. al. 2004).

Também os núcleos do processo-r parecem ter duas fontes distintas, a chamada forte para $A>\sim 130$ e a fraca, para nuclideos mais leves (SNEDEN et al. 2008), com o iodo na fronteira entre os dois domínios (SNEDEN et al. 2008).

Modelos para o processo-r de Kratz et al. (2007) indicam que iodo é produzido com Ba no processo-r, assim colocando o iodo dentro do componente forte. A componente fraca teria a sua origem em eventos mais frequentes enquanto a forte é devida a eventos raros. Supernovas de tipo II são um candidato natural para a componente fraca. Supernovas de colapso de núcleo comuns, de acordo com o usual modelo de ventos de neutrinos, produzem até o $\mathrm{Ag} / \mathrm{Cd}$ (WANAJO, 2013; BLISS et al. 2018). Porém, elementos ainda mais pesados encontram dificuldades em serem explicados por supernovas, especialmente os actinídeos.

\subsubsection{Nucleossíntese em Fusões de Estrelas de Nêutrons}

Porém, a recente detecção simultânea da fonte de ondas gravitacionais GW170817 (ABBOTT et al., 2017a, 2017b) e de uma kilonova associada a ela forneceu uma solução a esta dificuldade. A kilonova produziu uma enorme quantidade de elementos do processo-r, incluindo lantanídeos e actnídeos (PLAN et al. 2017). Após o decaimento dos elementos radioativos, este evento produziria cerca de 1-5 massas terrestres de európio e 3-13 massas terrestres de ouro (CÔTE et al. 2019). Esse evento é naturalmente explicada como uma Fusão de Estrela de Nêutrons (FENs). 
As Fusões de Estrelas de Nêutrons (FENs) são eventos raros onde são produzidas grandes quantidades de elementos pesados, já as supernovas de tipo II são eventos menos raros onde são produzidas quantidades menores desses elementos. Parece que as FENs são de longe a fonte dominante dos elementos do terceiro pico do processo-r, Os-Ir-Pt (incluindo Re e Au), e, provavelmente a única fonte dos actinídeos (THILEMANN et al. 2017). Porém, para nuclídeos mais leves do processo-r, a situação é menos clara.

O peso relativo da produção de elementos do processo-r por supernovas e FENs pode ser estimado pelo estudo de estrelas muito pobres em metal, já que os ambientes em que elas se formaram não teve tempo de acumular metais e os responsáveis pelo enricimento químico seriam só objetos de vida necessariamente curta como supernovas de tipo II, ou de vida que poderia ser curta, como as FENs. Algumas estrelas pobres em metal têm excessos moderados ou altos de elementos de processo r e são classificadas com base em suas razões [Eu / Fe] e [Ba / Eu]: estrelas r-I quando [Eu / Fe] $>0.3$ e $[\mathrm{Ba} / \mathrm{Eu}]<0$, r-II estrelas quando [Eu / Fe] $>1.0$ e $[\mathrm{Ba} / \mathrm{Eu}]<0$. Deve-se notar que Ba é um elemento predominantemente do processos (85\%) e está logo atém do segundo pico do processo-r e que o Eu é quase exclusivamente devido ao processo-r (98\%) e está localizado entre o segundo e o terceiro pico do processo-r. (SNEDEN et al. 2008). FNEs explicam o padrão de abundâncias das estrelas r-II, que também foi observado em galáxias anãs pobres em metais, como Reticulum II (FREBEL e BEERS 2018).

No entanto, fusões de estrelas de nêutrons podem não ser a única fonte de elementos do processo-r como os lantanídeos (CÔTE et al. 2019). Supondo que as fusões de estrelas de nêutrons sejam o único sítio de elementos do processo-r, modelos de evolução química galáctica não conseguem reproduzir a tendência decrescente de $[\mathrm{Eu} / \mathrm{Fe}]$ em $[\mathrm{Fe} / \mathrm{H}]>-1$ no disco da Via Láctea, consistentes com a fração de gama ray bursts e supernovas Tipo la em galáxias de tipo "early". Isso sugere um sítio de produção extra de Eu que estaria ativo no universo jovem, mas que desapareceria com o aumento da metalicidade e que seria responsável por cerca de $50 \%$ da produção de Eu nas primeiras épocas, antes de aparecerem supernovas de Tipo la. Classes raras de supernovas podem ser essa fonte adicional de processo-r, como supernovas magneto-rotacionais. Assim, a proporção de entre as contribuições para elementos do processo-r dos dois sítios (FENs e supernovas) abaixo do terceiro pico do processo-r tem grandes incertezas. 


\subsection{Fases da Evolução Estelar}

A evolução de uma estrela deve ser considerada de perto para se compreender a contribuição de cada fase para a origem dos elementos químicos. Cada faixa de massa estelar contribui de um modo distinto às abundâncias dos elementos químicos. Estrelas de massa intermediária, que são aquelas com massa entre 0,8 e 8 massas solares contribuem com sua morte ao enriquecimento químico do Universo e sua "morte" é como Nebulosa Planetária. Esse é o caso do Sol. Estrelas de alta massa têm mais de $~ 8$ massas solares e sua "morte" é como Supernova.

Como o tempo de vida de uma estrela cai com a sua massa, estrelas de massa mais baixa contribuem mais tarde à abundância dos elementos químicos do universo. As estrelas de alta massa já enriquecem o universo com seus elementos típicos (por exemplo, elementos alfas) quando ele é jovem, já as de massa intermediária só fazem uma grande contribuição com os elementos que produzem (por exemplo, nitrogênio), quando ele tem vários bilhões de anos de idade.

Cada fase da evolução estelar é importante de ser considerada para ser construir um quadro do enriquecimento químico do universo pelas estrelas.

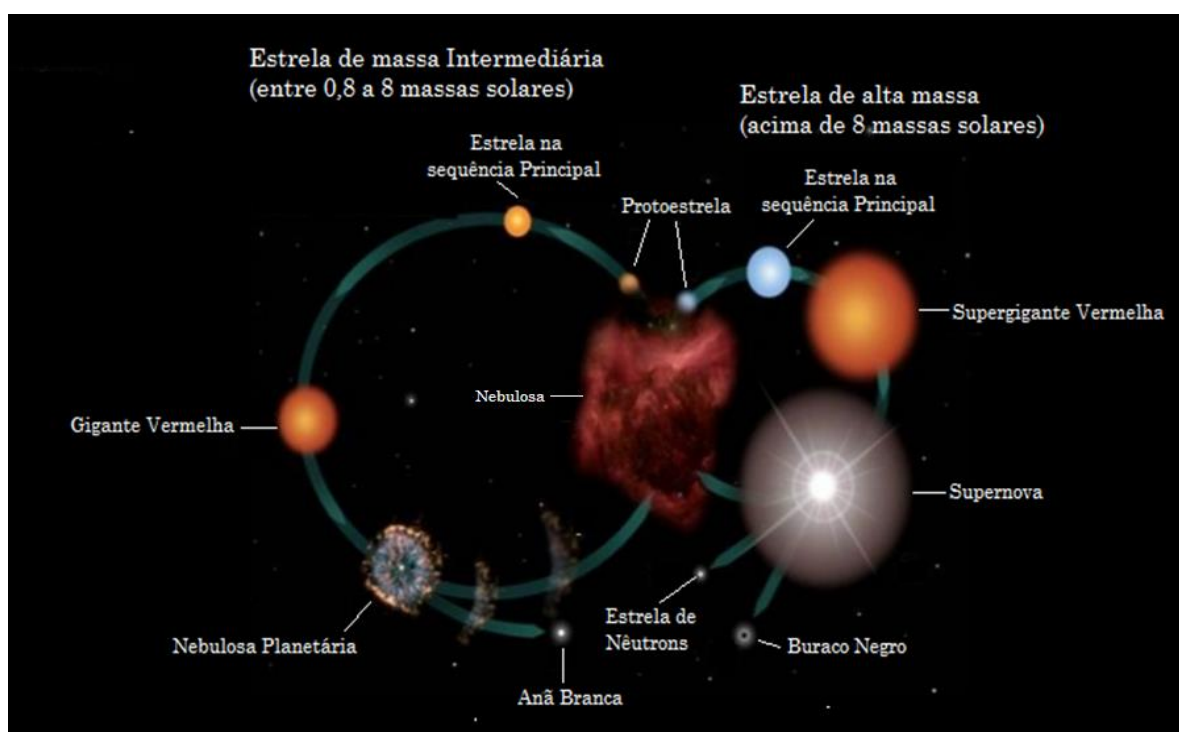

Fonte: Planetário e cine domem Johannes Kepler

Figura 2.13 - Evolução Estelar. 


\subsubsection{Protoestrela}

A protoestrela é a fase inicial da formação estelar. Inicia-se nas regiões mais densas da nebulosa que colapsa sob a ação da própria gravidade. À medida que se colapsa as nuvens liberam fragmentos. Esses fragmentos formam a protoestrela. A escala de tempo envolvida em todo esse processo é de milhões de anos.

\subsubsection{Sequência Principal}

Quando a estrela adquire um equilíbrio hidrostático, após alguns milhões de anos, a temperatura da estrela atinge um valor alto o suficiente para ocorrer reações nucleares transformando o hidrogênio em hélio. Quando isso ocorre, a estrela entra na fase da Sequência Principal, a mais longa da sua vida. Durante esta etapa de sua evolução, o interior da estrela ocorre um processo de autorregulação que mantem a estrela estável.

\subsubsection{Gigante Vermelha}

A fase da sequência principal se encerra quando o núcleo da estrela esgota o hidrogênio, convertido em hélio. Ocorre uma queda de pressão que faz com que a mesma sofra uma contração, que volta a estabilizar a estrutura da estrela. Criase um envoltório ainda rico em hidrogênio que continua a converter hidrogênio em hélio e seu envelope mais exterior se expande, reduzindo a temperatura da parte exterior da estrela, que se torna avermelhada e aumentando sua luminosidade. A estrela se torna uma gigante vermelha.

\subsubsection{Nebulosa Planetária e Anã Branca}

Estrelas de massa intermediária, (entre 0.8 a 8 massas solares), nos estágios avançados de sua evolução, sofrem oscilações violentas em seu envelope que não consegue manter e se destaca, gerando uma Nebulosa Planetária e deixando como resto uma anã branca. Este é o caso do Sol. Essas estrelas são as principais contribuidoras do carbono e nitrogênio do Universo.

\subsubsection{Supergigante}

Se a estrela iniciar sua vida com massa entre 10 e 25 massas solares, ao sair da sequência principal, ela se passará pela fase de supergigante. Após ocorrerá uma explosão de supernova e deixará como resto uma Estrela de Nêutrons. 
Se a estrela iniciar sua vida com massa entre 25 e 100 massas solares, no final o resto será um Buraco Negro.

\subsubsection{Estrela de Nêutrons}

As estrelas de nêutrons são objetos extremamente densos, com densidade entre cerca de 1 bilhão e 10 bilhões de toneladas por centímetro cúbico. Elas são formadas quando estrelas massivas, com cerca de 10 a 25 vezes a massa do Sol, no final de sua vida, explodem como supernova. Enquanto a maior parte do material da estrela é expelido para o universo em uma supernova, seu núcleo colapsa para criar uma estrela de nêutrons. Esse processo é o resultado de pressões tão extremas que os elétrons de fundem com os prótons. Em um sistema binário em que as duas estrelas eram massivas e deixaram como restos duas estrelas de nêutrons, no sistema, devido à perda de energia por ondas gravitacionais, as estrelas de nêutrons vão se aproximando e podem vir a sofrer uma fusão. Nesse processo, parte da matéria neutrônica sofre uma rápida descompressão, liberando elementos pesados (como ouro, tório e urânio) que podem contribuir significativamente às abundâncias cósmicas desses elementos.

\subsubsection{Buracos Negros}

Buracos negros são concentrações de massas tão extremas que a força da gravidade é tão forte que nem a luz consegue escapar. A região que delimita o buraco negro é chamada de horizonte de eventos e sua dimensão é dada pelo Raio de Schwarzschild. Em astrofísica, existem dois tipos de buracos negros:

\section{Buracos negros estelares}

Buracos negros estelares são buracos negros que possuem no máximo poucas dezenas de massas solares e são o resultado de uma supernova.

\section{Buracos negros supermassivos}

Buracos negros supermassivos são buracos negros com massas entre, milhões e bilhões de massas solares que se localizam no centro de grandes galáxias.

\subsubsection{Supernova tipo II}

A nomenclatura tipo II e tipo I se refere à presença de linhas de hidrogênio (tipo II) ou a sua ausência (tipo I) no espectro da supernova. O tipo I não é 
uma categoria uniforme, e têm três subtipos: la, Ib e lc. O tipo mais comum, la, é o resultado da evolução de um binário de estrelas de massa intermediário, em que o membro inicialmente mais massivo tornou-se uma anã branca e acretou massa da sua companheira até superar o limite de Chandrasekhar (cerca de 1,4 massa solar). Já os tipos lb e Ic, analogamente ao tipo II, são a explosão de uma estrela massiva no final da sua evolução. A diferença das supernovas de tipos lb e lc em relação às de tipo II, é que passaram por uma fase de intensos ventos estelares que removeram seu envelope de hidrogênio (nesta fase se apresentam como as chamadas estrelas Wolf-Rayet) antes de explodirem como supernova. Por isso não se observa linhas de hidrogênio no espectro de supernovas de tipo lb e Ic. Tanto as supernovas de tipo II como as de tipos lb e Ic são supernovas de colapso do núcleo.

\subsubsection{Supernova tipo la}

Esse tipo de supernova é originário de um sistema binário de estrelas, cada uma de massa intermediária (entre 0.8 que 8 massas solares) que, se estivessem isoladas, cada uma morreria como nebulosa planetária, deixando como resto uma anã branca. No sistema que produz uma supernova de tipo la, as coisas acontecem de um modo diferente. A estrela mais massiva do par chega ao final da sua vida e deixa como produto uma anã branca. Após, a estrela menor deixa a sequência principal e se expande, tornando-se uma gigante vermelha. Se as duas estrelas estiverem próximas o suficiente, o envelope da estrela inicialmente menor preenche o lobo de Roche comum a ambas as estrelas e a anã branca começa a capturar sua massa. A massa é transferida da companheira na fase de gigante vermelha até a anã branca formando um disco de acresção ao seu redor. A matéria capturada pode então cair sobre a anã branca que irá começar a aumentar de massa. Caso a anã branca ultrapasse o limite de Chandrasekhar (por volta de 1,4 massa solar), haverá um colapso da anã branca, produzindo uma explosão de supernova do tipo la. As supernovas de tipo la não deixam resto. Elas são as principais contribuidoras as abundâncias cósmicas dos elementos do grupo do ferro.

\subsection{Espalação}

A Espalação é outro processo de formação de núcleos atômicos, importante para explicar a abundância química de alguns elementos mais leves. 
Espalação é um processo em que um núcleo atômico se fragmenta em núcleos atômicos menores devido ao impacto de uma partícula de alta energia. No ambiente astronômico, esse processo ocorre entre raios cósmicos (partículas de alta energia, principalmente prótons e partículas alfas) e núcleos atômicos do meio interestelar (principalmente carbono, nitrogênio e oxigênio).

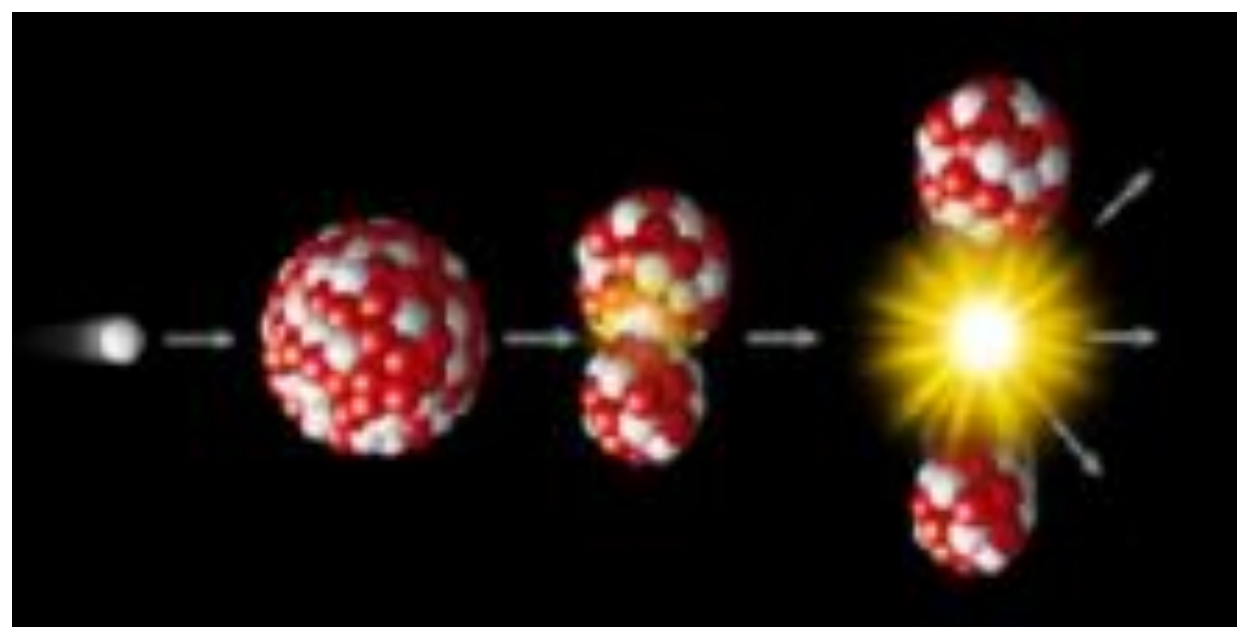

Fonte: https://www.todamateria.com.br/fissao-nuclear/

Figura 2.14 - Espalação por raios cósmicos.

A espalação produz lítio ( ${ }^{6} \mathrm{Li}$ e $\left.{ }^{7} \mathrm{Li}\right)$, berílio $\left({ }^{9} \mathrm{Be}\right)$ e boro $\left({ }^{10} \mathrm{~B}\right.$ e $\left.{ }^{11} \mathrm{~B}\right)$. Os isótopos ${ }^{6} \mathrm{Li}$, ${ }^{9} \mathrm{Be}$ e ${ }^{10} \mathrm{~B}$ têm origem exclusivamente nos raios cósmicos (KNELLER et al. 2008). Assim, berílio cósmico (do Sistema Solar, por exemplo) surgiu inteiramente no processo de espalação, já que ele tem apenas um isótopo estável, o ${ }^{9} \mathrm{Be}$. O boro tem dois isótopos estáveis, $\mathrm{O}^{11} \mathrm{~B}$, mais abundante $(80 \%)$ e o ${ }^{10} \mathrm{~B}(20 \%)$. A maior parte do boro cósmico, talvez a totalidade, tem origem na espalação, com algum espaço de até $30 \%$ para produção em estrelas.

Até recentemente, havia o cenário em que o lítio seria predominantemente destruído em estrelas, baseado em observações de estrelas pobres em metal, com abundâncias de lítio de cerca de $10 \%$ da abundância primordial, que foi denominado de platô de Spite (SPITE e SPITE, 1982). Isso estava em conflito com as abundâncias desse elemento no Sistema Solar maiores do que as primordiais. Ocorre que o lítio pode ser tanto destruído como produzido em estrelas, e se as observações se concentrarem em determinadas fases da evolução estelar, como na sequência principal ou no ramo das gigantes vermelhas, pode-se captar um déficit de lítio devido 
a mecanismo de destruição desse elemento que haviam atuado até aquele momento da evolução.

Uma solução para esse conflito seria a produção de lítio em fases avançadas da evolução estelar ou novas. Em ambos os casos estrelas de massa intermediária seriam as responsáveis. Duas observações recentes dão apoio a esse cenário. O Gaia-ESO Survey de aglomerados abertos revelou que a abundância estelar do lítio cresce com a metalicidade, indicando que o meio interestelar se enriquece em lítio com o tempo (RANDICH et al. 2020). A outra evidência é a observação de estrelas de baixa massa na fase de "red clump", que segue a fase de gigantes vermelhas indicou super-abundãncias de lítio por um fator de 40 em relação ao final do ramo das gigantes vermelhas, o que demonstra uma produção in situ de lítio (KUMAR et al. 2020).

Assim, o lítio tem uma origem tripla, na BBN, por espalação e em estrelas. Ele tem dois isótopos estáveis: ${ }^{6} \mathrm{Li} \mathrm{e}{ }^{7} \mathrm{Li}$, com abundâncias no Sistema Solar de 7.59\% e 92.41\%, respectivamente do total (ASPLUND et al. 2009). A quantidade de ${ }^{7} \mathrm{Li}$ devido à $B B N$ é $\mathrm{N} / \mathrm{N}_{H}=5,61 \times 10^{-10}$ (COC e VANGIONI, 2017). Esse valor corresponde a $29,5 \%$ da abundância cósmica total ( ${ }^{6} \mathrm{Li} \mathrm{e}{ }^{7} \mathrm{Li}$ ) do lítio, N/N $\mathrm{N}_{\mathrm{H}} 1,095 \times 10^{-9}$ (ASPLUND et al. 2009). Modelos de espalação de raios cósmicos prevêm uma razão ${ }^{7} \mathrm{Li} /{ }^{6} \mathrm{Li}=1,5$ para o lítio como origem em raios cósmicos (KNELLER et al. 2008). Como o ${ }^{6} \mathrm{Li}$ devido somente à espalação, o total de lítio $\left({ }^{6} \mathrm{Li}\right.$ e $\left.{ }^{7} \mathrm{Li}\right)$ do Sistema Solar devido a raios cósmicos é $2,5 \times 7.59 \%=19 \%$. Com esses números, $48,5 \%$ teriam origem ou no Big Bang ou raios cósmicos, e restariam $51,5 \%$ de origem estelar.

\subsection{Nebulosas}

Nebulosas são nuvens formadas por gás e poeira interestelar, muitas vezes associadas a regiões de formação estelar ou estrelas jovens, ou, no extremo oposto da evolução estelar, aos estágios finais da vida de uma estrela. Elas, portanto, são importantes ao conectarem o final da evolução de uma estrela ao enriquecimento em elementos químicos do meio interestelar e a evolução química das novas gerações estelares que nascerem desse meio.

As nebulosas estão entre os maiores objetos que existem nas galáxias. Seu nome vem do latim "Nubes" que significa nuvem. Elas são classificadas em 5 
categorias: emissão, reflexão, absorção ou escuras, planetárias e remanescentes de supernovas.

Nebulosas de Emissão. É o resultado da ionização do gás devido ao fluxo ultravioleta de estrelas próximas, produzindo emissão de fótons durante a recombinação dos íons. Devido à presença do hidrogênio ionizado $(\mathrm{H}$ II), também são chamadas de regiões $H$ II.

Nebulosas de Reflexão. Essas nebulosas estão próximas a estrelas mais frias do que as nebulosas de emissão e se apresentam na cor azulada devido ao fato da poeira presentes nessas nebulosas espalharem mais fortemente em curtos comprimentos de onda (no lado azul do espectro) a luz emitida por essas estrelas.

Nebulosas de Absorção ou Escuras: Apresentam-se como escuras por absorverem a luz de estrelas de fundo ou no seu interior. Algumas delas são regiões de formação estelar, porém as estrelas que nasceram no seu interior ainda estão encobertas pelo gás e poeira da nebulosa escura. Assim, algumas dessas nebulosas, quando observadas em longos comprimentos de onda - infravermelho, submilimétrico ou rádio -, são brilhantes nesses comprimentos de onda em seu interior, devido à formação estelar que aí está ocorrendo.

Nebulosas Planetárias: Recebem esse nome, pois quando foram observadas pela primeira vez pelo astrônomo William Herschel, foram confundidas com planetas. Porém, com a maior resolução das observações comprovou-se que era um fenômeno resultante do fim da vida de estrelas de massa intermediária.

Remanescentes de Supernovas: São os restos deixados pela explosão de uma Supernova.

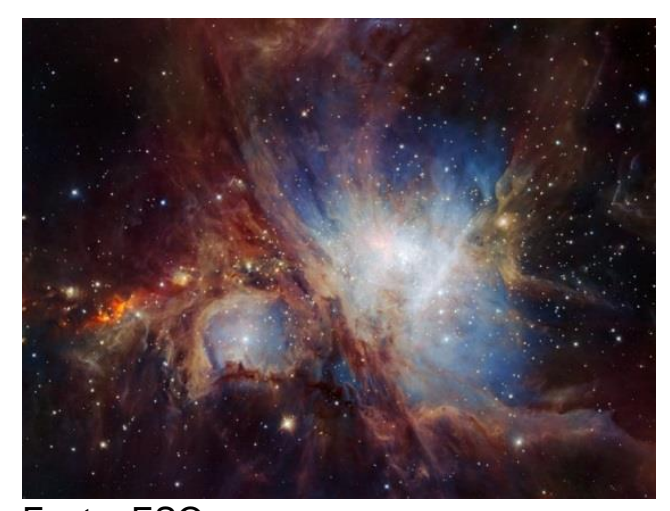

Fonte: ESO.org

Figura 2.15 - Nebulosa de Emissão. Nebulosa de Órion. 


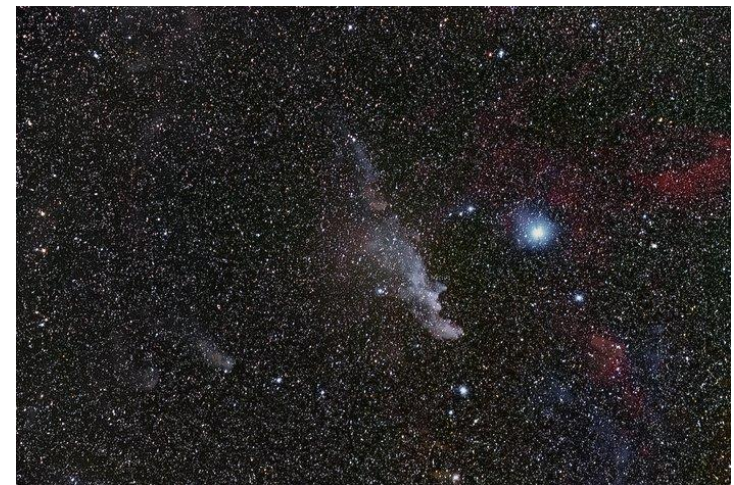

Fonte: ESO.org

Figura 2.16 - Nebulosa de Reflexão. Nebulosa Cabeça de Bruxa.

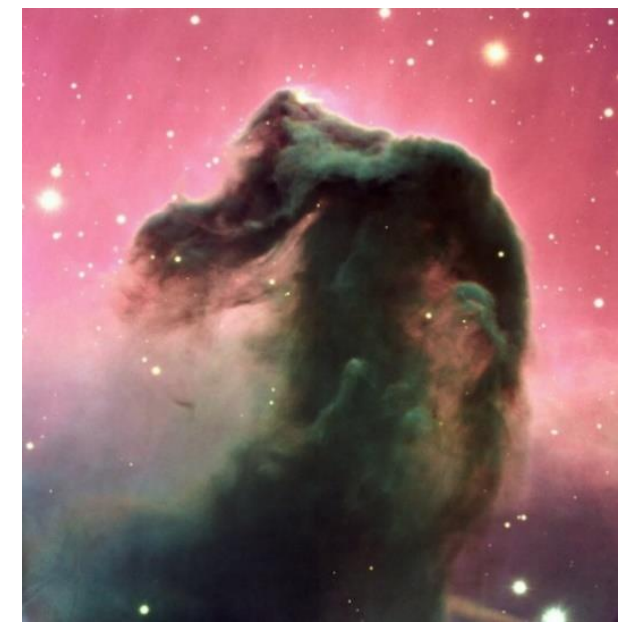

Fonte: ESO.org

Figura 2.17 - Nebulosa de Absorção ou Escura. Nebulosa Cabeça de Cavalo.

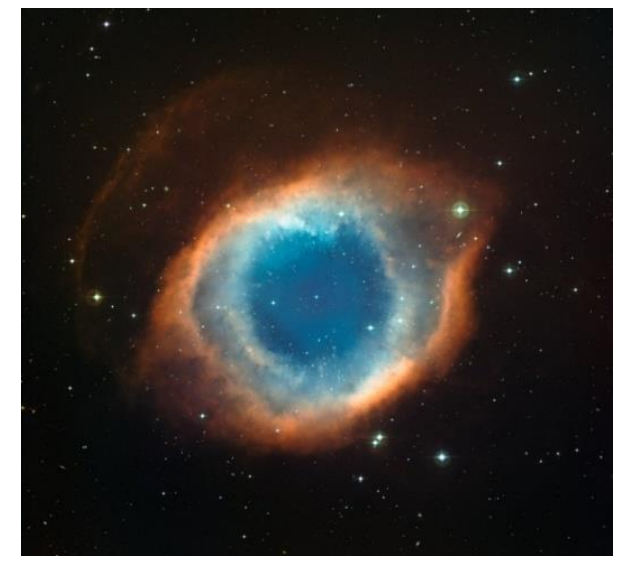

Fonte: ESO.org

Figura 2.18 - Nebulosa Planetária. Nebulosa Olho de Gato. 


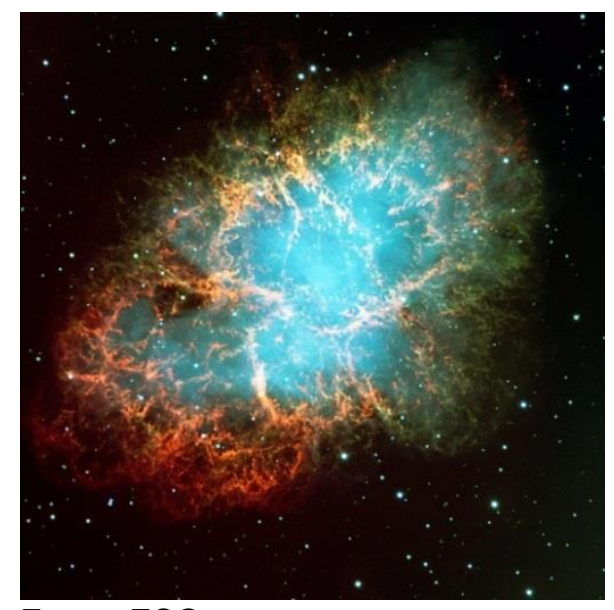

Fonte: ESO.org

Figura 2.19 - Remanescente de Supernova. Nebulosa do Caranguejo.

\subsection{Galáxias}

Galáxias são enormes conjuntos de estrelas, gás, poeira, nebulosas e matéria escura. Essas estruturas são sustentadas pela força gravitacional. Do ponto de vista da evolução química do Universo, esses sistemas são importantes, pois se o Universo não tivesse galáxias, os elementos formados durante a evolução estelar seriam dispersos no espaço e não estariam disponíveis para a formação de novas estrelas e, eventualmente, planetas. As galáxias são classificadas em 3 tipos: elípticas, espirais e irregulares.

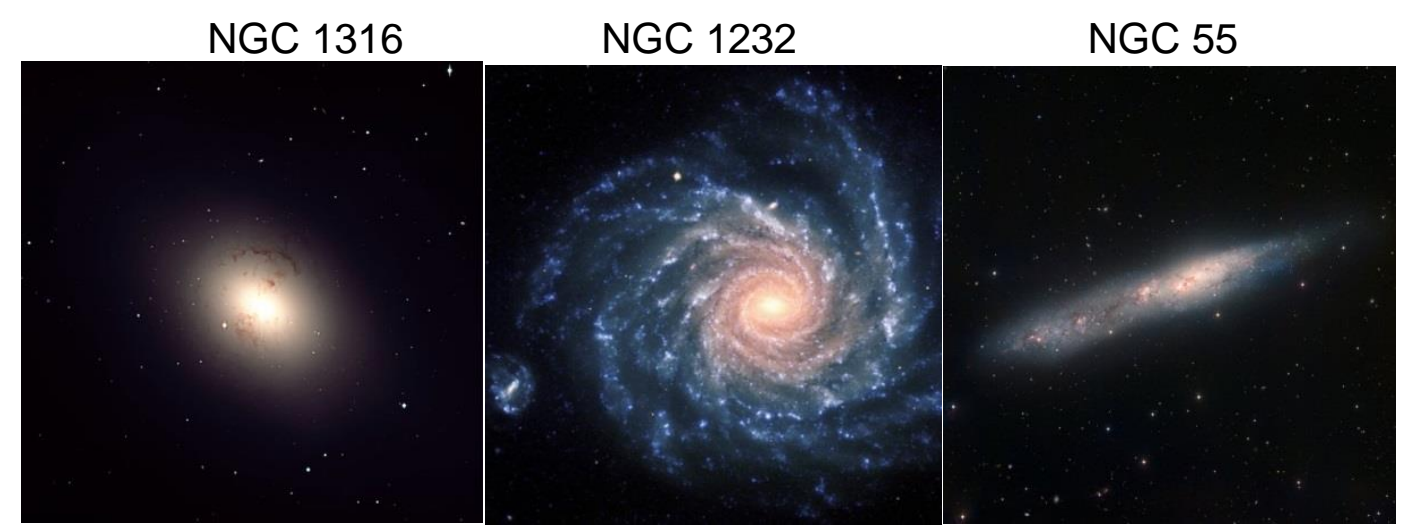

Fonte: ESO.org

Figura 2.20 - Tipos de galáxias: elíptica (NGC 1326), espiral (NGC 1232) e irregular (NGC 55). 
Galáxia elíptica: As galáxias elípticas têm aparência elíptica. Diferentemente das galáxias espirais, elas não têm traços característicos. Suas estrelas possuem órbitas aleatórias e poucas estrelas jovens. A maioria dessas galáxias tem pouco gás e pouca poeira, e se assemelham ao bojo das galáxias espirais.

Galáxia espiral: As galáxias espirais têm estrelas jovens e velhas. Nelas há formação estelar ainda em andamento. No bojo existe uma quantidade maior de estrelas mais velhas e nos braços uma maior atividade de formação estelar. Desta forma, os bojos das galáxias espirais têm uma tonalidade mais laranja e os braços uma tonalidade mais azul. A Via Láctea, onde se localiza o Sistema Solar, é uma galáxia espiral massiva.

Galáxia irregular: Galáxias irregulares são tipos de galáxias que apresentam uma estrutura desordenada ou caótica, ou seja, sem forma definida. Geralmente esse tipo de galáxia tem uma grande quantidade de estrelas jovens e continuam a gerar novas estrelas como resultado de uma intensa atividade de formação estelar. Essas galáxias em geral não possuem grandes dimensões, porém há algumas que são de maior porte, sendo o resultado de colisões entre outras galáxias. 


\section{O PORQUÊ APRENDER SOBRE OS ELEMENTOS QUÍMICOS}

O mundo da Ciência é fascinante, mas a compreensão das coisas que não conseguimos enxergar ou sentir certamente é intrigante. Todos os dias, deparamos com a rotina e não temos tempo de parar para refletir sobre e entender coisas que estão presentes no nosso cotidiano. Como por exemplo: como os átomos surgiram? Que processos são necessários para se fabricar átomos?

Hoje se sabe que somos feitos de átomos. O átomo é composto por um núcleo onde se encontra os prótons e nêutrons, e por elétrons que orbitam em níveis e subníveis. Os átomos formam a matéria do mundo que nos cerca. Mas, e de onde vêm os átomos?

Elemento químico é relativamente fácil de se definir: o conjunto dos átomos com o mesmo número atômico, ou seja, com a mesma quantidade de prótons em seu núcleo (FOGAÇA, 2020). Já a origem dos elementos químicos é mais complexa e de caráter astrofísico: parte deles no Big Bang (hidrogênio, deutério, hélio, lítio), parte em reações dos raios cósmicos no meio interestelar (lítio, berílio e boro), mas a maior parte deles durante o processo de evolução estelar.

Conforme a Base Nacional Comum Curricular (BRASIL, 2018), o conteúdo referente à Evolução Estelar é apresentado aos alunos no $9^{\circ}$ ano do ensino Fundamental em ciências. É nesse momento que se inicia a compreensão da importância da Química e da Astronomia no mundo que os cercam. Apropriando-se desse tema e sendo alfabetizados cientificamente de maneira a interpretar a tabela periódica se terá no futuro adultos críticos e atuantes na sociedade.

É de extrema importância que o aluno tenha conhecimento dos elementos químicos e de onde eles foram formados para ter maior entendimento do estudo que Ihe foi proposto. A partir daí o aluno passa a entender um pouco da importância da Química e da Astronomia, porém um dos primeiros passos para se aprender química é aprender a interpretar a tabela periódica, identificar cada elemento, identificar os períodos e famílias, saber o que isso significa, identificar os elementos naturais e os sintéticos. Tudo isso pode ser entendido com um bom estudo na tabela, mas de onde surgiram todos esses elementos?

Normalmente, sabemos da existência dos elementos, porém não sabemos como eles foram formados. Por isso o objetivo do presente projeto é ensinar a química através da astronomia, mostrando o surgimento desses elementos, de um modo 
lúdico onde os alunos se interessem a aprender. Ao se estudar as origens dos elementos químicos, os alunos verão que o conhecimento dos elementos não se limita a uma simples tabela, mas que há muitas histórias interessantes conectando-os não só às suas implicações para as tecnologias que usamos no dia a dia, mas também ao contexto astronômico que nos abarca.

Segundo Cunha (2012), o interesse daquele que aprende passou a ser a força motora do processo de aprendizagem, e o professor, o gerador de situações estimuladoras para aprendizagem. A falta de interesse do aluno nos dias de hoje decorre frequentemente das limitações de tempo do professor ou da falta de materiais que lhe são disponíveis, o que não permite que haja uma didática diferenciada.

Com os apelos da tecnologia, os alunos principalmente de escolas públicas, não têm mais interesse em aprender com os métodos tradicionais em escolas pobres de recursos. Muitos frequentam as aulas por obrigação, sem apresentar interesse pelas atividades propostas pelos professores e os mesmos não conseguindo atingir totalmente seus objetivos.

Ao se apresentar uma grande narrativa conectando os elementos às suas origens astronômicas, cria-se um ambiente motivacional de grande força. Assim, os elementos ganham uma dimensão cósmica. E, como é a proposta do presente trabalho, ao se apresentar essa conexão entre os elementos químicos e a astronomia, na forma de um jogo de tabuleiro, o aluno se sente impulsionado a explorar com prazer e ludicidade todo um universo de possibilidades.

A maior parte dos elementos químicos da Tabela Periódica foram gerados no interior de uma estrela. Como foi dito por Carl Sagan "Nós somos feitos de poeira de estrelas", portanto os elementos químicos que temos no nosso corpo, como o Oxigênio, o Carbono, o Hidrogênio, o Nitrogênio, o Cálcio, o Fósforo, o Potássio, o Enxofre, o Sódio, o Ferro, o Magnésio e o Cloro, todos eles foram formados em estrelas.

As abundâncias dos elementos químicos nos dão pistas sobre as origens deles. A Tabela Periódica do Astrônomo (Figura 3.1) apresenta os 10 elementos mais abundantes do Universo (McCall 2006). A área do quadrado correspondente à cada elemento químico é proporcional à sua abundância cósmica. É interessante comparar a Tabela Periódica do Astrônomo com a Tabela Periódica do Biólogo (Figura 3.2), que mostra os elementos mais abundantes na biologia terrestre. Deixando de lado os gases nobres, que são inertes, ou seja, quimicamente inativos, os 4 elementos 
quimicamente ativos mais abundantes no cosmos, $\mathrm{H}, \mathrm{O}, \mathrm{C}, \mathrm{N}$, conhecidos como CHON, também são os mais abundantes nos seres vivos da Terra. Explorar essas similaridades seria um poderoso recurso didático para uma abordagem transdisciplinar conjunta de astronomia, química e biologia.

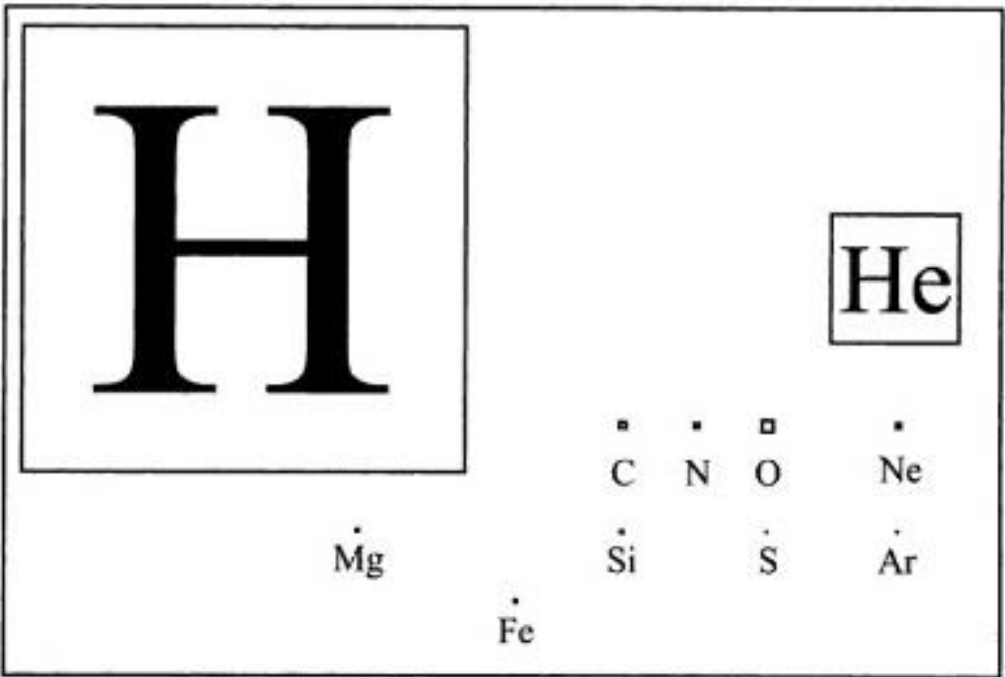

Fonte: McCall, 2006

Figura 3.1 - Tabela Periódica do Astrônomo.

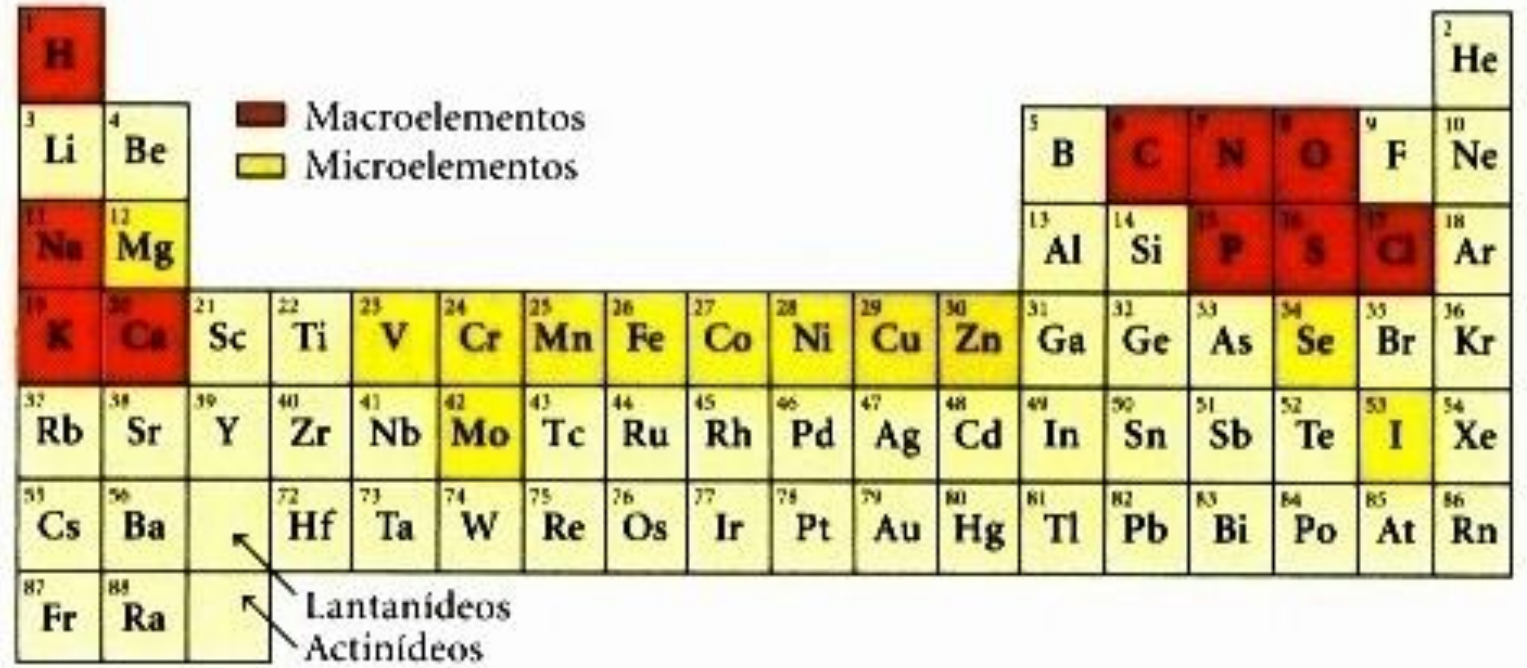

Fonte: Friaça, $2019 \mathrm{~b}$.

Figura 3.2 - Tabela Periódica do Biólogo. 
A discussão da Tabela Periódica do Astrônomo e da Tabela Periódica do Biólogo permite a realização de vários projetos de iniciação científica na escola dentro de uma perspectiva transdisciplinar. De modo a superar barreiras disciplinares tradicionais entre química, biologia, física, astronomia e geologia, pode-se explorar os dez eixos de pesquisa em astrobiologia (FRIAÇA et al. 2019a; SILVA, 2018):

- História da complexidade cósmica

- Universo molecular

- Habitabilidade

- Sistema Solar

- Exoplanetas

- Extremófilos

- Origens da vida

- Bioassinaturas

- Evolução das biosferas

- Ação humana na Terra e além

Vários dos temas dos eixos astrobiológicos podem ser desenvolvidos em conjunto com o estudo da origem e distribuição dos elementos químicos. A nucleossíntese e evolução estelar, tema do capítulo 2, pertence à "história da complexidade cósmica". O último eixo "ação humana na Terra e além" permite conexões entre química e ciências ambientais. Como a humanidade estaria perturbando os ciclos geoquímicos do Sistema Terra? (FRIAÇA 2009) Como a perturbação destes ciclos representa uma ameaça à biodiversidade e à humanidade? (FRIAÇA 2010) Como a presença humana no espaço e Sistema Solar poderia reduzir os estresses ambientais da mineração e geração de energia na Terra? (FRIAÇA 2012) Os ciclos geoquímicos podem ser entendidos como ciclos dos elementos químicos: o ciclo do carbono (aquecimento global e acidificação dos oceanos), ciclo do nitrogênio, ciclo do fósforo. Compreender as responsabilidades da sociedade sobre 0 gerenciamento dos elementos químicos daria uma grande contribuição à educação ambiental. 


\section{REFERENCIAL TEÓRICO}

\subsection{A história dos jogos na educação}

Os jogos já estavam presentes nas primeiras civilizações, apresentando cada jogo um conjunto de características e regras que os jogadores devem aceitar para a sua realização. O papel dos jogos na aprendizagem foi reconhecido por Platão, que considerou a importância de aprender brincando ao invés de pela repressão. Após a época de Platão, Aristóteles evidenciou a importância da ludicidade para a vida adulta.

Comenius (1592-1670) já defendia que a ludicidade estivesse presente no processo de aprendizagem, que os "os meninos sejam instruídos sobre os primeiros conceitos das Coisas do Mundo pelo jogo e pela brincadeira" (SCHELBAUER, 2010). A partir do século XVIII, devido à difusão dos ideais humanistas, os jogos didáticos passaram a ser utilizados como ferramenta pedagógica. Porém bem poucos tinham acesso a eles, sendo restritos às crianças da alta nobreza ou burguesia. Somente após a Revolução Francesa em 1789, os jogos se popularizaram como meio de aprendizagem, inicialmente voltados para o estímulo da leitura e a facilitação da realização de cálculos. Com o desenvolvimento histórico, o culto à razão do século XVIII cedeu lugar à uma percepção mais precisa do ser humano com não inteiramente racional. Assim, conforme assinala Huizinga (2007), a espécie humana passou a ser caracterizada não apenas como "homem racional", Homo Sapiens, mas também como "homem que joga", Homo Ludens, que, aliás, é o título do seu livro, primeiramente publicado em 1938.

No século XX, o pesquisador e psicólogo Lev Vygotsky reforçou a ideia de que os jogos facilitam o aprendizado. Ele relacionou o desenvolvimento intelectual à interação social causada pela prática de brincar. A palavra lúdica vem do latim Ludo que significa jogo ou divertimento. Assim, as atividades lúdicas são todos os movimentos cujo objetivo principal seja trazer prazer e divertir o praticante (SOARES, 2008).

Vários teóricos pioneiros da educação - Chateau (1987), Winnicott (1975), Mellou (1994), Piaget (1990), Vygotsky (2005), Wallon (2000), Elkonin (1998), 
Huizinga (1996) - ressaltam a importância da metodologia de ensino para crianças e adolescentes incluir uma dimensão lúdica.

Negrine (1998) assinala que brincar não significa que o jovem ou o adulto volte a ser criança, mas sim é um meio que possibilita ao ser humano integrar-se com os outros, consigo mesmo e com o meio social. O estudo de Negrine (1998) aponta que as atividades prazerosas agem no organismo causando sensações de liberdade e espontaneidade. Levando tudo isso em conta, podemos afirmar que as atividades lúdicas facilitam a aprendizagem de um indivíduo.

De acordo com Melo (2005), diversos estudos sobre atividades lúdicas vêm comprovar que o jogo, além de ser fonte de prazer e descoberta para o aluno, é uma tradução das situações sócio-históricas nas quais a cultura está imersa, sendo capaz de colaborar com o processo de construção do conhecimento do aluno.

\subsection{A importância dos jogos no ensino}

Acredita-se que jogos didáticos são fortes aliados no processo de ensino e aprendizagem, o que corrobora o conceito de educação consolidado por Jacques Delors nos seus Quatro Pilares da Educação (DELORS, 2003, p. 89-102). Delors afirma que a educação está alicerçada nos seguintes pilares: aprender a conhecer, aprender a fazer, aprender a viver com os outros e aprender a ser. Esses são tópicos essenciais para a transmissão de informação e comunicação no mundo globalizado em que se vive.

O jogo é uma ferramenta de desenvolvimento cognitivo e social. Brincando, a criança estimula a curiosidade, desenvolve a linguagem, o raciocínio, a concentração e atenção. Desde os tempos mais antigos, os jogos e brincadeiras estão presentes em diversas culturas, inclusive na cultura brasileira. Os jogos de tabuleiro mais antigos conhecidos remontam a aproximadamente 5.000 a.C.

Os arqueólogos encontraram dados feitos de ossos de punhos de ovelhas, entre povos antigos que utilizavam desses ossos como dados devido ao fato de serem aproximadamente cúbicos e dos lados serem fáceis de identificar.

Um dos jogos mais antigos que se conhece é o jogo "Mancala". Esse termo significa "mover" e o jogo é de origem africana. Já estava presente no antigo Egito, sendo considerado o pioneiro dos jogos de tabuleiro. Muitas tribos africanas ainda jogam a Mancala, assim preservando este legado cultural. 
Na Sabina Escola Parque do Conhecimento (em Santo André, São Paulo), ocorreu uma exposição de Cabo Verde (África Ocidental), na qual se realizou uma oficina com esse jogo, assim disponibilizando às crianças esse bem cultural.

O Mancala é um jogo cuja estratégia faz referência à germinação das sementes na terra e à colheita. No jogo também há correspondência entre o movimento das pedras e o movimento das estrelas na abóbada celeste.

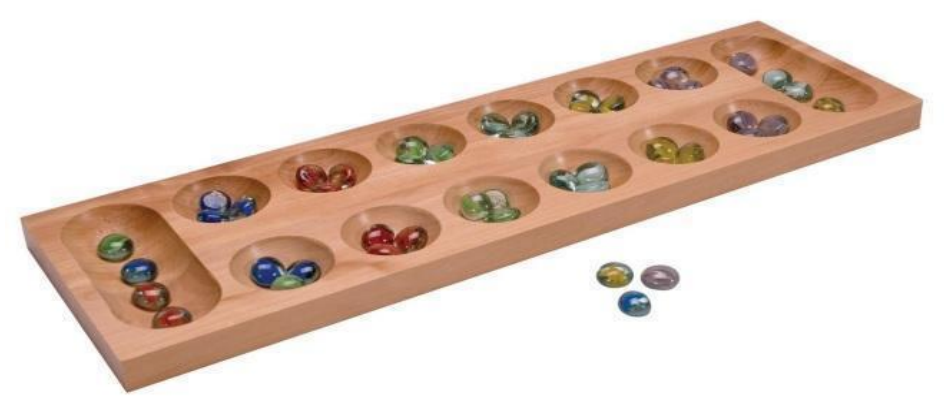

Figura 4.1 - Tabuleiro do Jogo Mancala.

Fonte: http://apaginaff5.blogspot.com/2011/01/jogos-de-mancala.html

Outro antigo jogo é o Senet, que significa "passagem da alma". Este jogo foi encontrado enterrado nas tumbas dos faraós. Os antigos egípcios acreditavam que após a morte os falecidos poderiam ficar entediados na outra vida, e por isso enterravam o jogo pertencente ao falecido para que ele desfrutasse de diversão pela eternidade. 


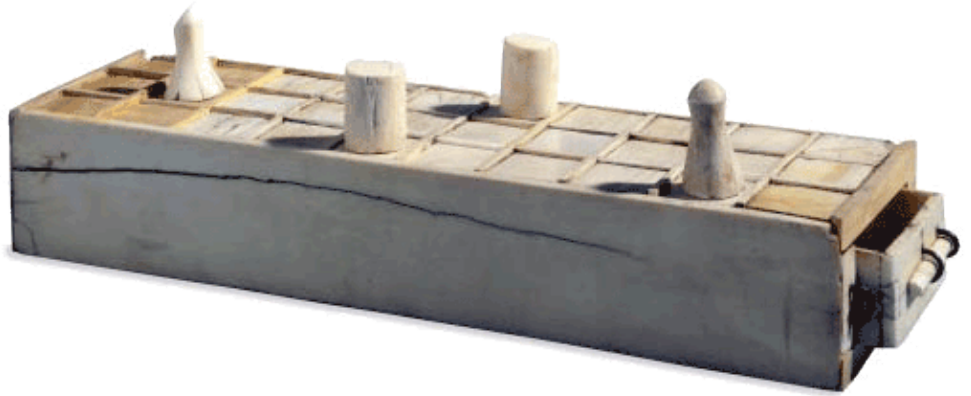

Figura 4.2 -Tabuleiro do Jogo Senet. Fonte: www.fascinioegito.sh06.com/senet.html

Com o passar do tempo, os avanços da tecnologia tornaram os jogos ainda mais atrativos. Nos dias atuais temos diversos tipos de jogos: jogos de cartas, jogos de tabuleiro, jogos de mesa, jogos de figurinhas colecionáveis, jogos de rua, vídeo games etc. Então, por que não incluir esses jogos na educação?

Ao longo desta pesquisa, foi verificado que, há muito tempo os professores procuram meios de estimular o interesse dos alunos. Cada professor tem seu jeito de tentar prender a atenção, usando desde técnicas tradicionais a pouco convencionais. Alguns dos recursos empregados são músicas fazendo uma paródia da matéria, aulas práticas com experimentos, vídeos relacionados a tema específico da matéria e jogos didáticos.

Há uma série de razões para os jogos estarem presentes dentro do contexto de aprendizado (SILVEIRA e BARONE, 1998, p.02). Um motivo fundamental e muito importante é a possibilidade de se construir autoconfiança. Outro é o incremento da motivação. Jogar é um método eficaz para a apreensão significativa daquilo que está sendo aprendido. Até mesmo o mais simples dos jogos pode ser empregado para proporcionar informações factuais e exercitar habilidades, conferindo destreza e promovendo competências.

$\mathrm{O}$ ato de jogar trabalha com raciocínio lógico, memória, coordenação motora, estratégia de trabalho em equipe, atenção, habilidades espaciais. O jogador aprende a lidar com a perda e o ganho. Portanto, o jogo é uma ferramenta importante para o desenvolvimento da criança fazendo com que ela adquira todas essas habilidades que vão perdurar por toda a sua vida.

De acordo com Kishimoto (1999), na Idade Média, os jogos foram proibidos por lei, pois eram associados ao mal, ao azar, ao vício, à libertinagem, à prostituição. Só no século XVI, após o Renascentismo, que se introduziram os jogos na educação. Desde então, os jogos são utilizados como ferramentas didáticas nas escolas. 
É importante ter uma forma de capturar a atenção dos alunos na hora de ensinar, seja com músicas, com humor, com brincadeiras, com aulas práticas ou com jogos. Com tanta tecnologia ao seu dispor, o aluno não tem mais interesse em aprender com os métodos tradicionais. Muitos frequentam as aulas por obrigação, sem apresentar interesse pelas atividades propostas pelos professores, que não conseguem atingir totalmente seus objetivos. Nesse contexto, os jogos são uma poderosa ferramenta motivacional. Os jogos existem desde os primórdios da humanidade e se tornaram parte integrante do nosso cotidiano e da nossa cultura. Ao jogar, o indivíduo se depara com a vontade de vencer que provoca uma sensação agradável e que aguça a sua percepção, pois as competições e os desafios são situações que mobilizam o ser humano por inteiro, em suas sensações e em suas ações. Assim, um jogo didático tem todo esse fundamento psicossocial. Como diz Fialho (2008), "Os jogos educativos com finalidades pedagógicas revelam a sua importância, pois promovem situações de ensino-aprendizagem e aumentam a construção do conhecimento, introduzindo atividades lúdicas e prazerosas, desenvolvendo a capacidade de iniciação e ação ativa e motivadora".

Jogos também seriam muito importantes para o ensino de astronomia. Segundo Damineli e Steiner (2010), a falta de formação específica em astronomia dos professores soma-se à ausência de material didático em astronomia e às muitas falhas nos livros didáticos que tratam do assunto. Assim, uma ferramenta para complementar o aprendizado será de grande ajuda no ensino de astronomia. Em seu livro "Jogos para o Ensino de Astronomia", Bretones (2014) retrata bem as dificuldades do professor em sala de aula.

Essas dificuldades foram consideradas ao se confeccionar um jogo de tabuleiro abordando astronomia em conjunto com química, mostrando como surgiram os elementos da Tabela Periódica e acrescentando aos estudos de química uma ferramenta mais dinâmica. Ao aplicarmos o jogo, tentamos despertar a curiosidade dos alunos pela astronomia e pela química e suas conexões, fomentando o interesse pela ciência e facilitando, ampliando e acelerando o ensino de ciências.

No jogo que desenvolvemos buscamos trabalhar transdisciplinarmente Química e Astronomia, enfatizando a origem dos elementos químicos. Para que o objetivo seja alcançado, utilizamos o jogo didático como instrumento facilitador de aprendizagem. Com base em princípios de jogos didáticos, produzimos um jogo de tabuleiro, no qual, através de uma sequência de etapas e com questões sendo 
colocadas a cada passo, vai-se realizando a construção de um conhecimento mais unificado dessas duas disciplinas.

\subsection{Transdisciplinaridade na educação}

Um dos desafios da educação contemporânea é preparar os estudantes para um mundo que passa por transformações extremamente rápidas e acúmulo de mensagens recebidas de diversas formas de mídia, muitas das quais não se caracterizam nem sequer como informações, mas antes como desinformação. Isso leva a uma opacidade do mundo e uma fragmentação do conhecimento. A transdisciplinaridade pode ser vista como uma nova maneira de se relacionar com os saberes, apropriada para enfrentar essa problemática atual. A perspectiva transdisciplinar promove na educação três atitudes básicas: rigor, tolerância e abertura. Enquanto rigor e tolerância formam um par de opostos complementares, a abertura é literalmente a "abertura" do ser para o não-ser, o eu para o outro, deste mundo para o universo, para possibilidades surpreendentes, para um "vácuo" criativo, que transforma o estudante/estudioso, em conjunto com o mundo onde atua (FRIAÇA, 2005).

Nesse ponto, deve-se distinguir três conceitos: multidisciplinaridade, interdisciplinaridade e transdisciplinaridade (MAX-NEEF, 2005). A multidisciplinaridade se refere à capacidade das disciplinas, atuando como unidades organizadas de conhecimento, de interagir umas com as outras a fim de compreender um objeto comum. Quando eles interagem, podem surgir uma compreensão que não foi alcançada antes por disciplinas isoladas. Implica cooperação entre disciplinas, sem coordenação. Normalmente ocorre entre áreas de conhecimento afins si e do mesmo nível hierárquico. Exemplos seriam a cooperação entre física, química e geologia, ou entre história, sociologia e linguagem.

A interdisciplinaridade considera uma abordagem vertical no sentido de que existem disciplinas que irão conduzir a direção da pesquisa. A equipe de trabalho multidisciplinar torna-se interdisciplinar a partir do momento em que todos os esforços são focados no cumprimento das metas e objetivos de uma ou mais disciplinas que realizam a coordenação da pesquisa. Um exemplo seria um projeto interdisciplinar na área da saúde, em que a medicina assume o papel de coordenação de disciplinas subordinadas, que podem ser a biologia, a química, a psicologia. 
Já a transdisciplinaridade ocorre quando há coordenação entre todos os níveis de saber. Implica uma hierarquia entre níveis de saber, onde em cada nível persistem várias disciplinas. Os níveis podem ser entendidos em termos de nossa compreensão e ação no mundo. Cada nível pode ser compreendido como uma pergunta. Por exemplo, nível (1), "o que existe?” (física, química, biologia...); nível (2), "o que somos capazes de fazer?" (engenharia, medicina, agricultura etc.), nível (3), "o que queremos fazer?" (políticas, planejamento, gerenciamento etc.), nível (4), "qual o valor do que fazemos?" (ética, filosofica etc.).

A distinção entre interdisciplinaridade e transdisciplinaridade remonta ao seminário Interdisciplinaridade: problemas de ensino e pesquisa na universidade, realizado em Nice em 1970 pela Organização para a Cooperação e Desenvolvimento Econômico (SANTOS et al. 2016). Nesse evento, Piaget, apresentou um modelo hierárquico, no qual a multidisciplinaridade - a mera soma das contribuições de disciplinas individuais - é a abordagem mais básica para a pesquisa ou currículo, e a interdisciplinaridade está um nível acima, coordenando e integrando várias disciplinas. A transdisciplinaridade está no topo da estrutura, transcendendo as fronteiras entre disciplinas e ciências e proporcionando um nível mais elevado de compreensão. O estágio das relações interdisciplinares seria sucedido pelo transdisciplinar, no qual essas conexões estariam situadas "dentro de um sistema total sem fronteiras estáveis entre as disciplinas". A motivação de Piaget para propor a transdisciplinaridade é que ela é necessária para compreender as relações entre a organização da vida e as estruturas físico-químicas.

Frequentemente se fala na metodologia da transdisplinaridade, mas seria melhor compreender a transdiciplinaridade como um ambiente cognitivo (FRIAÇA, JANOT PACHECO, 2014). A transdisciplinaridade vai além dos objetos de estudo. para considerar o ambiente no qual os objetos estão imersos. A pesquisa transdisciplinar não se concentra apenas no ambiente do objeto em estudo, mas também cria o ambiente. Enquanto que o estudo interdisciplinar circunda seu objeto de vários pontos de vista, na abordagem transdisciplinar, o objeto se expande em um espaço o envolvente, o espaço transdisciplinar. Nesse espaço ocorre a integração de vários pontos de vista, e a abertura para novas possibilidades que não eram esperadas no ponto de partida do estudo. Esse aspecto é extremamente relevante para a educação pois permite que vários estudantes se envolvam ativamente no aprendizado de ciências, dentro de um ambiente transdisciplinar, e o jogo, pela sua 
capacidade de promover interações, é uma grande ferramenta na construção de um espaço transdiciplinar.

\subsection{Astronomia nas escolas}

A astronomia está em nossas vidas desde o início dos tempos, despertando curiosidade e encantamento em todas as idades. Quando nos deparamos olhando para o céu, percebemos o quão vasto é o universo e como somos tão minúsculos nessa imensidão cósmica. A astronomia é uma ciência fascinante com a qual podemos envolver várias disciplinas fazendo com que os alunos se interessem mais nas aulas.

A Astronomia é uma ciência inseparável da cultura humana, que há milhares de anos, de forma explícita ou não, está presente em diversas formas de manifestações culturais e em fenômenos do nosso cotidiano. No entanto, ela tem se mantido afastada das salas de aula, o que leva a um amplo desconhecimento que pode ser observado em vários erros cometidos pelos meios de comunicação e, infelizmente, também por professores e autores de livros didáticos ao tratarem de fatos astronômicos.

A educação escolar possui um papel insubstituível como provedora de conhecimentos básicos e habilidades cognitivas e operativas necessárias para a participação na vida social e no que significa o acesso à cultura, ao trabalho, ao progresso e à cidadania. (LIBANEO, 1984 apud WEISSMANN, 1998).

Segundo Langhi \& Nardi (2010), com base em estudos da história da astronomia na escola, confirmam que, o primeiro curso de graduação em astronomia do Brasil foi elaborado em 1938, na antiga Universidade do Brasil, mas infelizmente com o decreto de 1942, o ensino foi modificado fazendo com que estes cursos perdessem a importância. Nos anos 60, algumas instituições de ensino superior ofereciam o curso de astronomia somente como uma disciplina optativa, como acontece até hoje.

De acordo com Queiroz (2008), os anos 90 foram marcados pela aprovação da Lei de Diretrizes e Bases da Educação Nacional (LDB), a criação das Diretrizes Curriculares Nacionais (DCN) pelo Conselho Nacional de Educação, e pela proposta dos Parâmetros Curriculares Nacionais (PCN), pelo Ministério da Educação. Com 
base nessas reformas educacionais, a matéria de Astronomia se agregou às disciplinas de Ciências e Geografia no ensino fundamental e Física no ensino médio (LANGHI, 2004).

Segundo o Currículo do Ensino de São Paulo: Ciências da Natureza e suas Tecnologias (SÃO PAULO, 2010), no 1ํano do ensino médio, a disciplina de Física aborda alguns temas relacionados à astronomia.

No $3^{\circ}$ semestre

Tema 1: Universo - Elementos que o compõem

Tema 2: Interação Gravitacional

No 4ํㅗㄴ Semestre

Tema 1: Universo - Sistema Solar

Tema 2: Universo - Evolução, Hipóteses e Modelos

Vemos que a presença da astronomia nas escolas ainda está em um estágio muito modesto, mostrando aos alunos muito pouco desse universo tão imenso que vivemos. $O$ ideal seria que o fascínio por esse assunto presente na mídia e na vida cotidiana seja trazido para a sala de aula.

\subsection{Ambientes não formais de ensino}

Segundo Bianconi \& Caruso (2005), pode-se classificar o ensino em três categorias. Há o ensino formal, no qual o aluno está presente na escola e é avaliado, há o ensino informal, que é aquele no qual a pessoa aprende a partir das experiências no cotidiano, e há a educação não formal, que se define como qualquer tentativa educacional organizada que se realiza fora do sistema formal de ensino.

Na Sabina Escola Parque do Conhecimento, trabalha-se com as crianças um ensino não formal, para o qual instrumentos de avaliação não são essenciais. No parque se ensina Matemática, Física, Química, Biologia, Geografia, Ciências naturais, Artes, História e Astronomia, não só para alunos de escolas, mas também ao público interessado em aprender ciência.

De fato, a astronomia não é uma matéria muito divulgada nas escolas. Para suprir essa deficiência, todos os anos, o Planetário e Cine Dome de Santo André Johannes Kepler, oferece cursos para professores, dos quais destacamos: 
$\checkmark$ GTTP (Galileo Teacher Training Program). Esse programa surgiu em 2009 pelo incentivo da UAI (União Astronômica Internacional) promovendo a formação de professores, ano este escolhido pela ONU como "Ano Internacional da Astronomia", celebrando os 400 anos do uso astronômico do telescópio por Galileu Galilei.

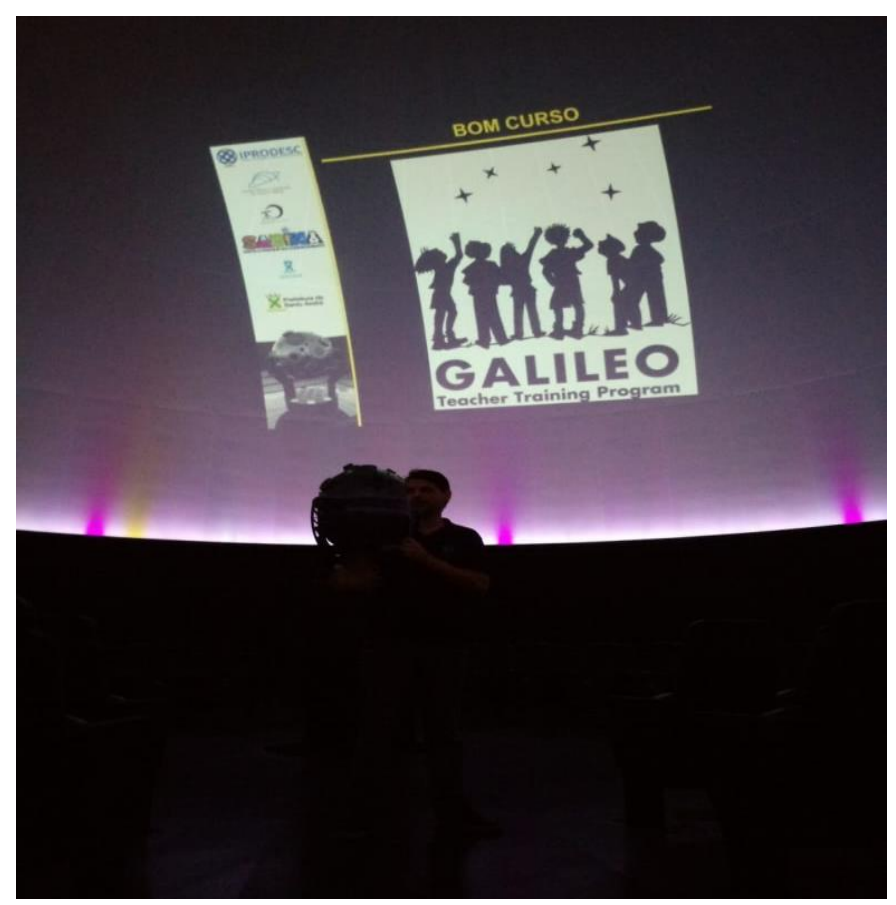

Figura 4.3 - GTTP (Galileo Teacher Training Program). Fonte: Planetario e cinedome de Santo André Johannes Kepler

\section{$\checkmark$ Curso de Ensino de Astronomia e as Estações de Aprendizagem}

Esse curso foi oferecido aos professores com o intuito de mostrar metodos diferenciados de abordar o mesmo tema em sala de aula. Neste curso, fui a responsável pela aula "Ensino de Astronomia e Jogos como Recursos em Sala de Aula", cuja finalidade era mostrar algumas maneiras de prender a atenção dos alunos em sala de aula com atividades práticas, entre elas os jogos. 


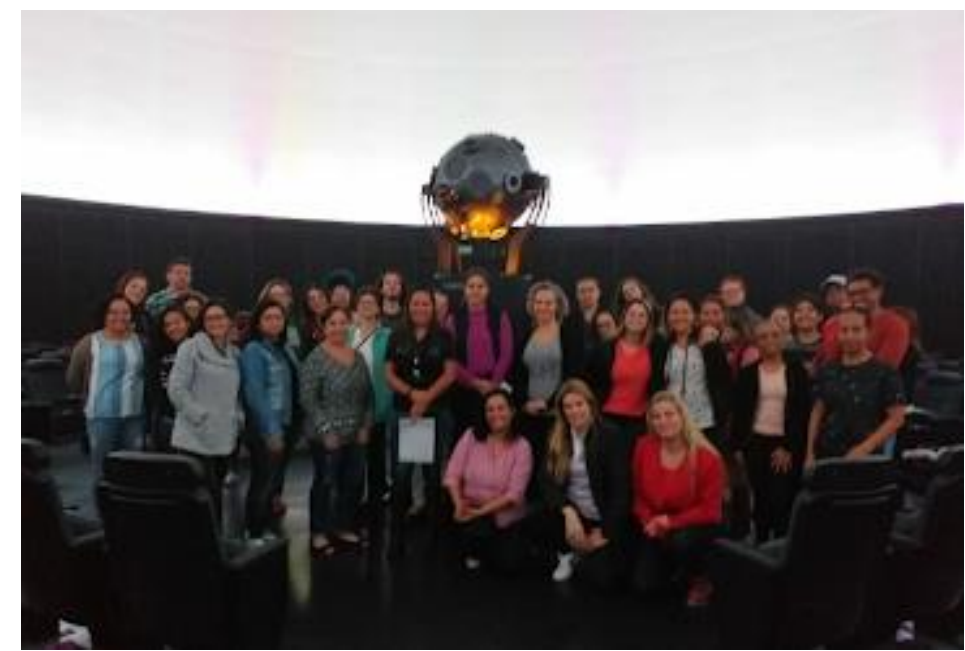

Figura 4.4 - OBA (Olimpíada Brasileira de Astronomia e Astronáutica). Fonte: Planetario e cinedome de Santo André Johannes Kepler

\section{$\checkmark$ OBA (Olimpíada Brasileira de Astronomia e Astronáutica)}

Outro curso que acontece no Planetário Johannes Kepler é o da OBA, no qual os alunos e professores das escolas do município de Santo André se preparam para ter um bom desempenho nessa competição, e até pleitear uma medalha de ouro. Nem todas as escolas têm esse incentivo, e por esse motivo, esse evento teria que ser mais difundido tanto entre escolas públicas como particulares.

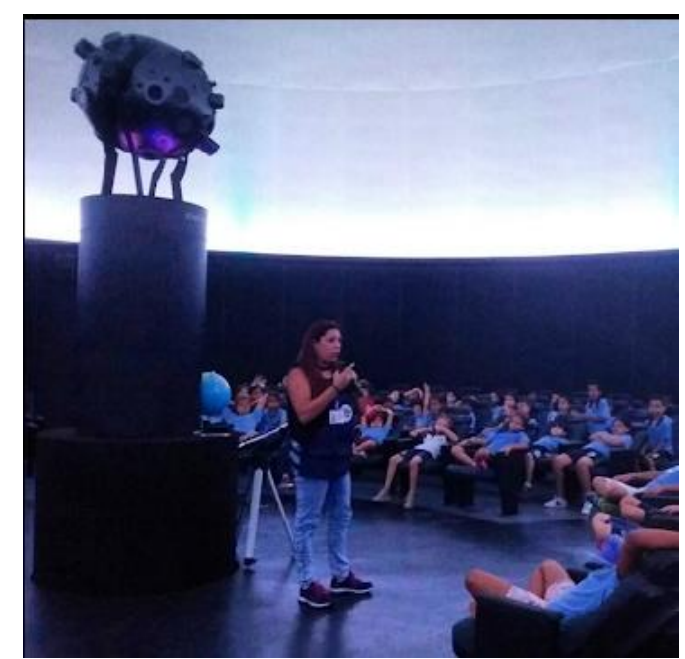

Figura 4.5 - Preparação para a OBA no Planetario e cinedome de Santo André Johannes Kepler. Fonte: Planetário e cinedome de Santo André Johannes Kepler. 


\section{DADOS, ANÁLISE E DISCUSSÃO}

Como o intuito deste trabalho é verificar como jogos podem ajudar a promover uma compreensão de química e astronomia, foi desenvolvido um jogo de tabuleiro e aplicado a alunos do $9^{\circ}$ ano do ensino fundamental e $1^{\circ}$ ano do ensino médio na escola estadual do município de Mauá para que eles tenham o conhecimento de onde e como os elementos químicos surgiram.

O jogo foi desenvolvido a partir da ideia do jogo perfil, o jogo possui um tabuleiro, 60 cartas, 5 fichas, 4 dados, 4 peões, uma tabela periódica personalizada, uma tabela periódica normal e uma ampulheta.

A tabela periódica "Origem dos Elementos Químicos" foi construída com inspiração naquela elaborada por Johnson $(2017,2019)$ para representar a fonte de nucleossíntese de cada elemento do Sistema Solar.

Na tabela "Origem dos Elementos Químicos", são representados todos os elementos naturais até o urânio, com a exceção do tecnécio $(Z=43)$ e do promécio $(Z=61)$, que são elementos radioativos artificiais. Cada quadradinho correspondente a um elemento é preenchido por triângulos ou faixas com áreas proporcionais à contribuição relativa de uma origem nucleossintética, que são indicadas por um código de cores. As fontes de nucleossíntese são: Big Bang, estrelas de alta massa, estrelas de massa intermediária, supernovas de tipo la, fusão de estrelas de nêutrons, espalação por raios cósmicos.

As abundâncias e razões isotópicas são do Sistema Solar (ASPLUND et al. (2009). Para os elementos produzidos por captura de nêutrons (processo-s e processo-r), isto é, do gálio $(Z=31)$ até o urânio $(Z=92)$, utilizam-se as razões entre processo-s e processo-r para a origem de cada elemento de Sneden et al. (2008).

O hidrogênio tem origem exclusivamente no Big Bang. A maior parte do hélio é sintetizado no Big Bang é 12\% em estrelas (seção 2.2.1). Supõe-se que o He de origem estelar seja produzido meio a meio em estrelas de alta massa (6\%) e estrelas de massa intermediária (6\%). Os elementos Be e B são produzidos exclusivamente por espalação, e o lítio, 29,5\% no Big Bang, 19\% por espalação e $51,5 \%$ em estrelas de massa intermediária (seção 2.4). Do carbono ( $Z=6)$ até o zinco $(Z=30)$, utilizou-se os resultados do modelo de evolução química para o disco de galáxias de Lanfrachi e Friaça (2003), considerando-se os parâmetros para a Via Láctea, a posição do Sol (8.2 kpc do centro da Galáxia) e momento de nascimento 
(4,6 bilhões de anos atrás), atualizando as prescrições de nucleossíntese (BARBUY et al. 2015; FRIAÇA e BARBUY, 2017; da SILVEIRA et al. 2018; ERNANDES et al. 2018; ERNANDES et al. 2020).

Para os elementos do processo-s, a proporção entre a contribuição de estrelas de alta massa e de massa intermediária (AGBs) provém dos modelos de Travaglio et. al. (2004), do gálio até o nióbio ( $Z=41)$; do molibdênio em diante, somente há a contribuição das AGBs (seção 2.2.5). Considera-se que os elementos do processo-r são unicamente devidos a supernovas de tipo II até o cádmio $(Z=48)$, e somente devidos a fusão de estrelas de nêutrons do índio $(Z=49)$ em diante, embora na verdade deva haver uma proporção entre os dois sítios até talvez os lantanídeos, se bem com um peso crescente da contribuição da fusão de estrelas de nêutrons com o número atômico (seção 2.2.6).

O tabuleiro tem no início uma representação do Big Bang, a partir de onde se percorre um caminho de 60 quadradinhos, cada um com elemento químico, com peões de cores diferentes representando o seu jogador. A segunda imagem do jogo será uma nebulosa de Orion (M42) por ser um "berçário de estrelas", a terceira imagem uma protoestrela, a quarta imagem, uma estrela da sequência com massa superior ao Sol, em cor azul, a quinta imagem, uma supergigante vermelha, a sexta imagem, uma supernova, a sétima imagem, uma estrela de nêutrons, a oitava imagem, um buraco negro, a nona imagem, uma nebulosa planetária, a décima imagem, uma protoestrela, a décima primeira imagem, o Sol, a décima segunda imagem, o Sistema Solar, a décima terceira e última imagem, a Terra, finalizando o jogo. Ao decorrer do jogo serão tiradas algumas cartas onde haverá informações sobre o elemento e se o jogador avança ou volta, assim deixando o jogo mais emocionante.

Mas antes de aplicar o jogo foi feito uma pequena pesquisa com os professores do município de Santo André que frequentaram o planetário que fica localizado na Sabina Escola Parque do conhecimento. 


\subsection{Questionário diagnóstico para professores}

No decorres da visita ao planetário, foi oferecido a 379 professores um questionário diagnóstico para investigar se são utilizados jogos em sala de aula como ferramenta de aprendizagem.

Resultados obtidos ao aplicar o questionário (JOGOS COMO RECURSOS EM SALA DE AULA)

Tabela 1- Número de professores por tipo de escola

\begin{tabular}{|l|l|l|}
\hline Escolas & Municipais de Santo André & $\mathbf{3 4 6}$ \\
\cline { 2 - 3 } & Escolas Particulares & $\mathbf{2 1}$ \\
\hline \multirow{2}{*}{} & Outras escolas públicas & 12 \\
\cline { 2 - 3 }
\end{tabular}

Tabela 2- Número de professores por nível escolar

\begin{tabular}{|l|l|l|}
\hline \multirow{10}{*}{ Ano escolar } & Ensino Fundamental 1 & $\mathbf{4 0}$ \\
\cline { 2 - 3 } & Ensino Fundamental 2 & $\mathbf{6 0}$ \\
\cline { 2 - 3 } & Ensino Fundamental 3 & $\mathbf{1 0 8}$ \\
\cline { 2 - 3 } & Ensino Fundamental 4 & $\mathbf{6 9}$ \\
\cline { 2 - 3 } & Ensino Fundamental 5 & $\mathbf{8 5}$ \\
\cline { 2 - 3 } & Ensino Fundamental 6 & $\mathbf{8}$ \\
\cline { 2 - 3 } & Ensino Fundamental 8 & $\mathbf{1}$ \\
\cline { 2 - 3 } & Ensino Fundamental 9 & $\mathbf{0}$ \\
\cline { 2 - 3 } & Ensino Médio 1 & $\mathbf{3}$ \\
\cline { 2 - 3 } & Ensino Médio 2 & $\mathbf{1}$ \\
\cline { 2 - 3 } & Ensino Médio 3 & $\mathbf{1}$ \\
\hline
\end{tabular}




\section{9 respostas}

\section{Gráfico 1.}

Tipo de escola

379 respostas

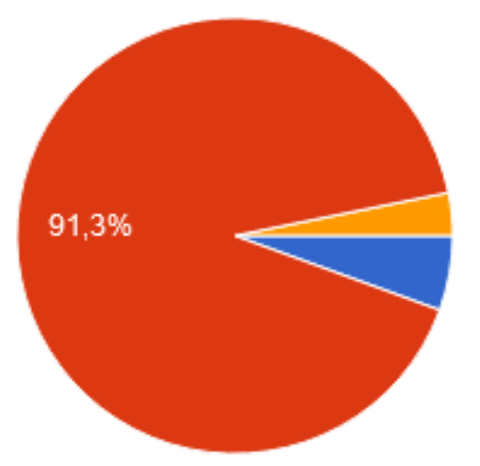

Particular

- Municipal de Santo André

Outra escola pública

\section{Gráfico 2.}

\section{Ano escolar}

379 respostas

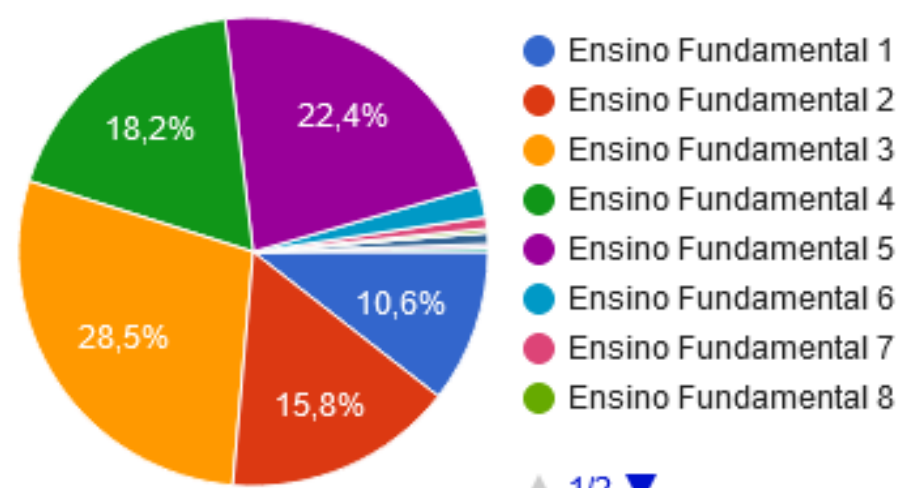

Ensino Fundamental 9

Ensino Médio 1

- Ensino Médio 2

Ensino Médio 3

$1 / 2$ 
Tabela 3 - Respostas dos professores do $1^{\circ}$ ano do Ensino Fundamental

\begin{tabular}{|l|l|l|l|}
\hline Questionário Diagnóstico & Sim & Não & Não apliquei nenhum jogo \\
\hline $\begin{array}{l}1^{\circ} \text { Você considera os jogos um } \\
\text { método de aprendizagem? }\end{array}$ & 40 & 0 & 0 \\
\hline $\begin{array}{l}2^{\circ} \text { Alguma vez você utilizou jogos } \\
\text { em sala de aula? }\end{array}$ & 39 & 1 & 0 \\
\hline $3^{\circ}$ O método foi satisfatório & 39 & 0 & 1 \\
\hline $\begin{array}{l}4^{\circ} \text { Você teve alguma dificuldade em } \\
\text { aplicar o jogo? }\end{array}$ & 9 & 30 & 1 \\
\hline $\begin{array}{l}5^{\circ} \text { Aplicaria novamente o jogo como } \\
\text { ferramenta didática? }\end{array}$ & 39 & 0 & 1 \\
\hline Total de professores: 40 & & & \\
\hline
\end{tabular}

\section{Gráfico 3.}

4. Você teve alguma dificuldade em aplicar o jogo?

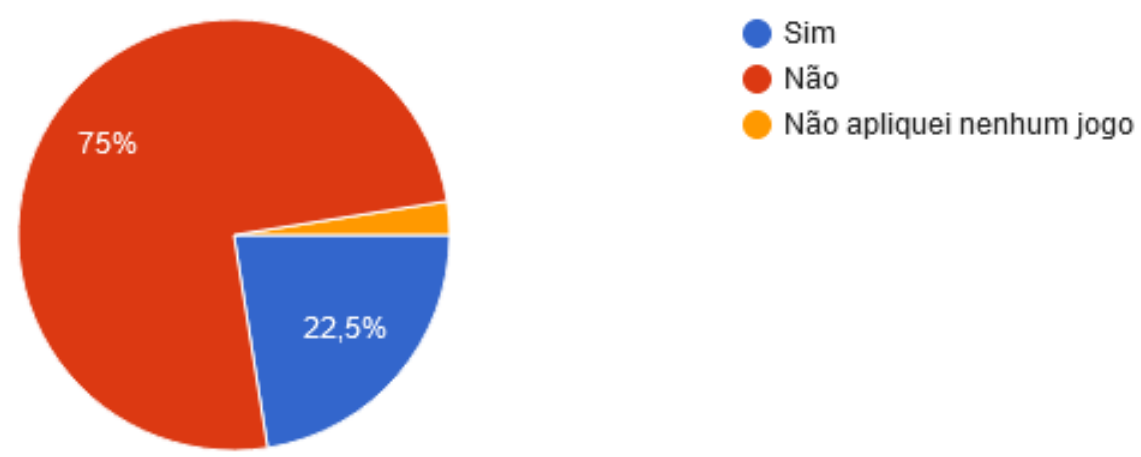


Se sim, qual (is)?

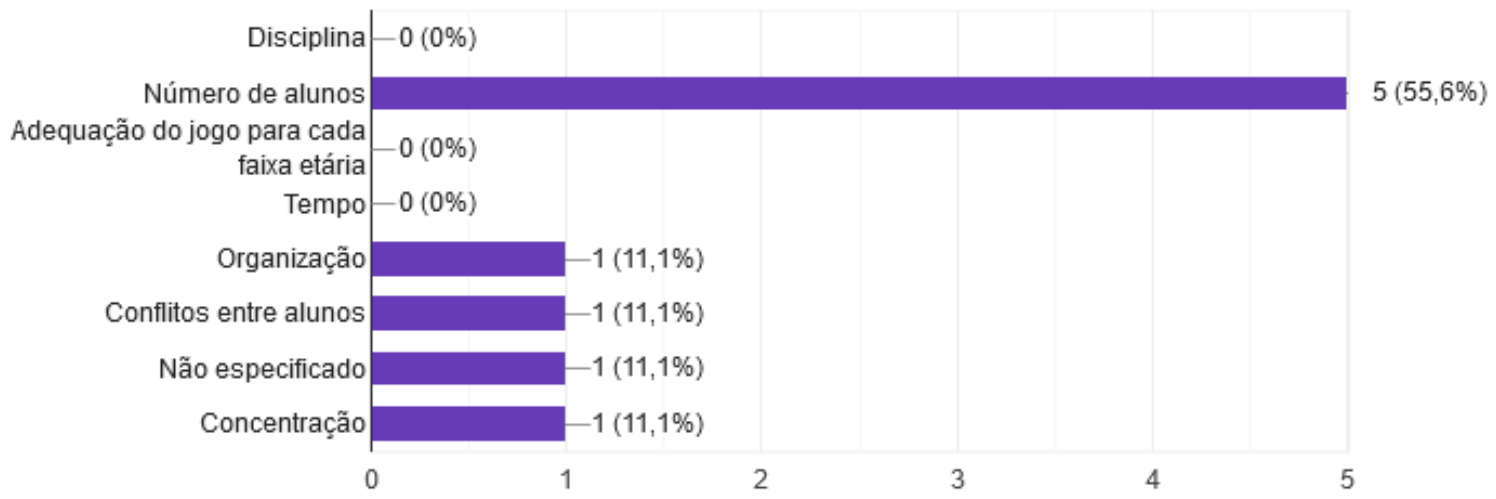

Como vemos na Tabela 3, a totalidade (40) dos professores do $1^{\circ}$ ano do ensino fundamental consideram os jogos como método de aprendizagem e apenas um não os utilizaram em sala de aula. Dos que os utilizaram, todos consideram o método satisfatório e aplicariam os jogos novamente em sala de aula, mas 22,5\% tiveram dificuldades. A maior dificuldade foi a quantidade de alunos em sala de aula.

Tabela 4- Respostas dos professores do $2^{\circ}$ ano do Ensino Fundamental

\begin{tabular}{|l|l|l|l|}
\hline Questionário Diagnóstico & Sim & Não & Não apliquei nenhum jogo \\
\hline $\begin{array}{l}1^{\circ} \text { Você considera os jogos um } \\
\text { método de aprendizagem? }\end{array}$ & 60 & 0 & 0 \\
\hline $\begin{array}{l}2^{\circ} \text { Alguma vez você utilizou } \\
\text { jogos em sala de aula? }\end{array}$ & 59 & 1 & 0 \\
\hline $3^{\circ}$ O método foi satisfatório & 59 & 0 & 1 \\
\hline $\begin{array}{l}4^{\circ} \text { Você teve alguma dificuldade } \\
\text { em aplicar o jogo? }\end{array}$ & 23 & 36 & 1 \\
\hline $\begin{array}{l}5^{\circ} \text { Aplicaria novamente } 0 \text { jogo } \\
\text { como ferramenta didática? }\end{array}$ & 58 & 1 & 1 \\
\hline Total de professores: 60 & & & \\
\hline
\end{tabular}




\section{Gráfico 4.}

4. Você teve alguma dificuldade em aplicar o jogo?

\section{0 respostas}

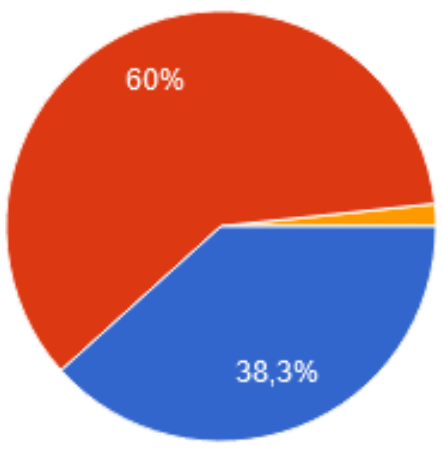

Sim

Não

Não apliquei nenhum jogo

Se sim, qual (is)?

\section{1 respostas}

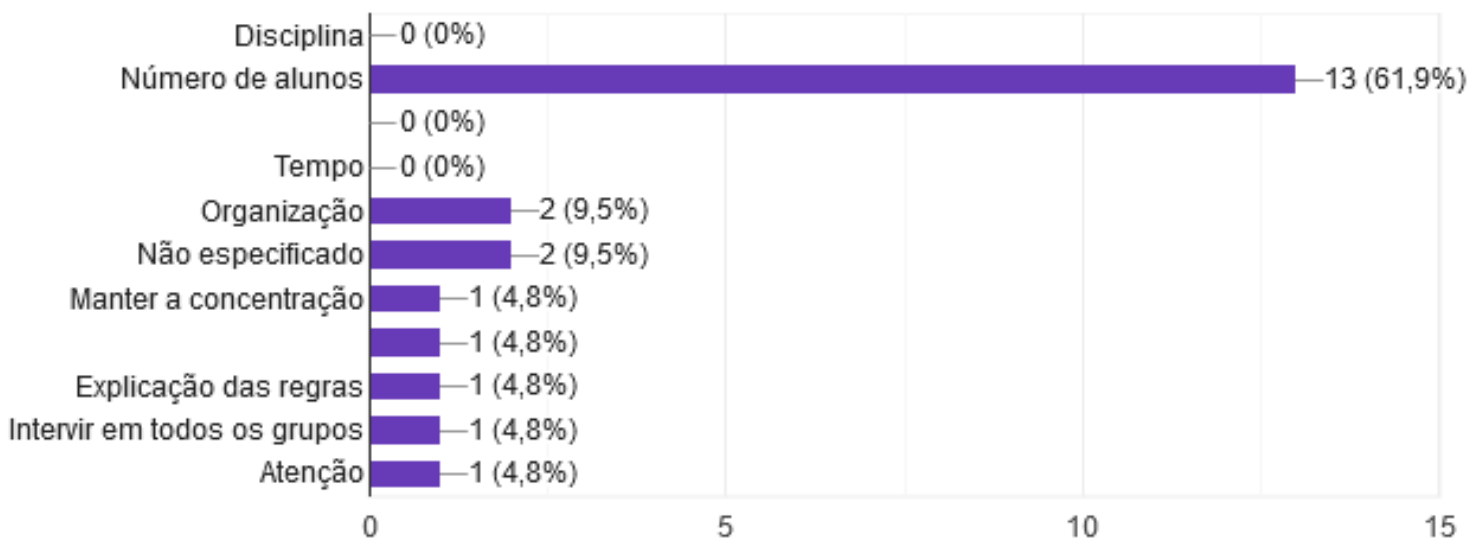

Os resultados para o $2^{\circ}$ ano do ensino fundamental (Tabela ) são muito semelhantes ao do $1^{\circ}$ ano. A totalidade $(60)$ dos professores do $1^{\circ}$ ano consideram os jogos como método de aprendizagem e apenas um não os utilizou em sala de aula. Dos que os utilizaram, todos consideram o método satisfatório e apenas um não aplicaria os jogos novamente em sala de aula. Porém a incidência de dificuldade em 
aplicar jogos foi $38,3 \%$, maior do que para o $1^{\circ}$ ano, $22,5 \%$. Novamente, a maior dificuldade foi a quantidade de alunos em sala de aula.

Tabela 5 - Respostas dos professores do $3^{\circ}$ ano do Ensino Fundamental

\begin{tabular}{|l|l|l|l|}
\hline Questionário Diagnóstico & Sim & Não & Não apliquei nenhum jogo \\
\hline $\begin{array}{l}1^{\circ} \text { Você considera os jogos um } \\
\text { método de aprendizagem? }\end{array}$ & 107 & 1 & 0 \\
\hline $\begin{array}{l}2^{\circ} \text { Alguma vez você utilizou jogos } \\
\text { em sala de aula? }\end{array}$ & 107 & 0 & 1 \\
\hline $3^{\circ}$ O método foi satisfatório & 106 & 1 & 1 \\
\hline $\begin{array}{l}4^{\circ} \text { Você teve alguma dificuldade em } \\
\text { aplicar o jogo? }\end{array}$ & 28 & 79 & 1 \\
\hline $\begin{array}{l}5^{\circ} \text { Aplicaria novamente o jogo como } \\
\text { ferramenta didática? }\end{array}$ & 107 & 1 & 0 \\
\hline Total de professores: 108 & & & \\
\hline
\end{tabular}

\section{Gráfico 5.}

4. Você teve alguma dificuldade em aplicar o jogo?

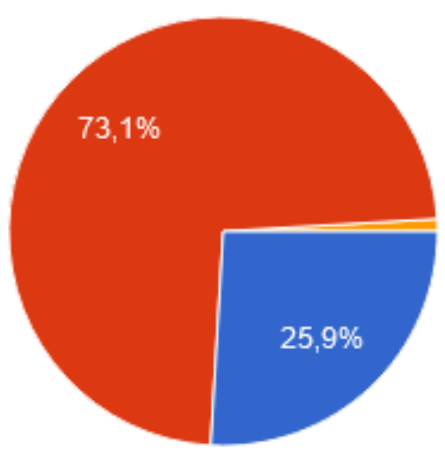


Se sim, qual (is)?

26 respostas

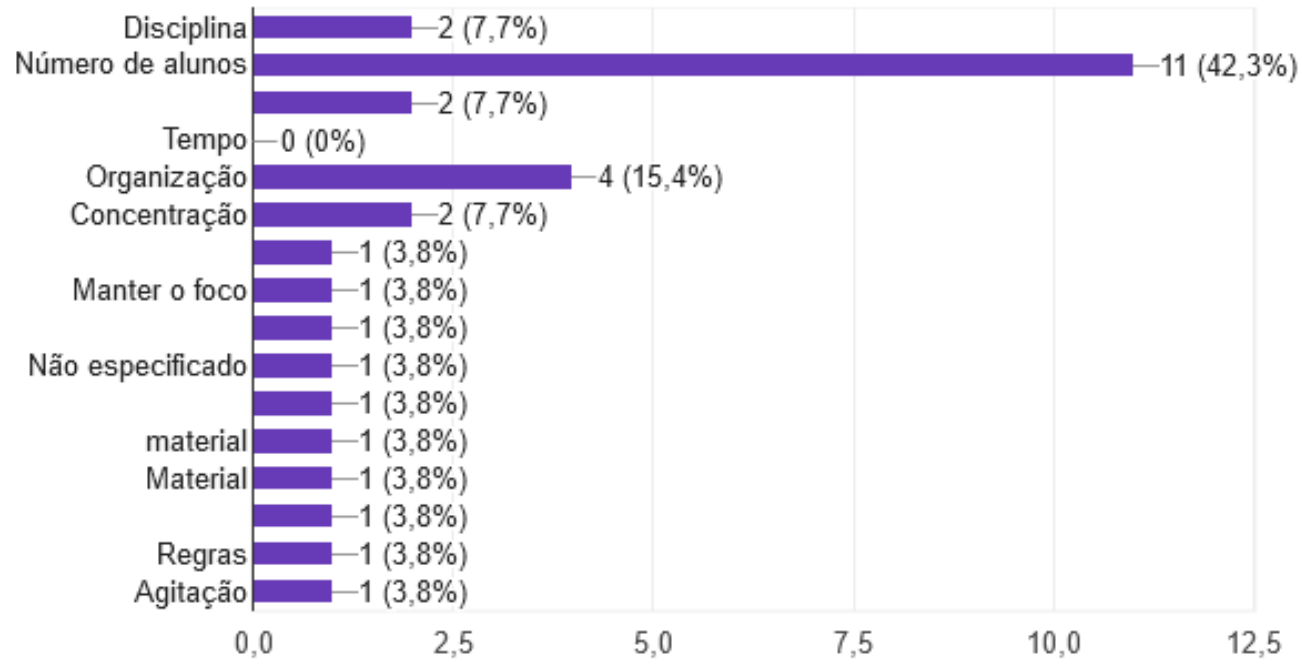

A partir da tabela, 5,99\% dos professores do $3^{\circ}$ ano do ensino fundamental, consideram os jogos como método de aprendizagem e $99 \%$ os utilizaram em sala de aula. 98\% consideraram o método satisfatório. Em comparação aos anos anteriores, a proporção de dificuldade em aplicar jogos continua a crescer. Para o $3^{0}$ ano é $42,3 \%$, contra $38,3 \%$ para o $2^{\circ}$ ano e $22,5 \%$ do que para o $1^{\circ}$ ano. A maior dificuldade continua a ser a quantidade de alunos em sala de aula (42,3\%), mas a organização desponta como importante $(15,4 \%)$. 
Tabela 6 - Respostas dos professores do 4 ano do Ensino Fundamental

\begin{tabular}{|l|l|l|l|}
\hline Questionário Diagnóstico & Sim & Não & Não apliquei nenhum jogo \\
\hline $\begin{array}{l}1^{\circ} \text { Você considera os jogos um } \\
\text { método de aprendizagem? }\end{array}$ & 69 & 0 & 0 \\
\hline $\begin{array}{l}2^{\circ} \text { Alguma vez você utilizou jogos } \\
\text { em sala de aula? }\end{array}$ & 69 & 0 & 0 \\
\hline $3^{\circ}$ O método foi satisfatório & 67 & 2 & 0 \\
\hline $\begin{array}{l}4^{\circ} \text { Você teve alguma dificuldade em } \\
\text { aplicar o jogo? }\end{array}$ & 22 & 47 & 0 \\
\hline $\begin{array}{l}5^{\circ} \text { Aplicaria novamente o jogo como } \\
\text { ferramenta didática? }\end{array}$ & 68 & 1 & 0 \\
\hline Total de professores: 69 &
\end{tabular}

\section{Gráfico 6.}

4. Você teve alguma dificuldade em aplicar o jogo?

$68,1 \%$

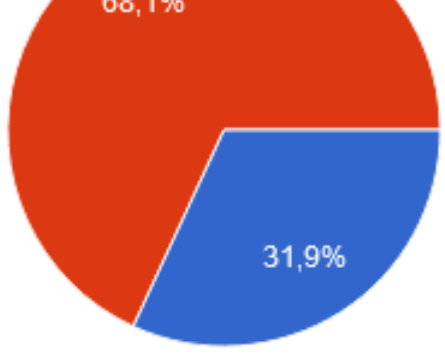

Não apliquei nenhum jogo 
Se sim, qual (is)?

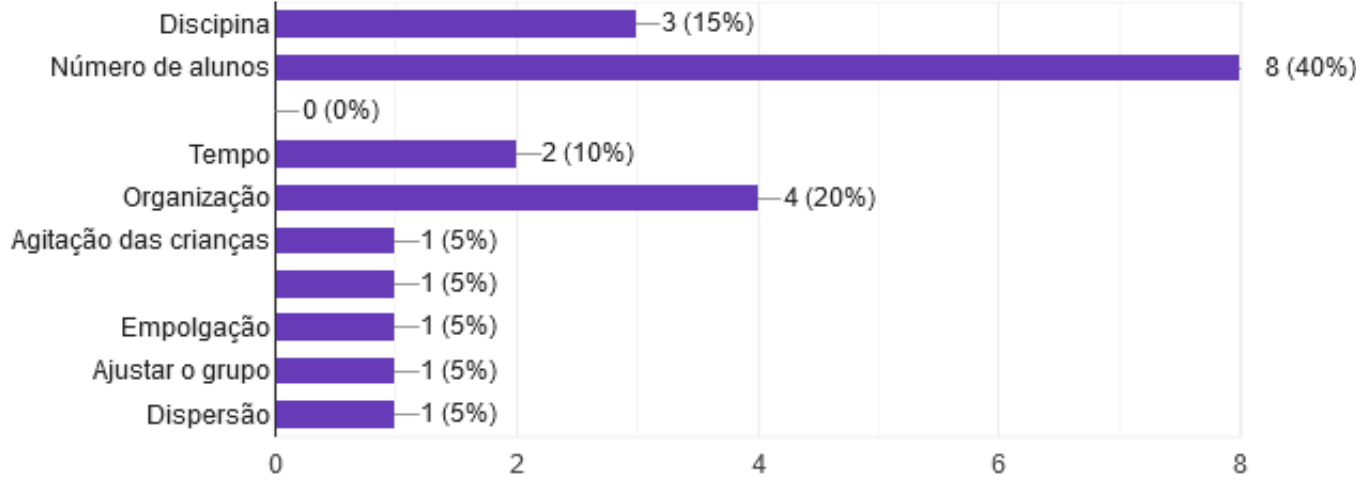

A partir da tabela 6 a cima $99 \%$ dos professores do $4^{\circ}$ ano do ensino fundamental, consideram os jogos como método de aprendizagem, aplicaria os jogos novamente em sala de aula, e no grafico 6,40\% tiveram dificuldades. A maior dificuldade foi a quantidade de alunos em sala de aula.

Tabela 7 - Respostas dos professores do 5 ano do Ensino Fundamental

\begin{tabular}{|l|l|l|l|}
\hline Questionário Diagnóstico & Sim & Não & Não apliquei nenhum jogo \\
\hline $\begin{array}{l}1^{\circ} \text { Você considera os jogos um } \\
\text { método de aprendizagem? }\end{array}$ & 85 & 0 & 0 \\
\hline $\begin{array}{l}2^{\circ} \text { Alguma vez você utilizou jogos } \\
\text { em sala de aula? }\end{array}$ & 83 & 2 & 0 \\
\hline $\begin{array}{l}3^{\circ} \text { O método foi satisfatório } \\
4^{\circ} \text { Você teve alguma dificuldade em } \\
\text { aplicar o jogo? }\end{array}$ & 22 & 60 & 3 \\
\hline $\begin{array}{l}5^{\circ} \text { Aplicaria novamente o jogo como } \\
\text { ferramenta didática? }\end{array}$ & 81 & 1 & 3 \\
\hline \begin{tabular}{l} 
Total de professores: 85 \\
\hline
\end{tabular} & & 3 & \\
\hline
\end{tabular}




\section{Gráfico 7.}

4. Você teve alguma dificuldade em aplicar o jogo?

\section{5 respostas}

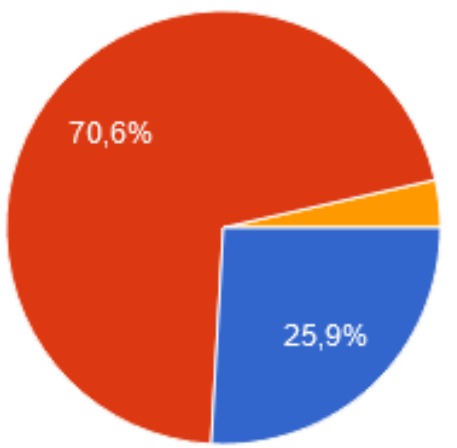

Se sim, qual (is)?

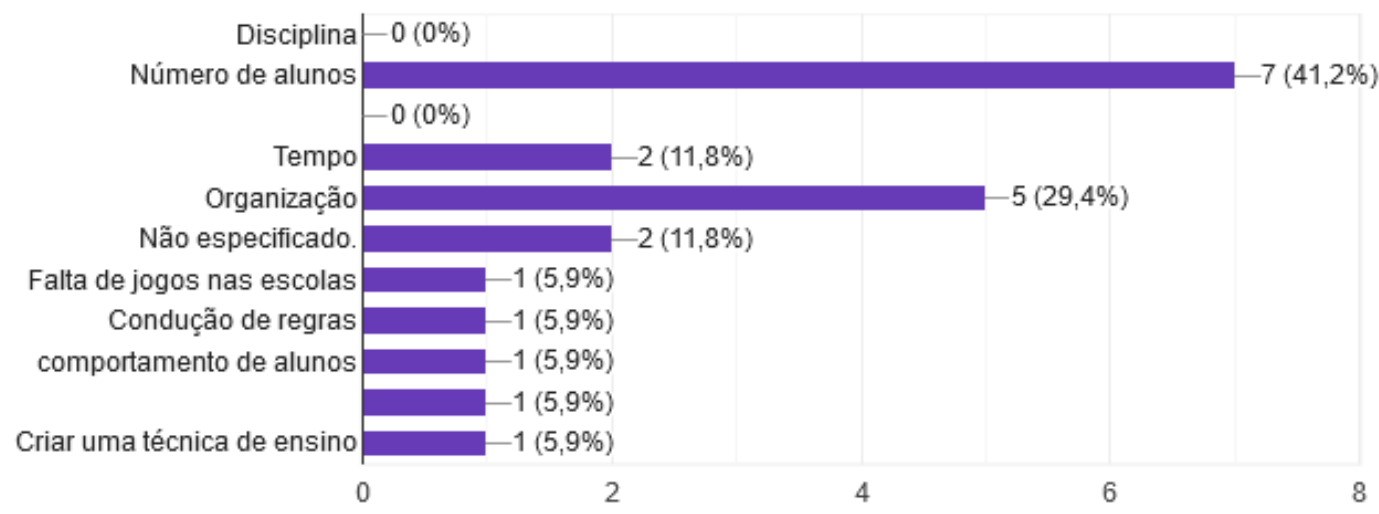

Como podemos observar na tabela 7 , todos os 85 professores do $5^{\circ}$ ano do ensino fundamental, consideram os jogos como método de aprendizagem, porém 3 professores dessa totalidade não aplicaram jogos em sala de aula e apenas 1 não aplicaria novamente, e no gráfico 7 , vemos que $41,2 \%$ tiveram dificuldade em aplicar os jogos em sala de aula devido a quantidade de alunos. 
Tabela 8 - Respostas dos professores do 60 ano do Ensino Fundamental

\begin{tabular}{|l|l|l|l|}
\hline $\begin{array}{l}\text { Questionário } \\
\text { Diagnóstico }\end{array}$ & Sim & Não & Não apliquei nenhum jogo \\
\hline $\begin{array}{l}1^{\circ} \text { Você considera os jogos } \\
\text { um método de } \\
\text { aprendizagem? }\end{array}$ & 8 & 0 & 0 \\
\hline $\begin{array}{l}2^{\circ} \text { Alguma vez você } \\
\text { utilizou jogos em sala de } \\
\text { aula? }\end{array}$ & 8 & 0 & 0 \\
\hline $3^{\circ}$ O método foi satisfatório & 7 & 1 & 0 \\
\hline $\begin{array}{l}4^{\circ} \text { Você teve alguma } \\
\text { dificuldade em aplicar o } \\
\text { jogo? }\end{array}$ & $\mathbf{8}$ & 6 & 0 \\
\hline $\begin{array}{l}5^{\circ} \text { Aplicaria novamente o } \\
\text { jogo como ferramenta } \\
\text { didática? }\end{array}$ & $\mathbf{8}$ & $\mathbf{0}$ & $\mathbf{0}$ \\
\hline \begin{tabular}{l} 
Total de professores: 8 \\
\hline
\end{tabular} & & \\
\hline
\end{tabular}

\section{Gráfico 8.}

4. Você teve alguma dificuldade em aplicar o jogo?

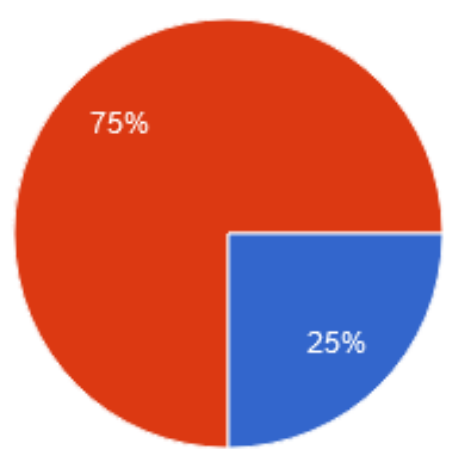


Se sim, qual (is)?

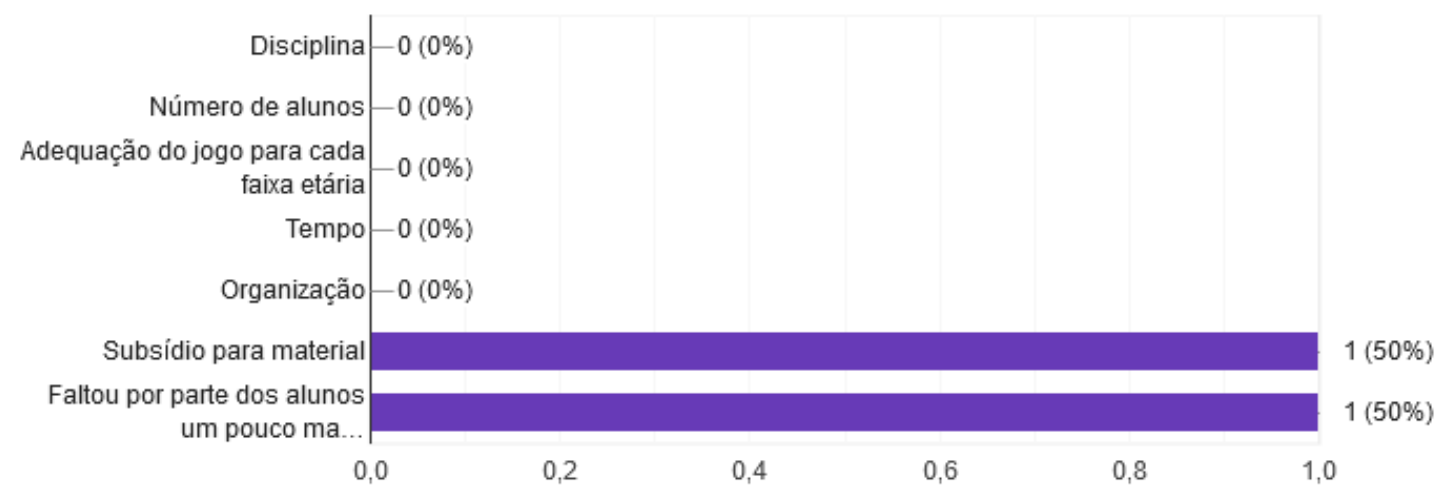

Já na tabela 8 podemos observar que as dificudades são diferentes dos demais, o gráfico nos mostra que 50\% tiveram dificuldades em subsídios de materiais e $50 \%$ tiveram dificuldades na falta de interesse dos alunos. Mesmo assim podemos afirmar com base na tabela que $8,99 \%$ dos professores do 60 ano do ensino fundamental, consideram os jogos como método de aprendizagem e aplicariam jogos novamente em sala de aula

Tabela 9 - Respostas dos professores do $7^{\circ}$ ano do Ensino Fundamental

\begin{tabular}{|l|l|l|l|}
\hline Questionário Diagnóstico & Sim & Não & Não apliquei nenhum jogo \\
\hline $\begin{array}{l}1^{\circ} \text { Você considera os jogos um } \\
\text { método de aprendizagem? }\end{array}$ & $\mathbf{3}$ & $\mathbf{0}$ & $\mathbf{0}$ \\
\hline $\begin{array}{l}2^{\circ} \text { Alguma vez você utilizou jogos } \\
\text { em sala de aula? }\end{array}$ & $\mathbf{3}$ & $\mathbf{0}$ & $\mathbf{0}$ \\
\hline $3^{\circ}$ O método foi satisfatório & $\mathbf{3}$ & $\mathbf{0}$ & $\mathbf{0}$ \\
\hline $\begin{array}{l}4^{\circ} \text { Você teve alguma dificuldade em } \\
\text { aplicar o jogo? }\end{array}$ & $\mathbf{3}$ & $\mathbf{0}$ & $\mathbf{0}$ \\
\hline $\begin{array}{l}5^{\circ} \text { Aplicaria novamente o jogo como } \\
\text { ferramenta didática? }\end{array}$ & $\mathbf{3}$ & $\mathbf{0}$ & $\mathbf{0}$ \\
\hline Total de professores: 3 & & \\
\hline
\end{tabular}


Como vemos na tabela 9 , a totalidade (3) dos professores do $7^{\circ}$ ano do ensino fundamenta consideram os jogos como método de aprendizagem, apesar da dificuldade com a organização, 100\% consideram o método satisfatório.

Tabela 10 - Respostas dos professores do 8 ano do Ensino Fundamental

\begin{tabular}{|l|l|l|l|}
\hline Questionário Diagnóstico & Sim & Não & Não apliquei nenhum jogo \\
\hline $\begin{array}{l}1^{\circ} \text { Você considera os jogos um } \\
\text { método de aprendizagem? }\end{array}$ & $\mathbf{0}$ & $\mathbf{0}$ \\
\hline $\begin{array}{l}2^{\circ} \text { Alguma vez você utilizou jogos } \\
\text { em sala de aula? }\end{array}$ & $\mathbf{1}$ & $\mathbf{0}$ & $\mathbf{0}$ \\
\hline $3^{\circ}$ O método foi satisfatório & $\mathbf{1}$ & $\mathbf{0}$ & $\mathbf{0}$ \\
\hline $\begin{array}{l}4^{\circ} \text { Você teve alguma dificuldade em } \\
\text { aplicar o jogo? }\end{array}$ & $\mathbf{0}$ & $\mathbf{1}$ & $\mathbf{0}$ \\
\hline $\begin{array}{l}5^{\circ} \text { Aplicaria novamente o jogo como } \\
\text { ferramenta didática? }\end{array}$ & $\mathbf{1}$ & $\mathbf{0}$ & $\mathbf{0}$ \\
\hline \begin{tabular}{l} 
Total de professores: 1 \\
\hline
\end{tabular} & & & \\
\end{tabular}

No total de 379 professores entrevistados, somente um professor aplicou jogos em sala de aula no $8^{\circ}$ ano do ensino fundamental, mas como podemos ver na tabela 10, o professor considera os jogos como método de aprendizagem, aplicaria os jogos novamente em sala de aula e não teve dificuldades.

Não foram obtidos dados para a avaliação do 9ํano do ensino médio. 
Tabela 11 - Respostas dos professores do $1^{\circ}$ ano do Ensino médio

\begin{tabular}{|l|l|l|l|}
\hline $\begin{array}{l}\text { Questionário } \\
\text { Diagnóstico }\end{array}$ & Sim & Não & Não apliquei nenhum jogo \\
\hline $\begin{array}{l}1^{\circ} \text { Você considera os } \\
\text { jogos um método de } \\
\text { aprendizagem? }\end{array}$ & $\mathbf{3}$ & $\mathbf{0}$ \\
\hline $\begin{array}{l}2^{\circ} \text { Alguma vez você } \\
\text { utilizou jogos em sala de } \\
\text { aula? }\end{array}$ & $\mathbf{3}$ & $\mathbf{0}$ & $\mathbf{0}$ \\
\hline $\begin{array}{l}3^{\circ} \text { método foi } \\
\text { satisfatório }\end{array}$ & $\mathbf{3}$ & $\mathbf{0}$ & $\mathbf{0}$ \\
\hline $\begin{array}{l}4^{\circ} \text { Você teve alguma } \\
\text { dificuldade em aplicar o } \\
\text { jogo? }\end{array}$ & $\mathbf{0}$ & $\mathbf{3}$ & $\mathbf{0}$ \\
\hline $\begin{array}{l}5^{\circ} \text { Aplicaria novamente o } \\
\text { jogo como ferramenta } \\
\text { didática? }\end{array}$ & $\mathbf{3}$ & $\mathbf{0}$ & $\mathbf{0}$ \\
\hline $\begin{array}{l}\text { Total de professores: } \mathbf{3} \\
\text { and }\end{array}$ & & \\
\hline
\end{tabular}

Os resultados para o $1^{\circ}$ ano do ensino médio (tabela) são semelhantes aos do $7^{\circ}$ ano do ensino fundamental. A totalidade (3) dos professores do $1^{\circ}$ ano do ensino médio consideram os jogos como métodos de aprendizagem e também consideram o método satisfatório. 
Tabela 12 - Respostas dos professores do 2 ano do Ensino médio

\begin{tabular}{|l|l|l|l|}
\hline Questionário Diagnóstico & Sim & Não & Não apliquei nenhum jogo \\
\hline $\begin{array}{l}1^{\circ} \text { Você considera os jogos um } \\
\text { método de aprendizagem? }\end{array}$ & $\mathbf{0}$ & $\mathbf{0}$ \\
\hline $\begin{array}{l}2^{\circ} \text { Alguma vez você utilizou jogos } \\
\text { em sala de aula? }\end{array}$ & $\mathbf{1}$ & $\mathbf{0}$ & $\mathbf{0}$ \\
\hline $3^{\circ}$ O método foi satisfatório & $\mathbf{1}$ & $\mathbf{0}$ & $\mathbf{0}$ \\
\hline $\begin{array}{l}4^{\circ} \text { Você teve alguma dificuldade em } \\
\text { aplicar o jogo? }\end{array}$ & $\mathbf{0}$ & $\mathbf{1}$ & $\mathbf{0}$ \\
\hline $\begin{array}{l}5^{\circ} \text { Aplicaria novamente o jogo como } \\
\text { ferramenta didática? }\end{array}$ & $\mathbf{1}$ & $\mathbf{0}$ & $\mathbf{0}$ \\
\hline \begin{tabular}{l} 
Total de professores: 1 \\
\hline
\end{tabular} & & & \\
\hline
\end{tabular}

No $2^{\circ}$ ano do ensino médio podemos observar na tabela que o resultado também foi semelhante ao do $8^{\circ}$ ano do ensino fundamental, somente um professor foi avaliado, mas como podemos ver na tabela 12, o professor considera os jogos como método de aprendizagem aplicaria os jogos novamente em sala de aula e não teve dificuldades. 
Tabela 13 - Respostas dos professores do 3ํano do Ensino médio

\begin{tabular}{|l|l|l|l|}
\hline Questionário Diagnóstico & Sim & Não & Não apliquei nenhum jogo \\
\hline $\begin{array}{l}1^{\circ} \text { Você considera os jogos um } \\
\text { método de aprendizagem? }\end{array}$ & $\mathbf{0}$ & $\mathbf{0}$ \\
\hline $\begin{array}{l}2^{\circ} \text { Alguma vez você utilizou jogos } \\
\text { em sala de aula? }\end{array}$ & $\mathbf{1}$ & $\mathbf{0}$ & $\mathbf{0}$ \\
\hline $3^{\circ}$ O método foi satisfatório & $\mathbf{1}$ & $\mathbf{0}$ & $\mathbf{0}$ \\
\hline $\begin{array}{l}4^{\circ} \text { Você teve alguma dificuldade em } \\
\text { aplicar o jogo? }\end{array}$ & $\mathbf{0}$ & $\mathbf{1}$ & $\mathbf{0}$ \\
\hline $\begin{array}{l}5^{\circ} \text { Aplicaria novamente o jogo como } \\
\text { ferramenta didática? }\end{array}$ & $\mathbf{1}$ & $\mathbf{0}$ & $\mathbf{0}$ \\
\hline \begin{tabular}{l} 
Total de professores: 1 \\
\hline
\end{tabular} & &
\end{tabular}

E, por fim, na tabela 13 vemos que somente um professor aplicou jogos no $3^{\circ}$ ano do ensino médio, mas como podemos observar, o professor considera os jogos como método de aprendizagem, aplicaria os jogos novamente em sala de aula e não teve dificuldades. 
Tabela 14 - Conclusão total das respostas dos professores

\begin{tabular}{|l|l|l|l|}
\hline Questionário Diagnóstico & Sim & Não & Não apliquei nenhum jogo \\
\hline $\begin{array}{l}1^{\circ} \text { Você considera os jogos um } \\
\text { método de aprendizagem? }\end{array}$ & 378 & 1 & 0 \\
\hline $\begin{array}{l}2^{\circ} \text { Alguma vez você utilizou jogos } \\
\text { em sala de aula? }\end{array}$ & 376 & 3 & 0 \\
\hline $3^{\circ}$ O método foi satisfatório & 369 & 4 & 6 \\
\hline $\begin{array}{l}4^{\circ} \text { Você teve alguma dificuldade em } \\
\text { aplicar o jogo? }\end{array}$ & 113 & 266 & 4 \\
\hline $\begin{array}{l}5^{\circ} \text { Aplicaria novamente o jogo como } \\
\text { ferramenta didática? }\end{array}$ & 365 & 5 & 4 \\
\hline Total de professores: 379 & & & \\
\hline
\end{tabular}

Observando a tabela acima vemos que 99\% dos professores entrevistados, utilizam os jogos como ferramenta didática e confirmam que ao jogar os alunos conseguem aprender a matéria proposta em sala de aula. Apesar das dificuldades de $29 \%$ dos professores, a grande maioria não teve problemas em executar a experiência, e somente $3,7 \%$ do total de entrevistados não aplicaram ou não aplicariam jogos em sala de aula. Diante dos resultados obtidos concluímos que a entrevista foi satisfatória reforçando assim a pesquisa de que jogos não são simples distrações e sim um instrumento de aprendizagem.

\subsection{APLICAÇÕES DO JOGO NA ESCOLA}

Ao conseguir contato com a escola, foram agendados dois dias e horários para a aplicação do jogo e o questionário diagnóstico.

A pesquisa foi realizada na Escola Estadual do município de Mauá Hans Grudzinski, para os alunos do 9a ano do ensino fundamental e alunos do $1^{\circ}$ ano do ensino médio. A aplicação do jogo e questionário foram realizados, nos dias 22 e 26 de novembro de 2019, no decorrer de duas aulas contabilizando um total de 100 minutos. 
No primeiro momento foi distribuído um questionário diagnóstico que foi elaborado com 5 perguntas com o intuito de avaliar o conhecimento dos alunos antes do jogo.

$1^{\circ} \mathrm{O}$ que é Astronomia?

$2^{\circ}$ Onde surgiu a maioria dos elementos químicos?

3ํํ que é uma Nebulosa?

4ํ Você já teve aula com jogos?

$5^{\circ} \mathrm{O}$ que você acha de jogos como meio de aprendizado?

O jogo foi apresentado e os alunos se dividiram em 4 grupos com aproximadamente 6 alunos e cada grupo com o seu representante.

No término do jogo os alunos responderam outro questionário diagnóstico para assim conseguir identificar se os jogos são realmente uma ferramenta de aprendizagem.

Para isso foi seguida uma série de perguntas:

$1^{\circ} \mathrm{O}$ que é Astronomia?

$2^{\circ}$ Onde surgiu a maioria dos elementos químicos?

3ㅇ $\mathrm{O}$ que é uma Nebulosa?

$4^{\circ}$ Você gostou do jogo "De Onde Eu Vim"?

$5^{\circ} \mathrm{O}$ que você achou do jogo como meio de aprendizado?

$6^{\circ} \mathrm{Em}$ uma breve frase me conte o que você aprendeu.

Como podemos observar, as perguntas do pós jogo são bem semelhantes para que possamos avaliar se os alunos realmente conseguiram adquirir novos conhecimentos durante o jogo. 
5.3 Questionário diagnóstico para alunos do 9ª ano do fundamental e $1^{\circ}$ ano do ensino médio

Resultados obtidos ao aplicar o questionário diagnóstico para o 9을 ano do ensino fundamental.

Tabela 15 - Respostas dos alunos do $9^{\circ}$ ano do Ensino Fundamental

\begin{tabular}{|c|c|c|c|}
\hline \multicolumn{4}{|c|}{ Questionário diagnóstico (pré-jogo) } \\
\hline \multicolumn{4}{|c|}{$1^{\circ} \mathrm{O}$ que é Astronomia? } \\
\hline (a) Estudo do zodíaco & \multicolumn{3}{|l|}{0} \\
\hline (b) Estudo dos astros & \multicolumn{3}{|l|}{24} \\
\hline (c) Estudo dos astronautas & \multicolumn{3}{|l|}{3} \\
\hline \multicolumn{4}{|c|}{$2^{\circ}$ Onde surgiu a maioria dos elementos químicos? } \\
\hline (a) Tabela periódica & \multicolumn{3}{|l|}{9} \\
\hline (b) Laboratório & \multicolumn{3}{|l|}{9} \\
\hline (c) Morte de estrelas & \multicolumn{3}{|l|}{9} \\
\hline \multicolumn{4}{|c|}{$3^{\circ} \mathrm{O}$ que é uma Nebulosa? } \\
\hline (a) Gás e poeira suja & \multicolumn{3}{|l|}{1} \\
\hline (b) Nuvem de matéria interestelar & \multicolumn{3}{|l|}{18} \\
\hline (c) Nuvem de fumaça preta & \multicolumn{3}{|l|}{8} \\
\hline $4^{\circ}$ Você já teve aula com jogos? & $\begin{array}{l}\text { Sim } \\
8\end{array}$ & $\begin{array}{l}\text { Não } \\
7\end{array}$ & $\begin{array}{l}\text { Não lembro } \\
12\end{array}$ \\
\hline $\begin{array}{l}5^{\circ} \mathrm{O} \text { que você acha de jogos como meio de } \\
\text { aprendizado? }\end{array}$ & $\begin{array}{l}\text { Legal } \\
19\end{array}$ & $\begin{array}{l}\text { Ruim } \\
1\end{array}$ & $\begin{array}{l}\text { Não sei } \\
7\end{array}$ \\
\hline 27 & & & \\
\hline
\end{tabular}


Questionário Diagnóstico (Pré Jogo) 9a ano do ensino fundamental.

\section{Gráfico 9.}

1ํㅡㄹ pergunta: O que é Astronomia?

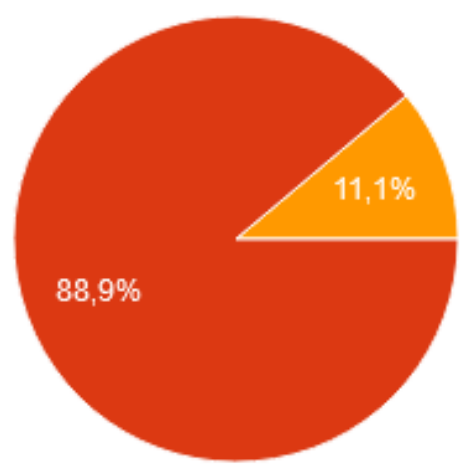

Como vemos no gráfico acima $88,9 \%$ dos alunos do 9ํao do ensino médio sabiam a resposta correta antes do jogo.

Gráfico 10.

2ª pergunta: Onde surgiu a maioria dos elementos químicos?

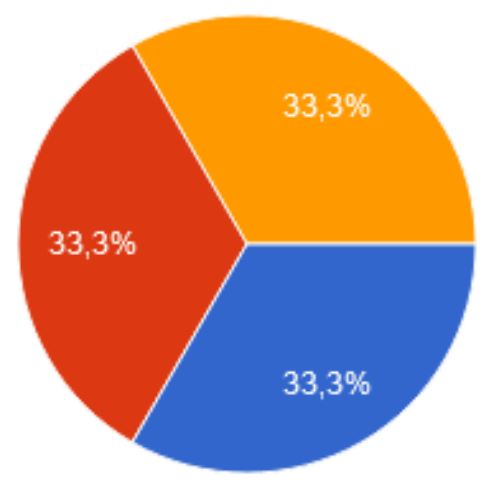

Tabela periódica

Laboratório

Morte de estrelas

Já na segunda pergunta vemos no gráfico acima que as respostas foram bem divididas, apenas $33,3 \%$ sabiam a resposta correta. 


\section{Gráfico 11.}

3ª pergunta: 0 que é uma Nebulosa?

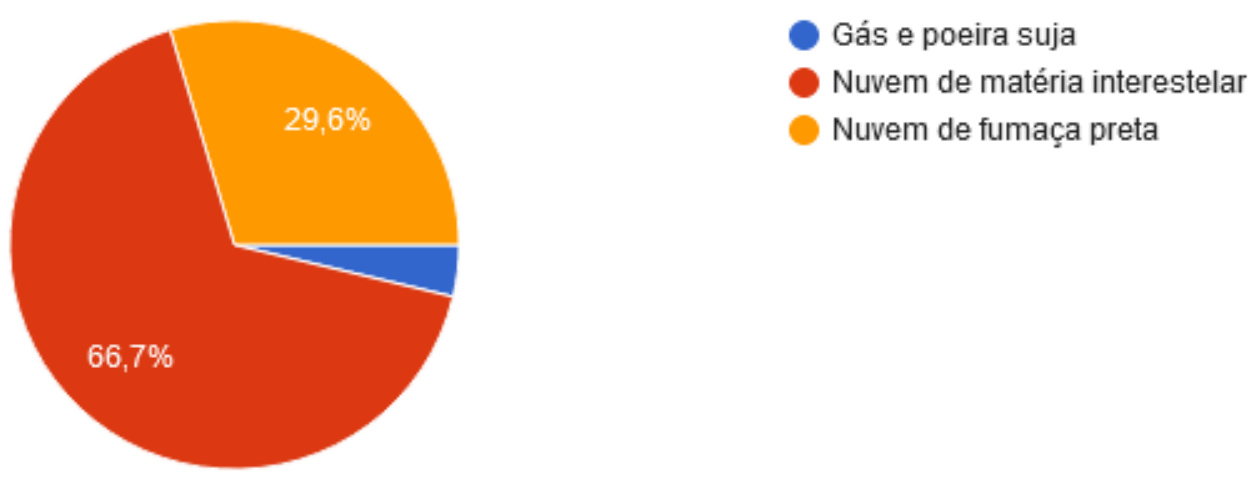

Como vemos no gráfico acima $66,7 \%$ sabiam o que é uma nebulosa.

\section{Gráfico 12.}

4ª pergunta: Você já teve aula com jogos?

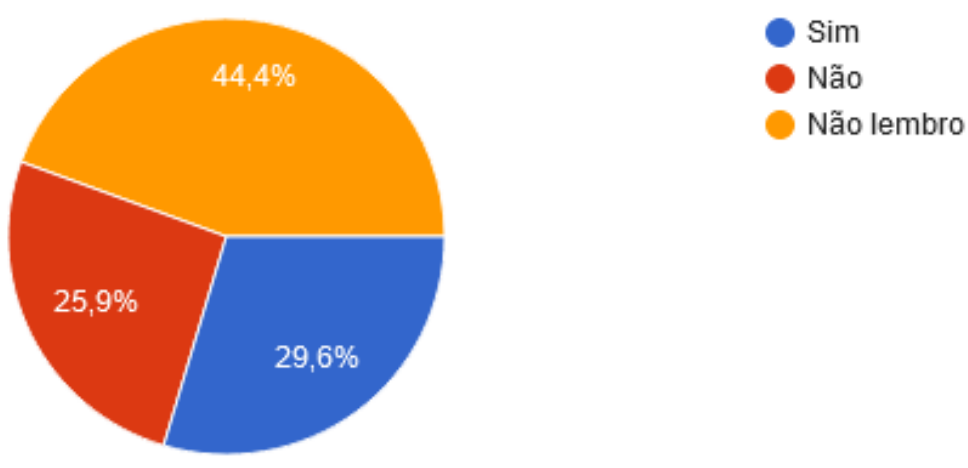

Se sim, em que ano(s) escolar(es)

6

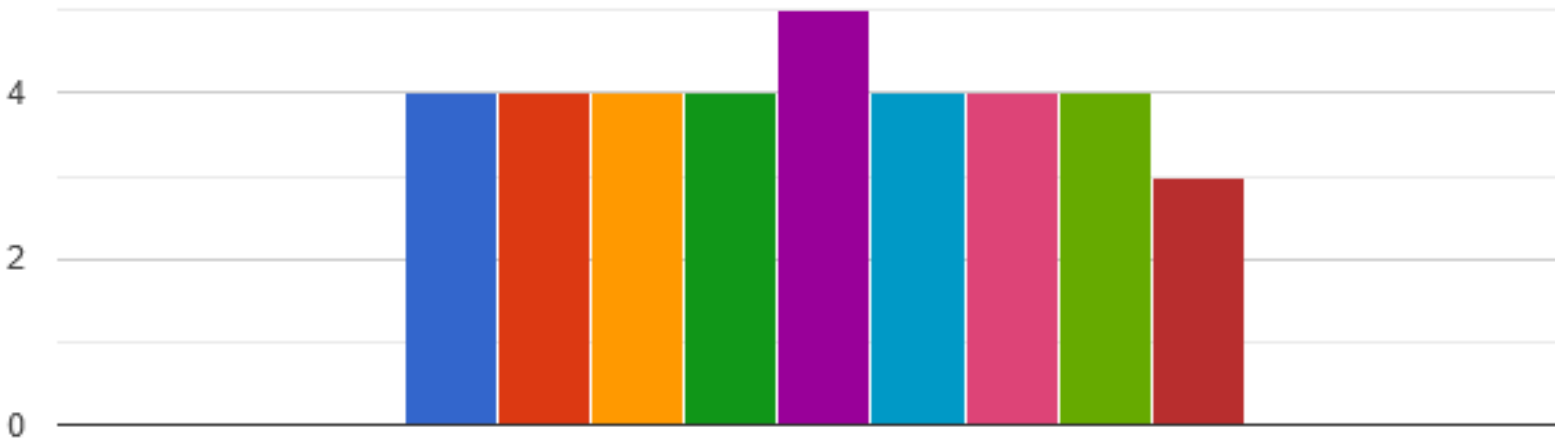




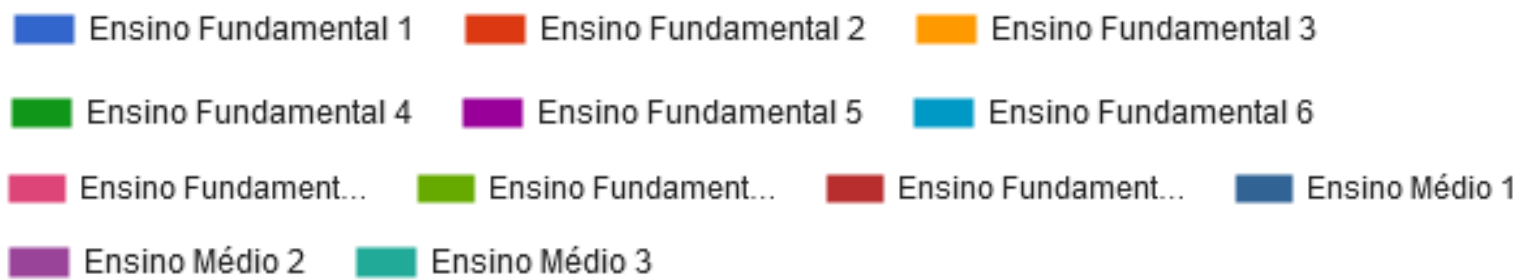

Nessa pergunta $44,4 \%$ dos alunos não lembram se tiveram aula com jogos em sala, e os que lembram, a maioria tiveram aula com jogos no 5 ano do ensino fundamental.

\section{Gráfico 13.}

\section{$5^{\text {a }}$ pergunta: 0 que você acha de jogos como meio de aprendizado?}

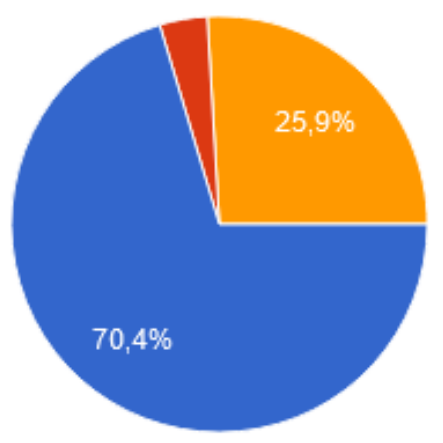

Legal, consigo aprender jogando

Ruim, não consigo aprender jogando

Não sei, nunca joguei na aula

E observando o gráfico acima vemos que a grande maioria dos alunos consideram o jogo como uma ferramenta de aprendizado.

Ao analisar esses dados foi percebido que os alunos tinham um certo conhecimento de astronomia, mas nem todos tinham conseguido relacionar a astronomia com a química. 
Tabela 16 - Respostas dos alunos do $9^{\circ}$ ano do Ensino Fundamental

\begin{tabular}{|c|c|c|c|}
\hline \multicolumn{4}{|c|}{ Questionário diagnóstico (pós-jogo) } \\
\hline \multicolumn{4}{|l|}{$1^{\circ} \mathrm{O}$ que é Astronomia? } \\
\hline (a) Estudo do zodíaco & \multicolumn{3}{|l|}{0} \\
\hline (b) Estudo dos astros & \multicolumn{3}{|l|}{24} \\
\hline (c) Estudo dos astronautas & \multicolumn{3}{|l|}{3} \\
\hline \multicolumn{4}{|c|}{$2^{\circ}$ Onde surgiu a maioria dos elementos químicos? } \\
\hline (a) Tabela periódica & \multicolumn{3}{|l|}{7} \\
\hline (b) Laboratório & \multicolumn{3}{|l|}{3} \\
\hline (c) Morte de estrelas & \multicolumn{3}{|l|}{17} \\
\hline \multicolumn{4}{|l|}{$3^{\circ}$ O que é uma Nebulosa? } \\
\hline (a) Gás e poeira suja & \multicolumn{3}{|l|}{2} \\
\hline (b) Nuvem de matéria interestelar & \multicolumn{3}{|l|}{22} \\
\hline (c) Nuvem de fumaça preta & \multicolumn{3}{|l|}{3} \\
\hline $4^{\circ}$ Você gostou do jogo "De Onde Eu Vim"? & $\begin{array}{l}\text { Sim } \\
17\end{array}$ & $\begin{array}{l}\text { Não } \\
4\end{array}$ & $\begin{array}{l}\text { Não sei } \\
6\end{array}$ \\
\hline $\begin{array}{l}5^{\circ} \mathrm{O} \text { que você achou do jogo como meio de } \\
\text { aprendizado? }\end{array}$ & $\begin{array}{l}\text { Gostei } \\
13\end{array}$ & $\begin{array}{l}\text { Não } \\
\text { gostei } \\
6\end{array}$ & $\begin{array}{l}\text { Não sei } \\
8\end{array}$ \\
\hline \multicolumn{4}{|c|}{\begin{tabular}{l|l}
$6^{\circ}$ Em uma breve frase me conte o que você & \\
aprendeu. & 22
\end{tabular}} \\
\hline
\end{tabular}

Observação: Todos os alunos responderam o questionário diagnóstico, porém nem todos participaram até o fim. 
Questionário Diagnóstico (Pós Jogo) 9ªno do ensino fundamental

\section{Gráfico 14.}

1a pergunta: $O$ que é Astronomia?

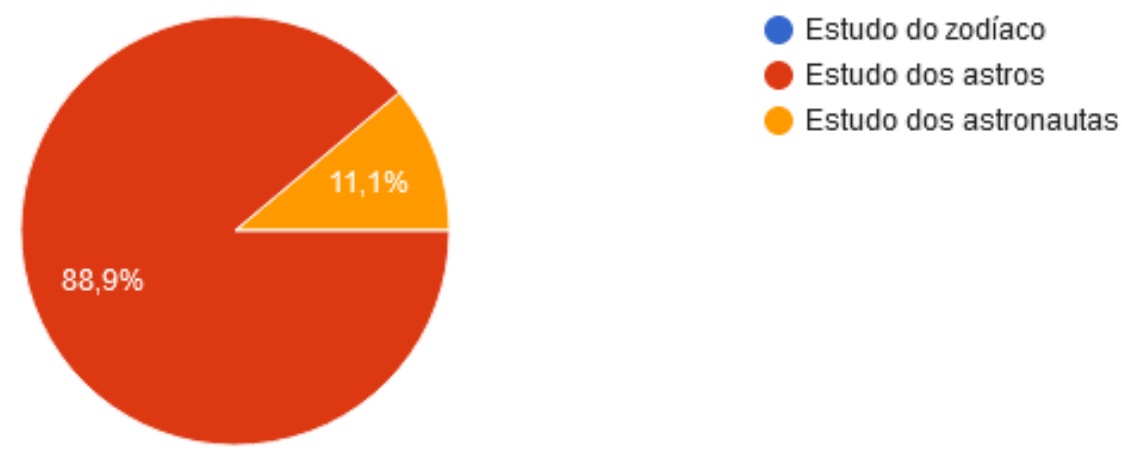

Como podemos observar, os resultados tanto do pré-questionário quanto do pós, são idênticos, não houve alteração das respostas.

\section{Gráfico 15.}

$2^{a}$ pergunta: Onde surgiu a maioria dos elementos químicos?

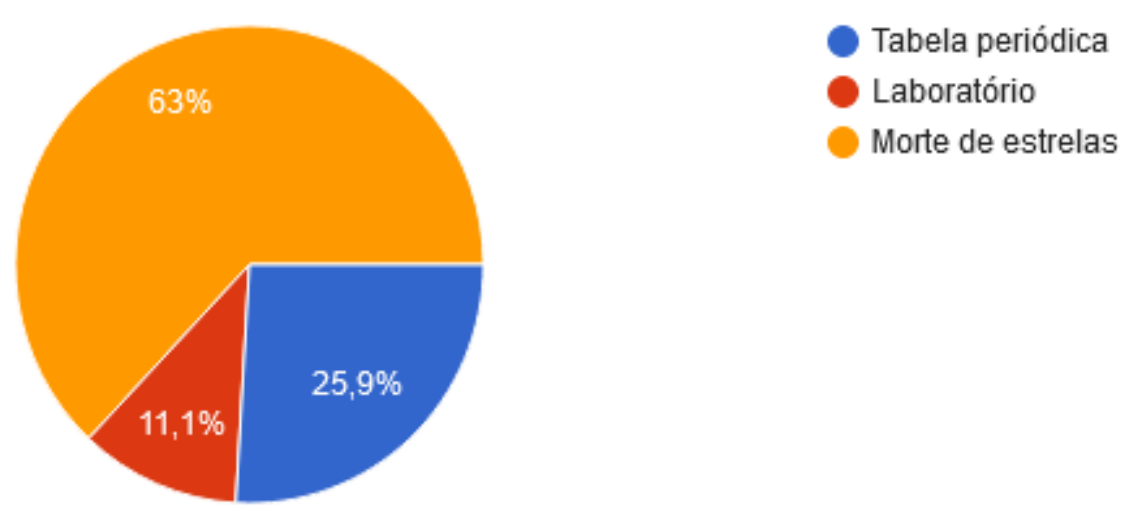

Já na $2^{\underline{a}}$ pergunta houve uma melhora significativa em comparação as respostas do pré questionário $63 \%$ dos alunos assinalaram a questão certa. 
Gráfico 16.

3ª pergunta: 0 que é uma Nebulosa?

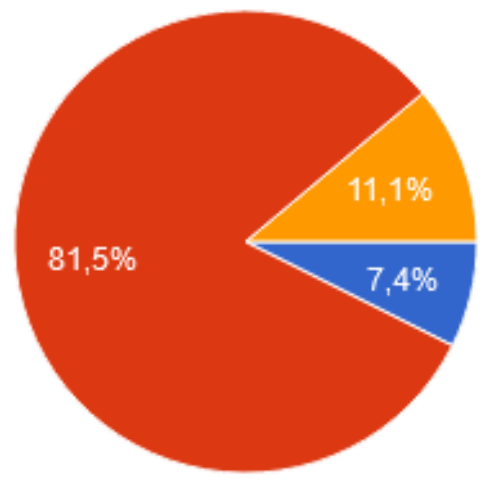

Gás e poeira suja

Nuvem de matéria interestelar

Nuvem de fumaça preta

Como vemos no gráfico acima $81,5 \%$ dos alunos acertaram a resposta, houve um pequeno aumento de respostas certas se comparado ao pré-questionário, no qual $66,7 \%$ dos alunos já sabiam a resposta.

\section{Gráfico 17.}

4ª pergunta: Você gostou do jogo "De Onde Eu Vim”?

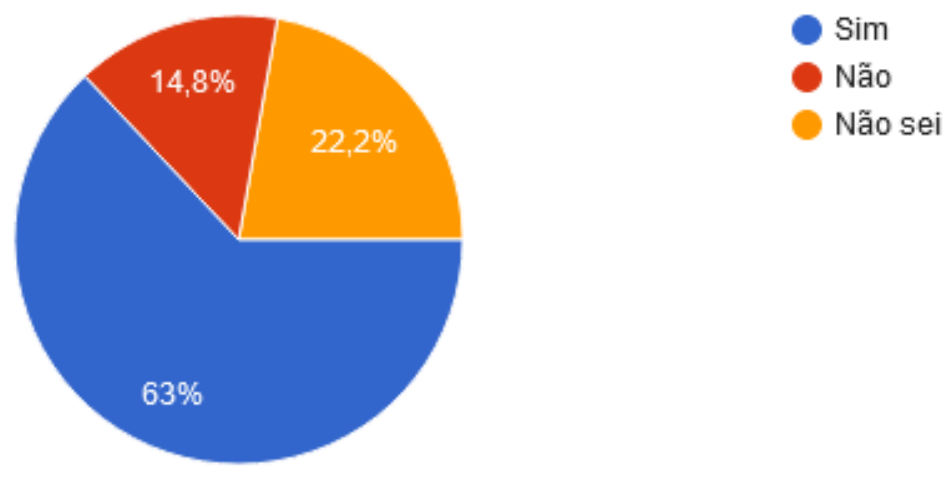

Apesar de 37\% dos alunos não terem gostado do jogo ou não quiseram opinar, 63\% dos alunos, o que é a grande maioria gostaram e perguntaram quando iriam jogar novamente pois o tempo tinha sido muito curto. 
Gráfico 18.

5a pergunta: 0 que você achou do jogo como meio de aprendizado?

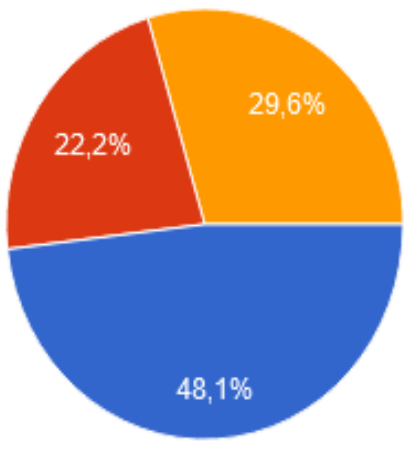

Gostei, consegui aprender jogando

Não gostei, não consegui aprender jogando

Não sei

Como foi dito anteriormente nem todos os alunos jogaram até o fim, muitos se dispersaram ao decorrer do jogo, mesmo assim responderam o questionário diagnóstico de pós jogo, mas apesar dos resultados obtidos considero válido pois $48,1 \%$ dos alunos gostaram e conseguiram aprender com o jogo.

6ª pergunta: Em uma breve frase me conte o que você aprendeu.

Muitas coisas

Tudo

Eu aprendi a composição dos objetos

Aprendi que a maioria dos elementos são formados por morte de estrelas

Que o ouro que tem na terra é o último, se acabar, acabou

Algumas coisas

Aprendi a composição dos elementos químicos

Origem de alguns elementos 
Eu aprendi um pouco mais da tabela periódica

Não aprendi muita coisa

Nada

A tabela periódica e seus elementos

Sobre a tabela periódica

Nada, não joguei

Eu aprendi sobre a tabela periódica

\section{De onde surgiu os elementos}

Nessa 6⿳亠丷厂 pergunta, os alunos expõem o que eles aprenderam com o jogo ou não aprenderam, e como podemos ver foram obtidas algumas respostas significativas.

\subsection{Conclusão dos resultados do $9^{\circ}$ ano do ensino fundamental}

Como podemos comparar com os dados obtidos, o $9^{0}$ ano do Ensino fundamental, teve uma pequena melhora do conhecimento depois do jogo "De Onde Eu Vim", tendo em vista que, os alunos ainda não tinham conhecimento da tabela periódica.

Ao apresentar o jogo, foi notado um interesse dos alunos para jogar, porém, conforme foi passando o tempo alguns alunos, mais ou menos $60 \%$, se dispersaram abandonando o seu grupo, mesmo assim os grupos conseguiram concluir o jogo até o final. 
Tabela 17 - Respostas dos alunos do $1^{\circ}$ ano do Ensino Médio

\begin{tabular}{|c|c|c|c|}
\hline \multicolumn{4}{|c|}{ Questionário diagnóstico (pré-jogo) } \\
\hline \multicolumn{4}{|l|}{$1^{\circ} \mathrm{O}$ que é Astronomia? } \\
\hline (a) Estudo do zodíaco & \multicolumn{3}{|l|}{0} \\
\hline (b) Estudo dos astros & \multicolumn{3}{|l|}{41} \\
\hline (c) Estudo dos astronautas & \multicolumn{3}{|l|}{1} \\
\hline \multicolumn{4}{|l|}{$2^{\circ}$ Onde surgiu a maioria dos elementos químicos? } \\
\hline (a) Tabela periódica & \multicolumn{3}{|l|}{2} \\
\hline (b) Laboratório & \multicolumn{3}{|l|}{22} \\
\hline (c) Morte de estrelas & \multicolumn{3}{|l|}{18} \\
\hline \multicolumn{4}{|l|}{$3^{\circ}$ O que é uma Nebulosa? } \\
\hline (a) Gás e poeira suja & \multicolumn{3}{|l|}{2} \\
\hline (b) Nuvem de matéria interestelar & \multicolumn{3}{|l|}{36} \\
\hline (c) Nuvem de fumaça preta & \multicolumn{3}{|l|}{4} \\
\hline $4^{0}$ Você já teve aula com jogos? & $\begin{array}{l}\text { Sim } \\
12\end{array}$ & $\begin{array}{l}\text { Não } \\
12\end{array}$ & $\begin{array}{l}\text { Não lembro } \\
18\end{array}$ \\
\hline $\begin{array}{l}5^{\circ} \mathrm{O} \text { que você acha de jogos como meio de } \\
\text { aprendizado? }\end{array}$ & $\begin{array}{l}\text { Legal } \\
26\end{array}$ & $\begin{array}{l}\text { Ruim } \\
0\end{array}$ & $\begin{array}{l}\text { Não sei } \\
16\end{array}$ \\
\hline \multicolumn{4}{|l|}{ Total de alunos: 42} \\
\hline
\end{tabular}


Questionário Diagnostico (Pré Jogo) 1ํano do ensino médio.

\section{Gráfico 19.}

1a pergunta: $O$ que é Astronomia?

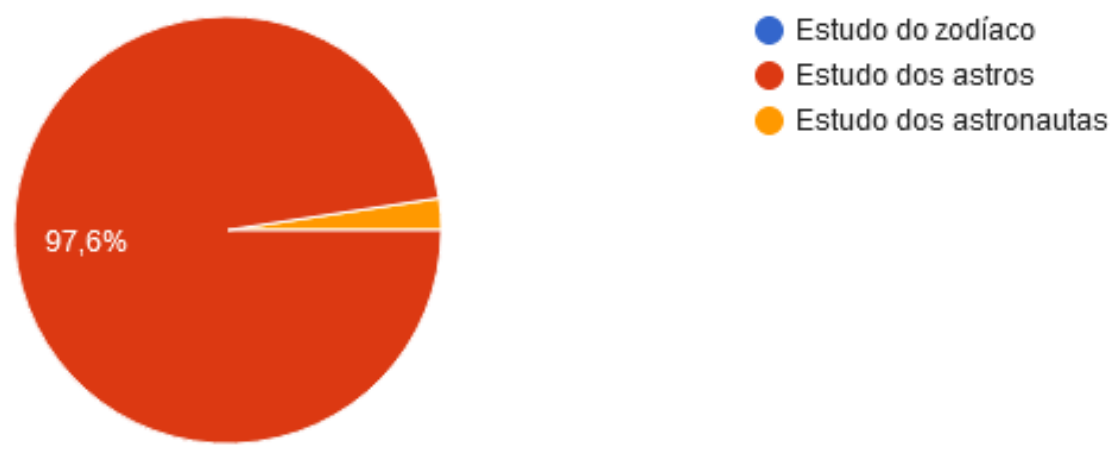

Como vemos no gráfico acima $97,6 \%$ dos alunos do $1^{\circ}$ ano do ensino médio sabiam a resposta correta.

\section{Gráfico 20.}

$2^{\mathrm{a}}$ pergunta: Onde surgiu a maioria dos elementos químicos?

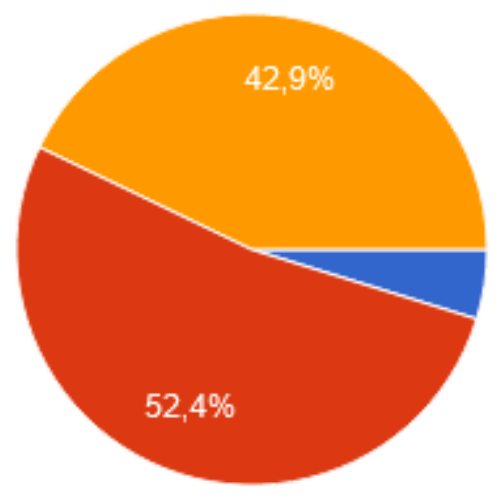

Tabela periódica

Laboratório

Morte de estrelas

Como é observado no gráfico acima a maioria dos alunos não sabiam sobre a origem dos elementos químicos, somente $42,9 \%$ responderam corretamente. 
Gráfico 21.

$3^{\text {a }}$ pergunta: $O$ que é uma Nebulosa

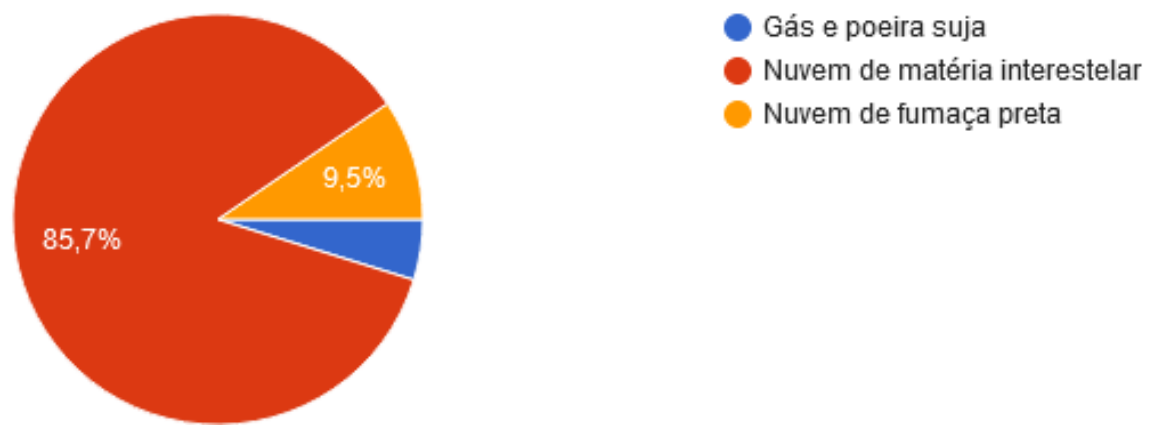

Já na pergunta (3) 85,7\% dos alunos já tinham um conhecimento prévio do que é uma Nebulosa.

\section{Gráfico 22.}

$4^{\text {a }}$ pergunta: Você já teve aula com jogos?

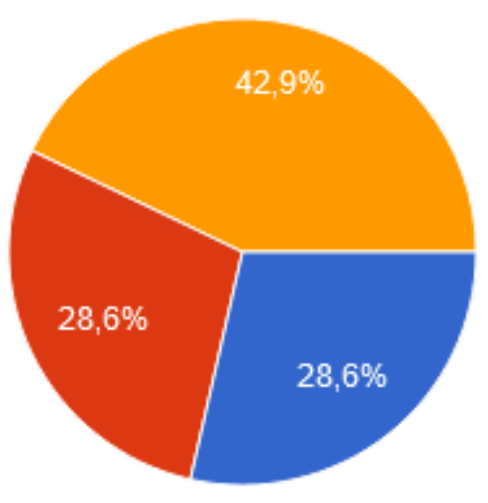

Sim

Não

Não lembro 
Se sim, em que ano(s) escolar(es)

3

2

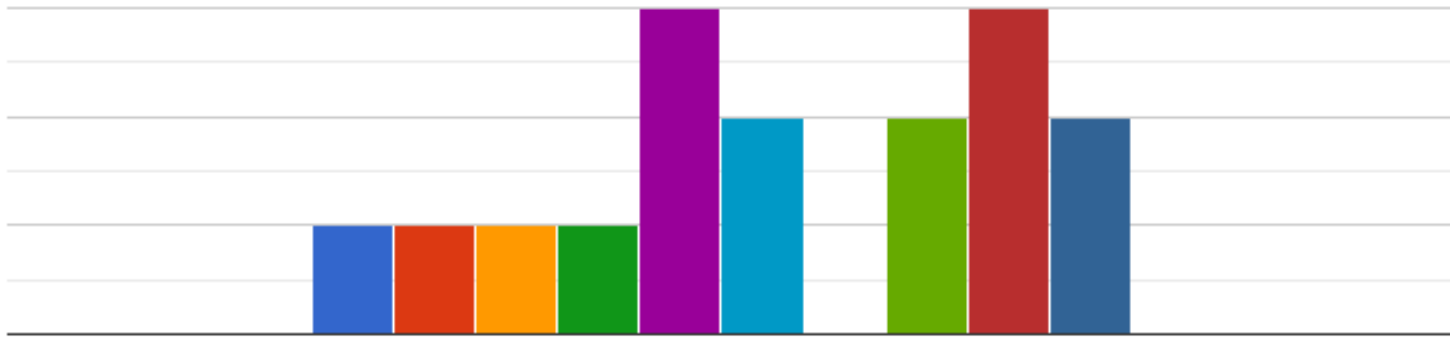

Linha 1

Ensino Fundamental 1

Ensino Fundamental 2 Ensino Fundamental 3

Ensino Fundamental 4

Ensino Fundamental 5

Ensino Fundamental 6

Ensino Fundament...

Ensino Fundament..

Ensino Fundament..

Ensino Médio 1

Ensino Médio 2 Ensino Médio 3

Nessa pergunta $71,5 \%$ dos alunos não lembram ou não tiveram aula com jogos, e os que lembram, a maioria tiveram aula com jogos no $5^{\circ}$ ano do ensino fundamental e no 9 ano do ensino fundamental.

\section{Gráfico 23.}

5a pergunta: $O$ que você acha de jogos como meio de aprendizado?

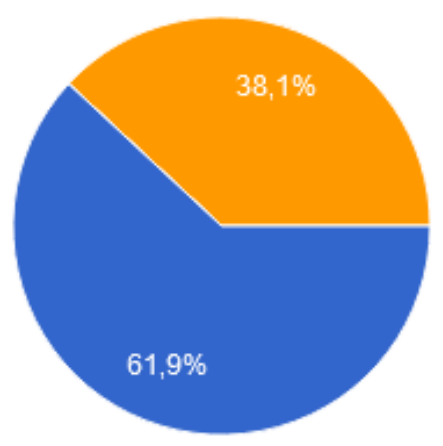

Legal, consigo aprender jogando

- Ruim, não consigo aprender jogando

Não sei, nunca joguei na aula 
Como vemos no gráfico acima $61,9 \%$ dos alunos consideram o jogo como meio de aprendizado, os outros $38,1 \%$ nunca jogaram em sala de aula.

Ao analisar os dados acima foi percebido que os alunos tinham um certo conhecimento de astronomia, um pouco mais se comparado ao $9^{\circ}$ ano do ensino médio, mas igualmente ao $9^{\circ}$ ano nem todos tinham conseguido relacionar a astronomia com a química.

Tabela 18 - Respostas dos alunos do $1^{\circ}$ ano do Ensino Médio

\begin{tabular}{|c|c|c|c|}
\hline \multicolumn{4}{|c|}{ Questionário diagnóstico (pós-jogo) } \\
\hline \multicolumn{4}{|l|}{$1^{\circ} \mathrm{O}$ que é Astronomia? } \\
\hline (d) Estudo do zodíaco & \multicolumn{3}{|l|}{0} \\
\hline Estudo dos astros & \multicolumn{3}{|l|}{42} \\
\hline (f) Estudo dos astronautas & \multicolumn{3}{|l|}{0} \\
\hline \multicolumn{4}{|c|}{$2^{\circ}$ Onde surgiu a maioria dos elementos químicos? } \\
\hline (g) Tabela periódica & \multicolumn{3}{|l|}{0} \\
\hline (h) Laboratório & \multicolumn{3}{|l|}{6} \\
\hline (i) Morte de estrelas & \multicolumn{3}{|l|}{36} \\
\hline \multicolumn{4}{|l|}{$3^{\circ}$ O que é uma Nebulosa? } \\
\hline (j) Gás e poeira suja & \multicolumn{3}{|l|}{2} \\
\hline (k) Nuvem de matéria interestelar & \multicolumn{3}{|l|}{38} \\
\hline (I) Nuvem de fumaça preta & \multicolumn{3}{|l|}{1} \\
\hline $4^{\circ}$ Você gostou do jogo "De Onde Eu Vim"? & $\begin{array}{l}\text { Sim } \\
37\end{array}$ & $\begin{array}{l}\text { Não } \\
2\end{array}$ & \begin{tabular}{|l} 
Não sei \\
3
\end{tabular} \\
\hline $\begin{array}{l}5^{\circ} \mathrm{O} \text { que você achou do jogo como meio de } \\
\text { aprendizado? }\end{array}$ & $\begin{array}{l}\text { Gostei } \\
37\end{array}$ & $\begin{array}{l}\text { Não gostei } \\
2\end{array}$ & $\begin{array}{l}\text { Não sei } \\
3\end{array}$ \\
\hline $\begin{array}{l}6^{\circ} \text { Em uma breve frase me conte o } q \\
\text { aprendeu. }\end{array}$ & le você & 28 & \\
\hline
\end{tabular}


Questionário Diagnóstico (Pós Jogo) 1ํo ano do ensino médio

\section{Gráfico 24.}

1a pergunta: 0 que é Astronomia?

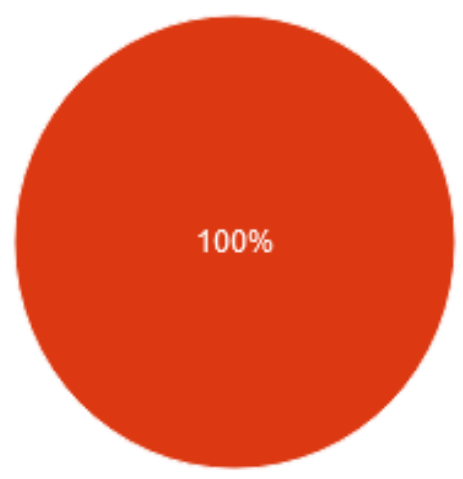

Estudo do zodíaco

Estudo dos astros

Estudo dos astronautas

Como podemos observar no gráfico acima, todos os alunos conseguiram responder corretamente à questão, mesmo sendo uma pequena melhora, pois $97,6 \%$ já sabiam a resposta correta. Apenas um aluno não havia identificado a Astronomia como o estudo dos astros, o que esclarecido durante o jogo.

Gráfico 25.

$2^{2}$ pergunta: Onde surgiu a maioria dos elementos químicos?

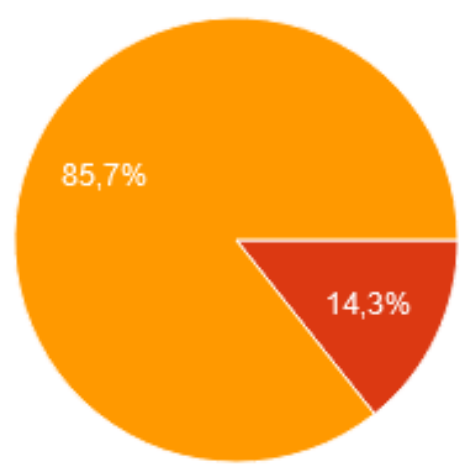

Tabela periódica

Laboratório

Morte de estrelas

Como podemos ver no gráfico acima, foi obtido uma grande melhora comparada a resposta do questionário de pré-jogo, de $42,9 \%$ dos alunos que sabiam antes do jogo subiu para $85,7 \%$ respostas certas depois do jogo. 
Gráfico 26.

3a pergunta: $O$ que é uma Nebulosa?

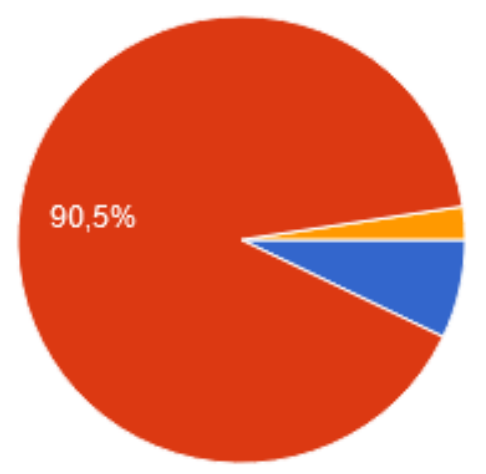

Também na pergunta 3 foi obtido uma melhora considerável em comparação com a resposta do questionário de pré jogo, dos $85,7 \%$ de alunos que já sabiam, subiu para $90,5 \%$ de alunos com a resposta certa.

\section{Gráfico 27.}

\section{4ª pergunta: Você gostou do jogo "De Onde Eu Vim"?}
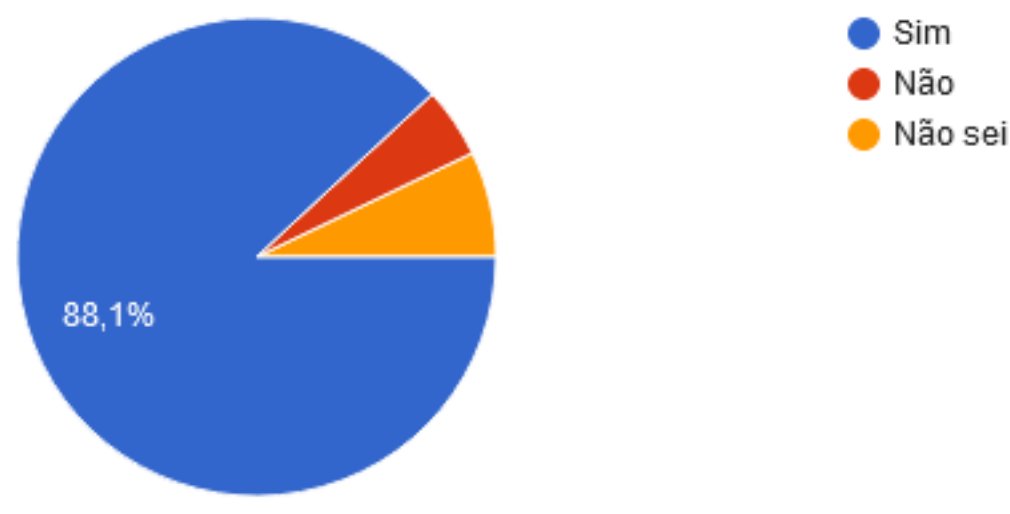

O gráfico acima mostra que $88,1 \%$ dos alunos gostaram de jogar e pediram para que a professora deixasse o jogo para jogarem outras vezes. 


\section{Gráfico 28.}

5ª pergunta: $O$ que você achou do jogo como meio de aprendizado?

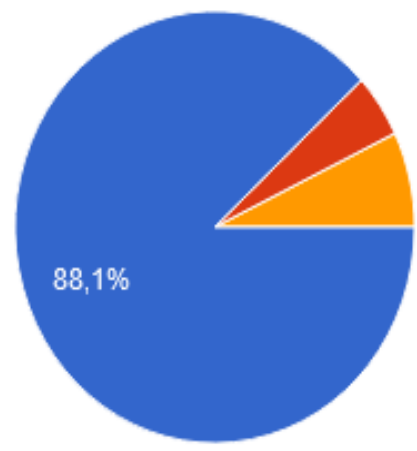

Gostei, consegui aprender jogando

Não gostei, não consegui aprender jogando

Não sei

Como podemos observar no gráfico, a mesma quantidade de alunos que gostaram do jogo é a mesma que consideram o jogo como meio de aprendizagem.

\section{6 pergunta: Em uma breve frase me conte o que você aprendeu.}

Aprendemos a conhecer os elementos

Sobre os elementos químicos

aprendi sobre a matéria prima de alguns elementos

Aprendi muito

Sobre astros

Nada eu perdi

Nada

Maioria dos elementos químicos vem do big bang

Aprendemos os elementos químicos 
Que toda sala 'é muito competitiva

Aprendi de onde os elementos veem

Tudo

Aprendi sobre a origem dos elementos químicos

Aprendi sobre o espaço

Alguns itens da tabela periódica

Aprendi sobre os elementos químicos

A trabalhar em equipe

Sobre elementos químicos

Meio que foi um estudo divertido

Sistema solar e tabela periódica

A origem dos elementos químicos

Eu aprendi de onde vem os elementos químicos

Os nomes, símbolos e para que servem os elementos

Aprendi vários elementos da tabela periódica

Aprendi muitas coisas que eu não sabia

Nessa $6^{a}$ pergunta, tanto no $9^{\circ}$ do ensino fundamental ano quanto no $1^{\circ}$ ano do ensino médio os alunos expõem o que eles aprenderam ou não com o jogo. Houve um avanço significativo do conhecimento sobre a origem dos elementos químicos, embora tenha havido um equívoco decorrente do jogo, expresso na resposta "Maioria dos elementos químicos vem do big bang." 


\subsection{Conclusão dos resultados do $1^{\circ}$ ano do ensino médio}

Conforme os dados obtidos, nota-se que o $1^{\circ}$ ano do ensino médio obteve melhor resultado se comparado o resultado do $9^{\circ}$ ano.

Os alunos ficaram mais centrados no jogo e conseguiram absorver muito mais conhecimento, $99 \%$ dos alunos terminaram o jogo com um grupo vencedor, ressaltando que os alunos do $1^{\circ}$ ano do ensino médio tinham mais conhecimento em relação a astronomia e até mesmo a química pois já tinham sido apresentados à tabela periódica. 


\section{CONSIDERAÇÕES FINAIS}

Como pudemos perceber no decorrer de todo o trabalho, os jogos não só são uma fonte de diversão, mas também ferramentas didáticas importantes para o envolvimento e desenvolvimento da criança e do adolescente na sala de aula.

A partir da pesquisa realizada foi possível perceber a visão dos alunos em relação à forma com que a química e a astronomia podem ser aprendidas, de uma maneira diferenciada, a qual desperte o seu interesse.

No início da pesquisa, houve o temor de que os alunos não quisessem participar por se tratar de uma matéria um pouco complexa, mas a partir dos resultados essa expectativa não se cumpriu e a grande maioria ficou empolgada em participar, e se possível jogariam novamente.

Ao início da apresentação do jogo, foi distribuído um questionário diagnóstico de pré-jogo, para identificar os conhecimentos prévios dos alunos, e, ao término do jogo foi aplicado novamente um questionário diagnóstico de pós-jogo, com o intuito de distinguir se o jogo teve eficácia como instrumento de ensino.

Infelizmente devido à falta de tempo e de disponibilidade da escola, o questionário diagnostico de pós-jogo teve que ser aplicado logo após término do jogo.

Em relação aos alunos do $9^{\circ}$ ano do ensino fundamental, foi percebido que, devido ao fato deles não terem aprendido e nem visto uma tabela periódica, não tiveram tanto interesse no jogo, e alguns foram se dispersando ao longo da atividade, dificultando um pouco a condução da pesquisa. Mesmo assim, a maioria dos alunos gostaram do jogo e pediram para a professora aplicar outras vezes.

Já os alunos do $1^{\circ}$ ano do ensino médio se mostraram interessados do início ao fim, e, como vimos nos resultados, tiveram um excelente desempenho de aprendizagem com o jogo proposto. A familiaridade prévia com a tabela periódica em sala de aula justificaria esse resultado positivo.

Os professores, por sua vez, ficaram entusiasmados com o poder pedagógico do jogo e pediram para disponibilizar o "De Onde Eu Vim?", com o propósito de aplicá-lo nos demais alunos em sala de aula. Construiu-se uma plataforma no Google Classroom (Sala de Aula Google), na qual os professores poderão ter acesso ao jogo, como exibido abaixo. 


Passo a Passo de como acessar o Google sala de aula
Em seu gmail clique no ícone, Google sala de aula (Classroom). Em seguida clique
no símbolo +, logo após clique em "participar da turma". Insira o código a3j73iy,
depois clique em participar para entrar. Lá o professor vai encontrar todas as
informações necessárias para confeccionar o jogo.

Apesar das aulas serem complexas e precisarem ter bastante conteúdo, modificar a didática de vez em quando, trazendo e utilizando novas propostas, pode representar um elemento facilitador importante, como exemplificado pelo jogo "De Onde Eu Vim?".

$\mathrm{O}$ ato de jogar, dentro da perspectiva dos Quatro Pilares da Educação de Jacques Delors (DELORS, 2003, p. 89-102), possibilita o aprender a reconhecer, exercita a atenção, a memória e o pensamento do aluno. A experiência lúdica ativa o "aprender a viver com os outros", que vai além do conhecimento teórico. O jogo é um meio para o aluno aprender a trabalhar em equipe notando as diferenças e semelhanças entre as pessoas, uma experiência que ele pode levar consigo para o seu cotidiano e futuramente e por fim ativar o "aprender a fazer". Então conseguirá usar os seus conhecimentos na prática levando esses ensinamentos para o mercado de trabalho e a transformação da sociedade.

Com experiência acumulada ao longo desta pesquisa, deu para perceber o quanto os alunos estão desmotivados em aprender. Sempre quando há alguma atividade diferente na escola é perceptível a mudança de interesse dos alunos. Quem nunca ficou empolgado quando tinha excursão na escola nem que seja para museus? Isso é devido a mudança da rotina. Às vezes, uma mudança, por mais simples que seja gera uma melhor disposição para o aprendizado, principalmente na escola pública, a grande maioria das quais não tem tantos recursos.

E principalmente agora na era da tecnologia que os alunos estão mais dinâmicos, não é fácil conquistá-los só com conteúdo na lousa. Jogos de tabuleiro, envolvendo vários jogadores, podem ser um importante instrumento de envolvimento da sala de aula na aprendizagem de um tema.

Os jogos não só na química, mas em outras matérias são um diferencial para que a aula se torne prazerosa tanto para o aluno como para o professor. Neste 
trabalho, isso é verificado tanto pelos comentários dos alunos durante o jogo, e depois dele, quando eles pediram que o professor utilizasse mais estratégias como essas, assim como pelas solicitações dos professores de disponibilizar o "De Onde Eu Vim?".

Quando entrei na sala de aula e a professora me apresentou e explicou que sou professora de química, pude perceber a cara de descontentamento dos alunos. Porém, depois que falei como iria ser a aula, com jogos e iriamos falar não só da química, mas também de astronomia, o clima mudou, todos os alunos começaram a ajudar na arrumação das mesas e carteiras, para que começássemos logo. Essa é a força de convencimento de uma narrativa que coloca o ensino de uma disciplina, como a química, dentro de um contexto maior. E que contexto pode ser maior do que o astronômico?

O professor tem em suas mãos várias ferramentas valiosíssimas, das quais muitas vezes não tem consciência, para que a sua aula seja de grande valor, e uma das mais importantes é a imaginação. 


\section{REFERÊNCIAS BIBLIOGRÁFICAS}

ABBOTT, B. P., et al. (LIGO Scientific Collaboration and the Virgo Collaboration). GW170817: observation of gravitational waves from a binary neutron star inspiral. Phys. Rev. Lett., v. 119, p. 161101, 2017 a.

ABBOTT, B. P., ABBOTT, R., ABBOTT, T. D., et al. Estimating the Contribution of Dynamical Ejecta in the Kilonova Associated with GW170817. The Astrophysical Journal, v. 850, p. L39, 2017b.

ADE, P. A. R., et al. (Planck Collaboration). Planck 2015 results XIII. Cosmological parameters. Astron. Astrophys., v. 594 , p. A13 (63 páginas), 2016.

ALMEIDA, P N de. Educação lúdica. São Paulo: Loyola, 1998.

ALMEIDA, P. C. A.; BIAJONE, J. Saberes docentes e formação inicial de professores: implicações e desafios para as propostas de formação. Educação e pesquisa, v. 33, n. 2, p. 281-295, 2007.

ALPHER, R.A. ; BETHE, H.; GAMOW, G. The origin of chemical elements. Phys. Rev., v. 73, p. 803-804, 1948.

ALVES S,L. Interpretando a tabela periódica. 2016. Disponível em: http://mundoeducacao.bol.uol.com.br/quimica/interpretando-tabela-periodica.htm.

ASPLUND, M.; GREVESSE, N.; SAUVAL, A. J.; SCOTT, P. The chemical composition of the Sun. Annual Reviews of Astronomy and Astrophysics, v. 47, p. 481-522, 2009.

BARBUY, B. ; FRIAÇA, A. C. S.; da SILVEIRA, C. R. ; HILL, V.; ZOCCALLI, M.; MINNITI, D.; RENZINI, A.; ORTOLANI, S.; Gómez, A. Zinc abundances in Galactic bulge field red giants: Implications for damped Lyman-a systems Astron. Astrophys., v. 580, p. A40 (16 páginas), 2015.

BLISS, J.; WITT, M.; ARCONES, A.; MONTES, F.; PEREIRA, J. Survey of Astrophysical Conditions in Neutrino-driven Supernova Ejecta Nucleosynthesis. The Astrophysical Journal, v. 855, p. 135-143, 2018.

BRASIL. Ministério da Educação. Secretaria de Educação Básica. Base Nacional Comum Curricular. Brasília: MEC, 2018. Disponível em: http://basenacionalcomum.mec.gov.br/wpcontent/uploads/2018/12/BNCC_19dez2018_site.pdf

BRASIL. Ministério da Educação. PCN Ensino Médio + Orientações Educacionais Complementares aos Parâmetros Curriculares Nacionais. 
Ciência da Natureza, Matemática e suas Tecnologias. Brasília: MEC/SEF, 1998.

Disponível em: http://portal.mec.gov.br/seb/arquivos/pdf/CienciasNatureza.pdf

BIONCONE, M; CARUSO, F. Apresentação - Educação não-formal. Ciência e

Cultura, v. 57 n. 4, p. 20, Out./Dezembro 2005

BRETONES, Paulo Sergio. Jogos para o Ensino de Astronomia. Campinas: Editora Átomo. 2014.

BURBIDGE, M.; BURBIDGE, G.R.; FOWLER, W.A.; HOYLE, F. Synthesis of elements in Stars. Rev. Mod. Phys., v. 29, 547-650, 1957.

COC, A.; VANGIONI, E. Primordial nucleosynthesis. International Journal of Modern Physics E, v. 26, n. 8, p. 1741002 (20 páginas), 2017.

CÔTE , B.; FRYER, C. L.; BELCZYNSKI, K.; KOROBKIN, O.; CHRUŚLIŃKA, M.; VASSH N.; MUMPOWER, M. R.V.; LIPPUNER, J.; SPROUSE, T. M.; SURMAN, R.; WOLLAEGER, R. The Origin of r-process Elements in the Milky Way. The Astrophysical Journal, v. 855, p. 99 (9 páginas), 2018.

CÔTE, B.; , EICHLER, M.; ARCONES, A.; HANSEN, C. J.; SIMONETTI, P.; FREBEL, A.; FRYER, C. L.; PIGNATARI, M.; REICHERT, M.; BELCZYNSKI, K.; MATTEUCCI, F. Neutron Star Mergers Might not be the Only Source of $r$-Process Elements in the Milky Way. arXiv:1809.03525v3, 2019.

CUNHA, M. B. Jogos no Ensino de Química: Considerações Teóricas para sua Utilização em Sala de Aula. Química Nova na Escola, v. 34, n. 2, p. 92-98, Maio 2012.

DAMINELI, A.; STEINER, J. O Fascínio da Universo. São Paulo: Editora Odysseus, 2010.

DAMINELI, A, et al. $O$ céu que envolve: introdução a astronomia para educadores e iniciantes. São Paulo: Editora Odysseus, 2011.

DELORS, J. Os quatro pilares da educação. In: DELORS, J. (Org.) Educação - um tesouro a descobrir. São Paulo: Cortez, 2003.

ERNANDES, H.; BARBUY, B.; ALAVES-BRITO, A.; FRIAÇA, A.; SIQUEIRAMELLO, C.; ALLEN, D. M. Iron-peak elements Sc, V, Mn, Cu, and Zn in Galactic bulge globular clusters. Astron. Astrophys., v. 616, p. A18 (17 páginas), 2018.

ERNANDES, H.; BARBUY, B.; FRIAÇA, A. C. S.; HILL, V. ; ZOCCALLI, M.; MINNITI, D.; RENZINI, A.; ORTOLANI, S. Cobalt and copper abundances in 56 Galactic bulge red giants. Astron. Astrophys., v. 640, p. A89 (16 páginas), 2020. 
FIALHO, N, N. Os jogos pedagógicos como ferramenta de ensino. 2008. Disponível em:

https://www.editorarealize.com.br/revistas/conedu/trabalhos/TRABALHO_EV073_MD 1_SA16_ID552_06092017182851.pdf.

FOGAÇA, J. R. V. Ordem de reatividade dos metais. Brasil Escola. 2020. Disponível em: https://brasilescola.uol.com.br/quimica/ordem-reatividade-dosmetais.htm.

FREBEL, A.; BEERS, T. C. The formation of the heaviest elements. Physics Today, v. 71, n. 1, p. 30-37, 2018.

FRIAÇA, A. C. S. O Vácuo e o Espaço Transdisciplinar. In: Amâncio C. S. Friaça, Luiza Klein Alonso, Mariana Lacombe, Vitória Mendonça de Barros (Orgs.). Educação e Transdisciplinaridade III, p. 439-415. TRIOM, São Paulo. 2005.

FRIAÇA, A. C. S. O planeta chega ao seu limite. Le monde Diplomatique Brasil, n. 29, p. 9, dezembro/2009.

FRIAÇA, A. C. S. Biosfera ameaçada. Le monde Diplomatique Brasil, n. 39, p. 38, outubro/2010.

FRIAÇA, A.C.S. A energia renovável vai ao espaço. Le Monde Diplomatique Brasil, n. 59, p. 12-13, jun./2012.

FRIAÇA, A.C.S. What is Astrobiology? AGA0316 - A Vida no Contexto Cósmico. Notas de Aula. 2019a. Disponível em: http://www.astro.iag.usp.br/ amancio/aga0316_notas/01aga0316_whatisastrobiology .pdf

FRIAÇA, A.C.S. What is Life? AGA0316 - A Vida no Contexto Cósmico. Notas de Aula. 2019b. Disponível em:

http://www.astro.iag.usp.br/ amancio/aga0316_notas/02aga0316_whatislife.pdf

FRIAÇA, A. C. S.; BARBUY, B. Tracing the evolution of the Galactic bulge with chemodynamical modelling of alpha-elements. Astron. Astrophys., v. 598, p. A121 (15 páginas), 2017.

FRIAÇA, A. C. S; DAL PINO, E.; SODRÉ JR, L.; JATENCO-PEREIRA, V. Astronomia: Uma Visão Geral do Universo. São Paulo: EDUSP, 2000.

FRIAÇA, A. C. S.; JANOT PACHECO, E. Life in the cosmic context: an astrobiology course as an experiment in transdisciplinarity. Revista Mexicana de Astronomía y Astrofísica, v. 44, p. 127, 2014. 
FUMAGALLI, L. O Ensino de Ciências Naturais no Nível Fundamental da Educação Formal: argumentos a seu favor. In: WEISSMANN, H. (Org.). Didática das ciências naturais: contribuições e reflexões. Trad. Beatriz Affonso Neves. Porto Alegre: ArtMed, 1998.

GRAY, T. Os Elementos. Uma Exploração Visual dos Átomos Conhecidos no Universo. São Paulo: Editora Blucher, 2011.

HORVATH; J. E. O ABCD da Astronomia e Astrofísica. São Paulo: Editora Livraria da Física, 2008.

HUIZINGA, J. Homo ludens: o jogo como elemento da cultura. 5 ed. São Paulo: Perspectiva, 2007

JOHNSON, J.A. Populating the periodic table: Nucleosynthesis of the elements. Science 63, 474, 2019.

JOHNSON, J.A. Origin of the elements in the Solar Dystem. 2017. Disponivel em: http://blog.sdss.org/2017/01/09/origin-of-theelements-in-the-solarsystem/

KISHIMOTO, T. M. Jogo, brinquedo, brincadeira e educação. São Paulo: Cortez, 1999.

KNELLER, J.P.; PHILLIPS, J.R.; WALKER, T.P. The Spallagenic Production Rates of Lithium, Beryllium and Boron. arXiv:0008073, 2008.

KRATZ, K.-L.; FAROUQUI, K.; PFEIFFER, B.; TRURAN, J. W.; SNEDEN, C.; COWAN, J. J. Explorations of the r-Processes: Comparisons between Calculations and Observations of Low-Metallicity Stars. The Astrophysical Journal, v. 662, p. 39-52, 2007.

KUMAR, Y.B.; REDDY, B.E.; CAMPBELL, S.W.; MABEN, S.; ZHAO, G.; TING, Y. Discovery of ubiquitous lithium production in low-mass stars. Nat. Astron., v. 4, 1059-1063, 2020.

LANFRANCHI, G. A. ; FRIAÇA, A. C. S. Clues to the nature of damped Lyman a systems from chemical evolution models. MNRAS, v. 343, p. 481-503, 2003.

LANGHI, R.; NARDI, R. Ensino da astronomia no Brasil: educação formal, informal, não-formal e divulgação científica. Revista Brasileira de Ensino de Física, v. 31, n. 4, p. 4402-11, 2009.

LIBANEO, J. C. Didática y práctica histórico-social. Revista Ande, ano 4, n. 8 , 1984. 
LIMA, E.C. et al. Uso de Jogos Lúdicos Como Auxílio Para o Ensino de Química. Discente do 6o Semestre do Curso de Licenciatura em Química - Centro Universitário Amparense - UNIFIA. São Paulo. 2012.

LONGHINI, M. D. Ensino de Astronomia na Escola: Concepções, ideias e práticas na escola. Campinas: Editora Átomo. 2014.

MACIEL, W. J. Formação dos elementos químicos. Revista USP, n. 62, p. 66-73, jun/ago 2004.

MAX-NEEF, M.A. Foundations of transdisciplinarity. Ecological Economics, v. 53, p. 5-16, 2005.

MCCALL, B. J. Optical and Infrared Observations of Diffuse Clouds. In: Proceedings of the International Astronomical Union, Volume 1, Symposium S231: Astrochemistry: Recent Successes and Current Challenges, August 2005, p. 165 - 174, 2006.

MERRILL, PW. Spectroscopic Observations of Stars of Class S. The Astrophysical Journal, v. 116, 21-26, 1952.

MORAIS; Antônio Manuel Alves. A Origem dos Elementos Químicos: uma abordagem inicial. São Paulo: Editora Livraria da Física, 2009.

MOYLES, J R. Só brincar? O papel do brincar na educação infantil. Tradução: Maria Adriana Veronese. Porto Alegre: Artmed, 2002.

NEGRINE, A. Terapias corporais: a formação pessoal do adulto. Porto Alegre: Edita, 1998.

PLAN, E.; D'AVANZO, P.; BENETTI, S., et al. Spectroscopic identification of rprocess nucleosynthesis in a double neutron-star merger. Nature, v. 551, p. 67 (13 páginas), 2017.

QUEIROZ, V. A Astronomia Presente nas Séries Iniciais do Ensino Fundamental das Escolas Municipais de Londrina. Dissertação de Mestrado, Universidade Estadual de Londrina. Londrina, 2008.

RANDICH, S.; PASQUINI, L.; FRANCIOSINI, E. et al. The Gaia-ESO Survey: Galactic evolution of lithium at high metallicity. Astronomy and Astrophysics, v. 640, p. L1 (5 páginas), 2020.

SANTANA, E. M., REZENDE, D. de B. O Uso de Jogos no ensino e aprendizagem de Química: Uma visão dos alunos do 9 ano do ensino fundamental. XIV Encontro Nacional de Ensino de Química (XIV ENEQ). Universidade Federal do Paraná. Curitiba, 2008. 
SANTANA, E. M. O Uso do Jogo Autódromo Alquímico como Mediador da Aprendizagem no Ensino de Química. Dissertação de Mestrado. Instituto de Física. Universidade de São Paulo. São Paulo, 2012.

SANTOS, C. M. D.; ALABI, L. P.; FRIAÇA, A. C. S.; GALANTE, D. On the parallels between cosmology and astrobiology: a transdisciplinary approach to the search for extraterrestrial life. International Journal of Astrobiology, v. 15, n. 4, p. 251-260, 2016

SÃO PAULO. Secretaria da Educação. Currículo do Ensino de São Paulo: Ciências da Natureza e suas Tecnologias. Ensino Fundamental - Ciclo Il e Ensino Médio. São Paulo: SEE, 2010.

SARTINI, B. A, et al. Uma Introdução à Teoria dos Jogos: II Bienal da Sociedade Brasileira de Matemática. Universidade Federal da Bahia. 2004

SCHELBAUER, A. R. Orbis sensualium pictus: das lições ilustradas de Comenius no século XVII às lições de coisas da escola primária no século XIX. In: BRITO, S. H. S. et al. (Org.) A organização do trabalho didático na história da educação. Campinas: Autores Associados, 2010.

SILVA, L. M. A. Guia para o ensino de Astrobiologia na Amazônia: contextualizações para a educação básica. Dissertação de Mestrado. Universidade de São Paulo. Instituto de Astronomia, Geofísica e Ciências Atmosféricas. 2018.

SILVEIRA, R. S; BARONE, D. A. C. Jogos Educativos computadorizados utilizando a abordagem de algoritmos genéticos. IV Congresso RIBIE, Brasília 1998.

da SILVEIRA, C. R.; BARBUY, B. ; FRIAÇA, A. C. S.; HILL, V. ZOCCALLI, M. ; RAFELSKI, M.; GONZALES, O. A.; MINNITI, D.; RENZINI, A.; ORTOLANI, S. Oxygen and zinc abundances in 417 Galactic bulge red giants. Astron. Astrophys., v. 614, p. A149 (27 páginas), 2018.

SNEDEN, C.; COWAN, J. J.; GALLINO, R. Neutron-Capture Elements in the Early Galaxy. Annu. Rev. Astron. Astrophys., v. 46, p. 241-248. 2008.

SPITE, F.; SPITE, M. Abundance of lithium in unevolved halo stars and old disk stars-Interpretation and consequences Astron. Astrophys., v. 115, p. 357, 1982.

STALEY, J. T.. Astrobiology, the Transcendent Science: the Promise of Astrobiology as an Integrative Approach for Science and Engineering Education and Research. Current Opinion in Biotechnology, 14, 347-354, 2003. 
TERUYA, N.; DUARTE, S. B. Núcleos exóticos e síntese dos elementos químicos. Química Nova, v. 35, n. 2, p. 360-366, 2012

THILEMANN, F.-K.; EICHLER, M.; PANOV, I.V.; WEHMEYER, B. Neutron Star Mergers and Nucleosynthesis of Heavy Elements. Annual Review of Nuclear and Particle Science, 67, 253-274, 2017.

TRAVAGLIO, C.; GALLINO, R.; BUSSO, M.; GRATTON, R. Lead: asymptotic giant branch production and galactic chemical evolution. The Astrophysical Journal, v. 549, p. 346-352, 2001.

TRAVAGLIO, C.; GALLINO, R.; ARNONE, E.; COWAN, J.; JORDAN, F.; SNEDEN, C. Galactic Evolution of Sr, Y, and Zr: A Multiplicity of Nucleosynthetic Processes. The Astrophysical Journal, v. 601, p. 864, 2004.

VANGIONI-FLAM, E.; CASSÉ, M.; AUDOUZE, J. Lithium-Beryllium-Boron: Origin and Evolution. Physics Reports, v. 333-334, p. 365-387, 2000

VYGOTSKY, L. S. A formação social da mente: 0 papel do brinquedo no desenvolvimento. 7a ed., São Paulo: Martins Fontes, 2007.

VYGOTSKY, L. S. Pensamento e Linguagem, 3. ed, São Paulo: Martins, 2005.

VYGOTSKY, L. S. Psicologia Pedagógica. São Paulo: Martins, 2001.

VYGOTSKY, L. S. A Construção do Pensamento e da Linguagem. São Paulo: Martins, 2000.

VYGOTSKY, L. S. O Desenvolvimento Psicológico na Infância. São Paulo: Martins.1999.

WADDELL, T.G.; RYBOLT, T.R. The chemical adventures of Sherlock Holmes: Sherlock Holmes and the Nebulous Nitro. Journal of Chemical Education, v.73, n.6, p.1157, 1996.

WADDELL, T.G.; RYBOLT, T.R. The chemical adventures of Sherlock Holmes: The Baker Street Burning. Journal of Chemical Education, v.75, n.4, p.484, 1998.

WADDELL, T.G.; RYBOLT, T.R. The chemical adventures of Sherlock Holmes: The Ghost of Gordon Square. Journal of Chemical Education, v.77, n.4, p.471, 2000.

WADDELL, T.G.; RYBOLT, T.R. The chemical adventures of Sherlock Holmes: The shroud of Spartacus. Journal of Chemical Education, v.78, n.4, p.471, 2001. 
WANAJO, S. The r-process in Proto-neutron-star Wind Revisited.

Astrophysical Journal Letters, v. 770, p. L22-27, 2013.

WATANABE, M; RECENA, M. C. P; Memória Orgânica - Um jogo didático útil no processo de ensino e aprendizagem. IV Encontro Nacional de Ensino de Química (XIV ENEQ). Universidade Federal do Paraná, Curitiba 2008.

WATANABE, M. e RECENA, M.C.P. Jogo de Memória - A contribuição do lúdico no aprendizado de funções orgânicas. XIII Encontro Nacional de Ensino de Química. Campinas,2006.

WINNICOTT, D. W. O brincar e a realidade. Rio de Janeiro: Imago, 1975, p. 203. 


\section{APÊNDICE}

\section{APÊNDICE A}

\section{Produto Final}

\section{TABELA PERIÓDICA}

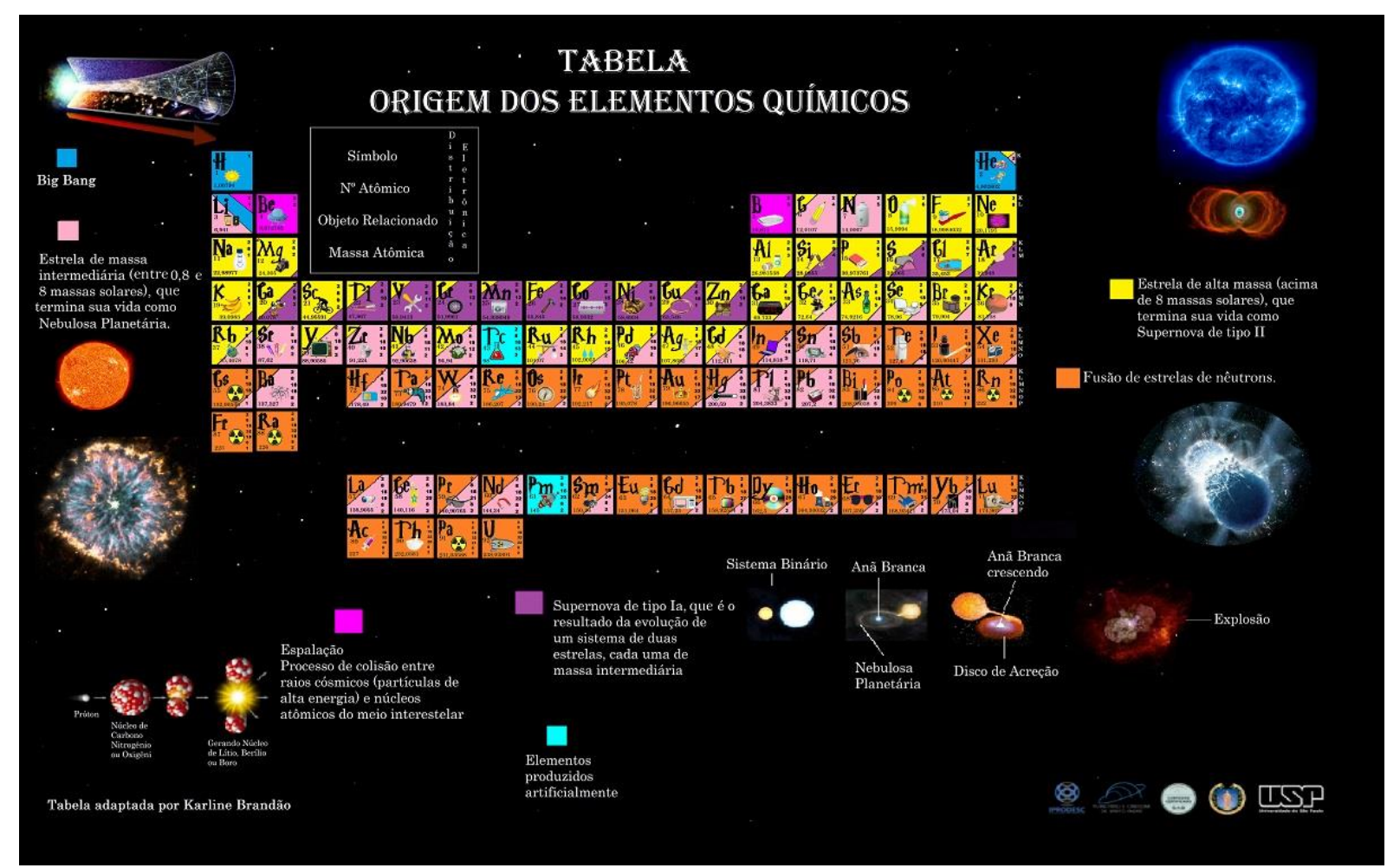

A tabela mede $59,5 \mathrm{~cm}$ de largura e $39,5 \mathrm{~cm}$ de altura. 
TABELA PARA AJUDA

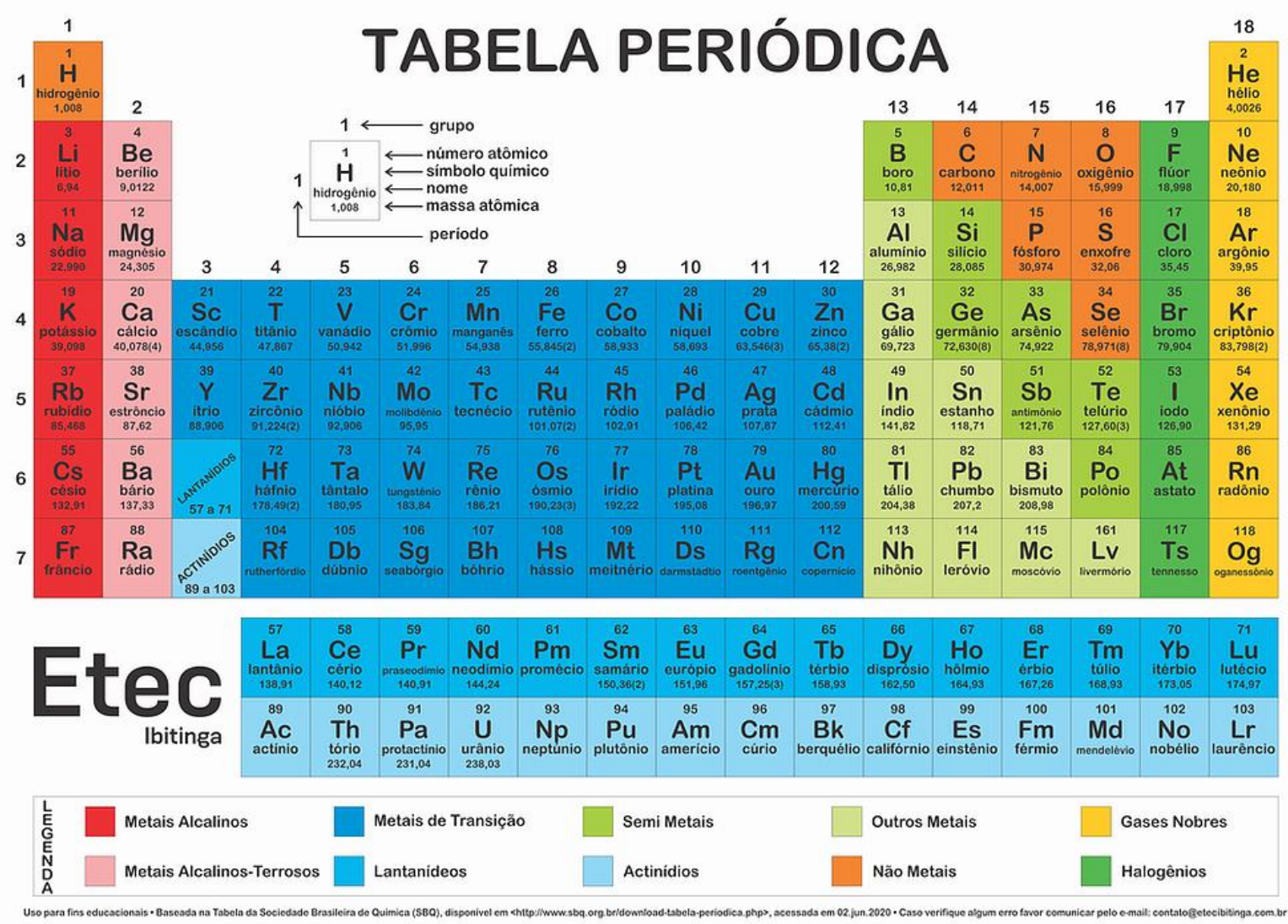

Fonte: https://etecdeibitinga.wixsite.com/novo/post/tabela-peri\%C3\%B3dica 
TABULEIRO DO JOGO

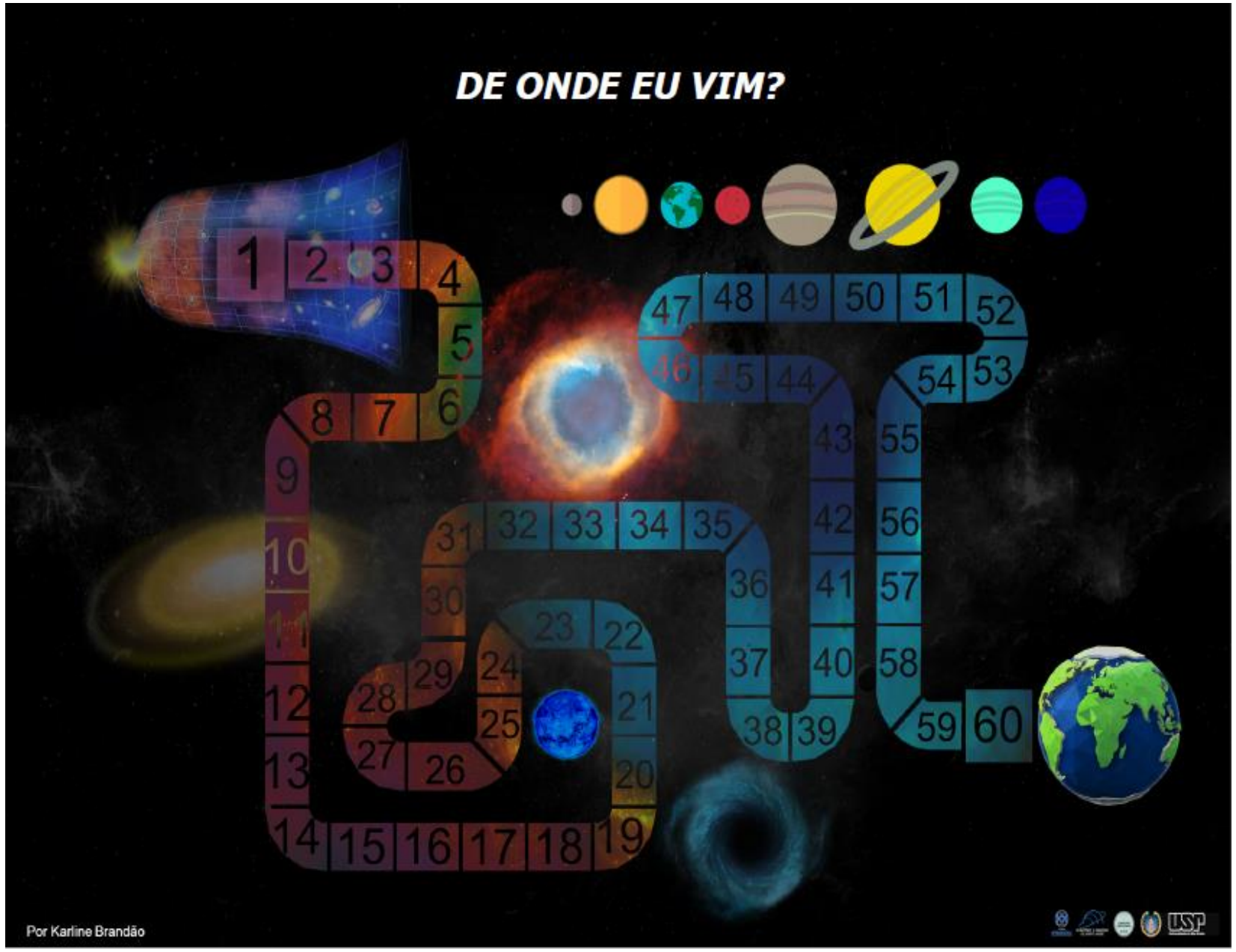

O tabuleiro mede $84 \mathrm{~cm}$ de largura e $60 \mathrm{~cm}$ de altura. 
CARTAS

Frente
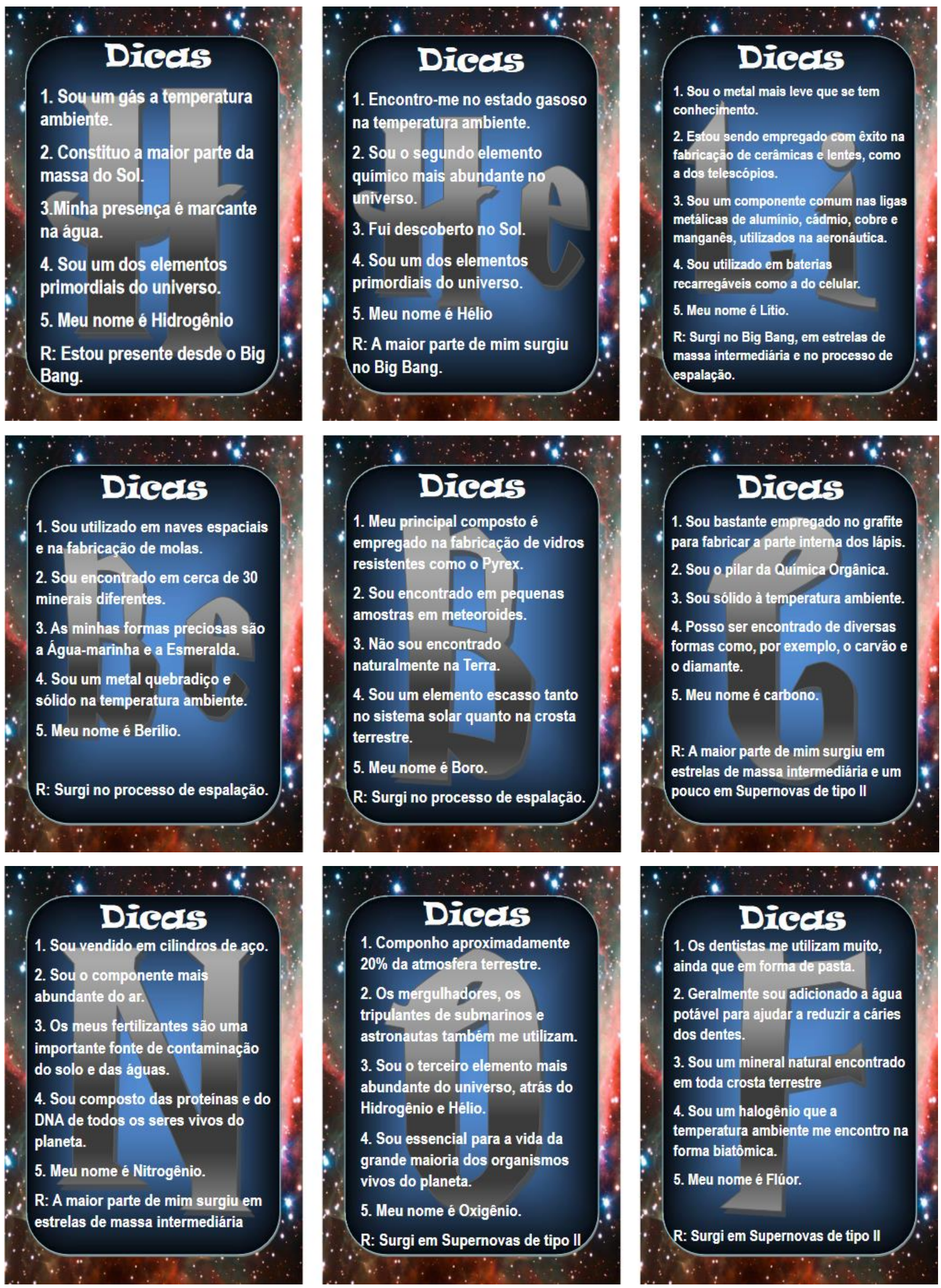

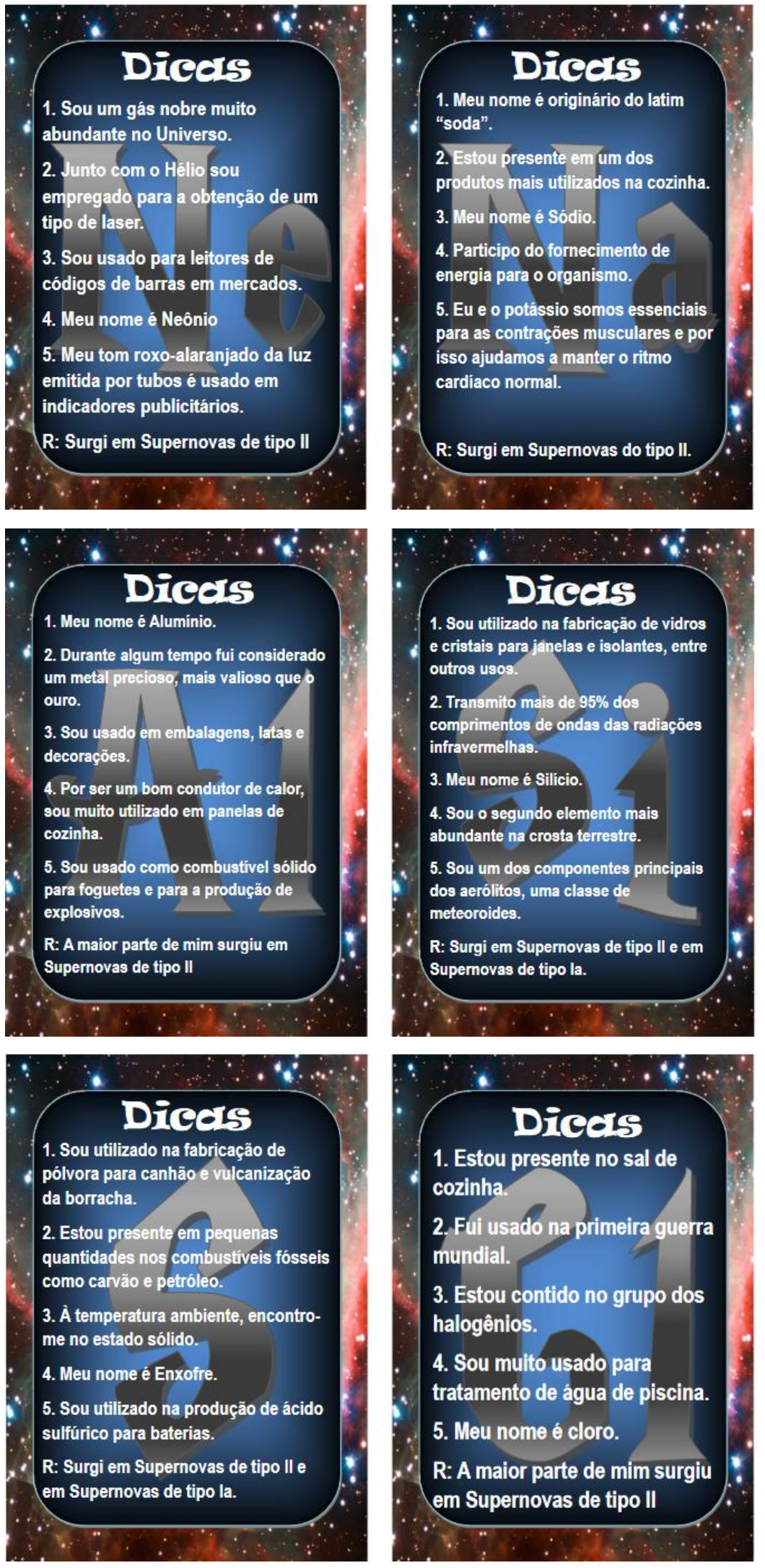
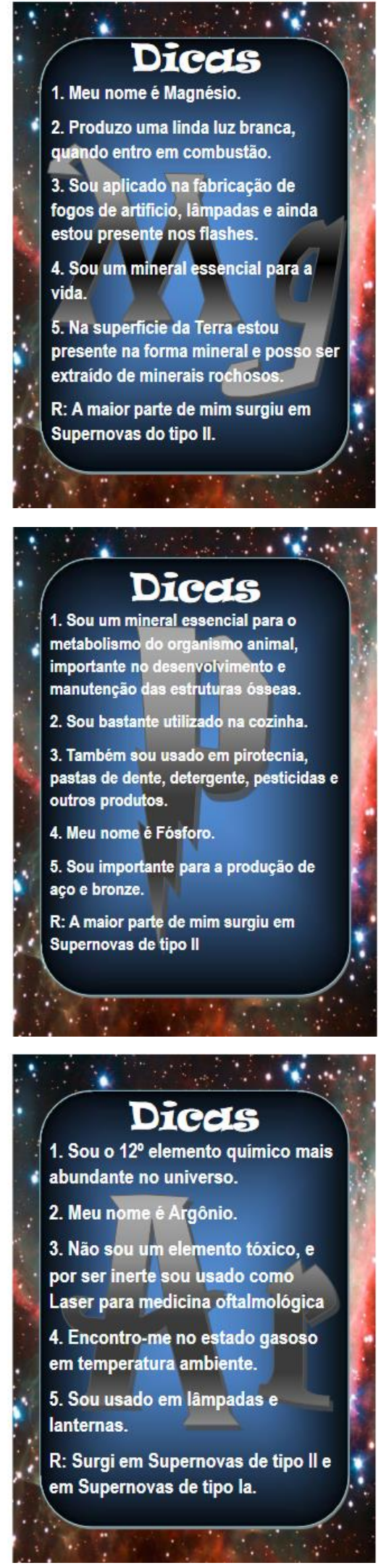

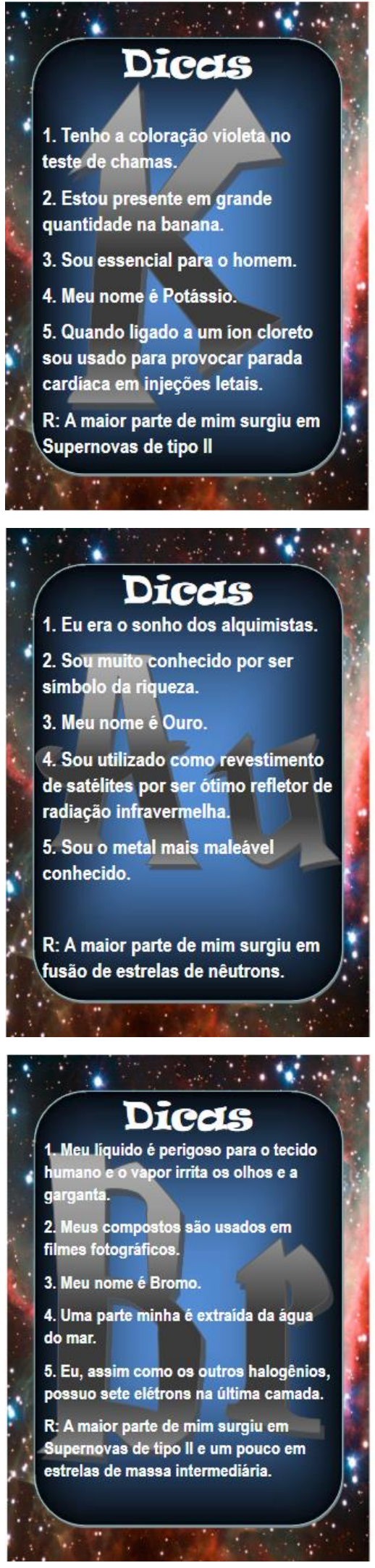
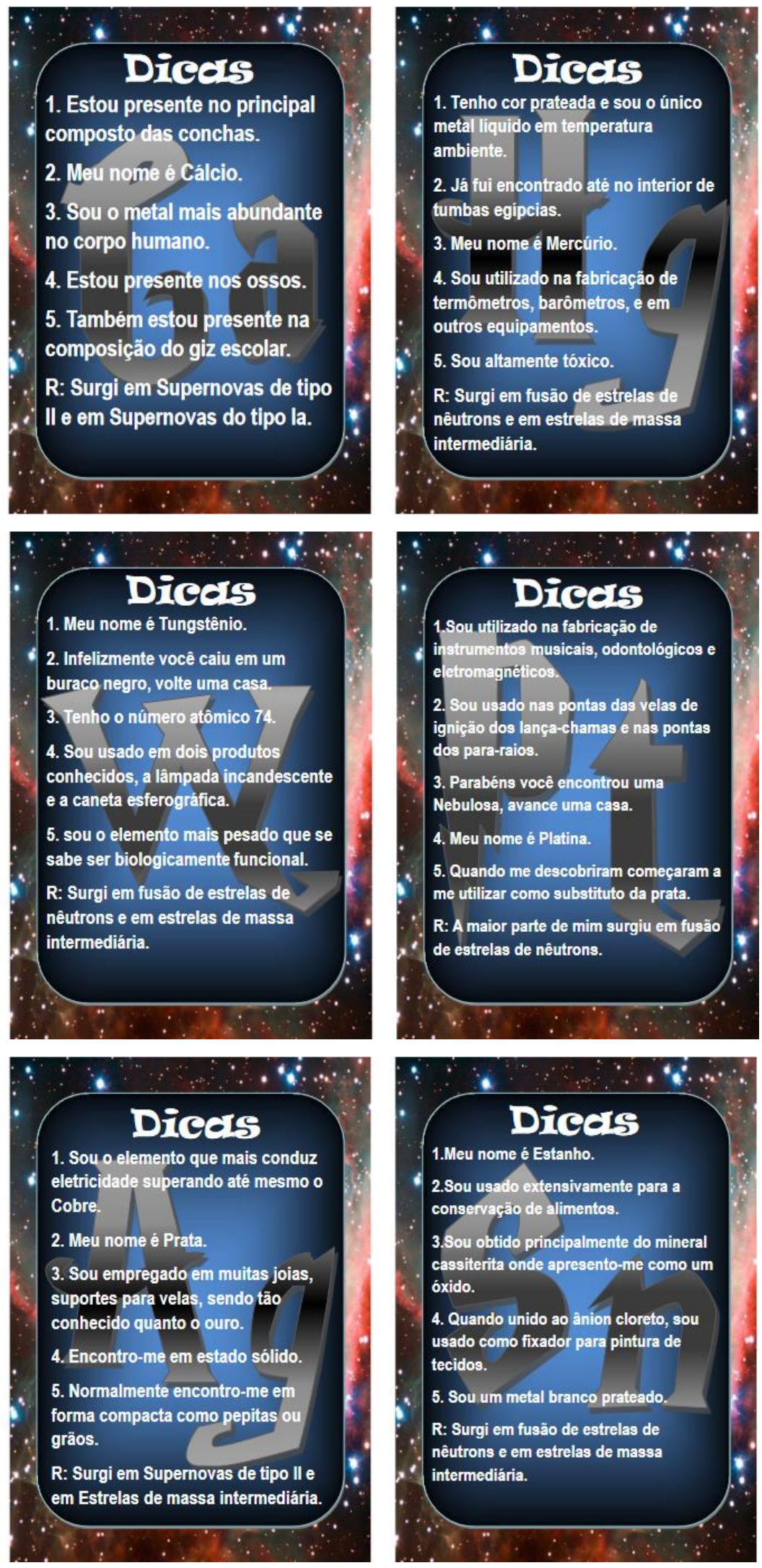

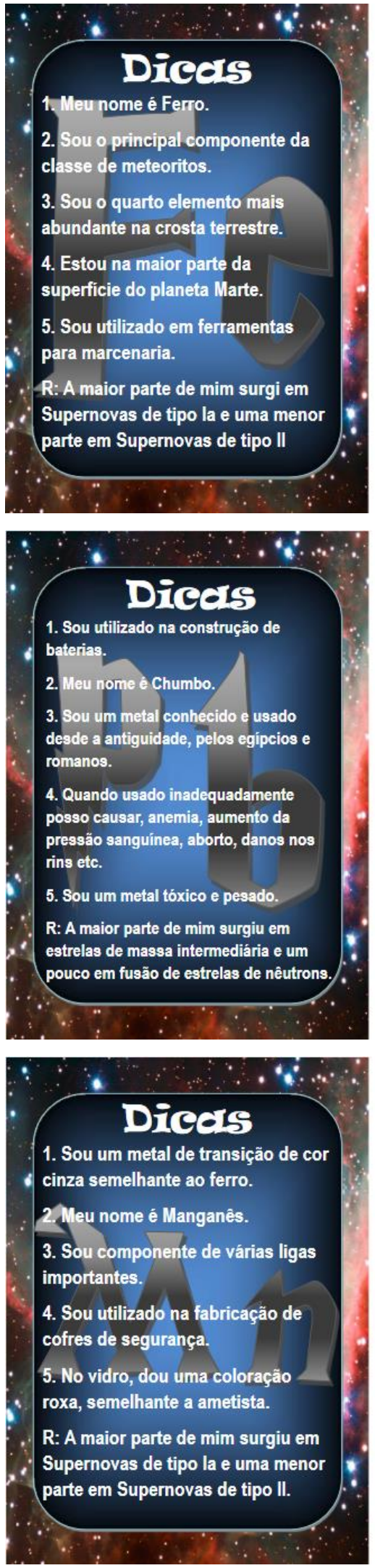
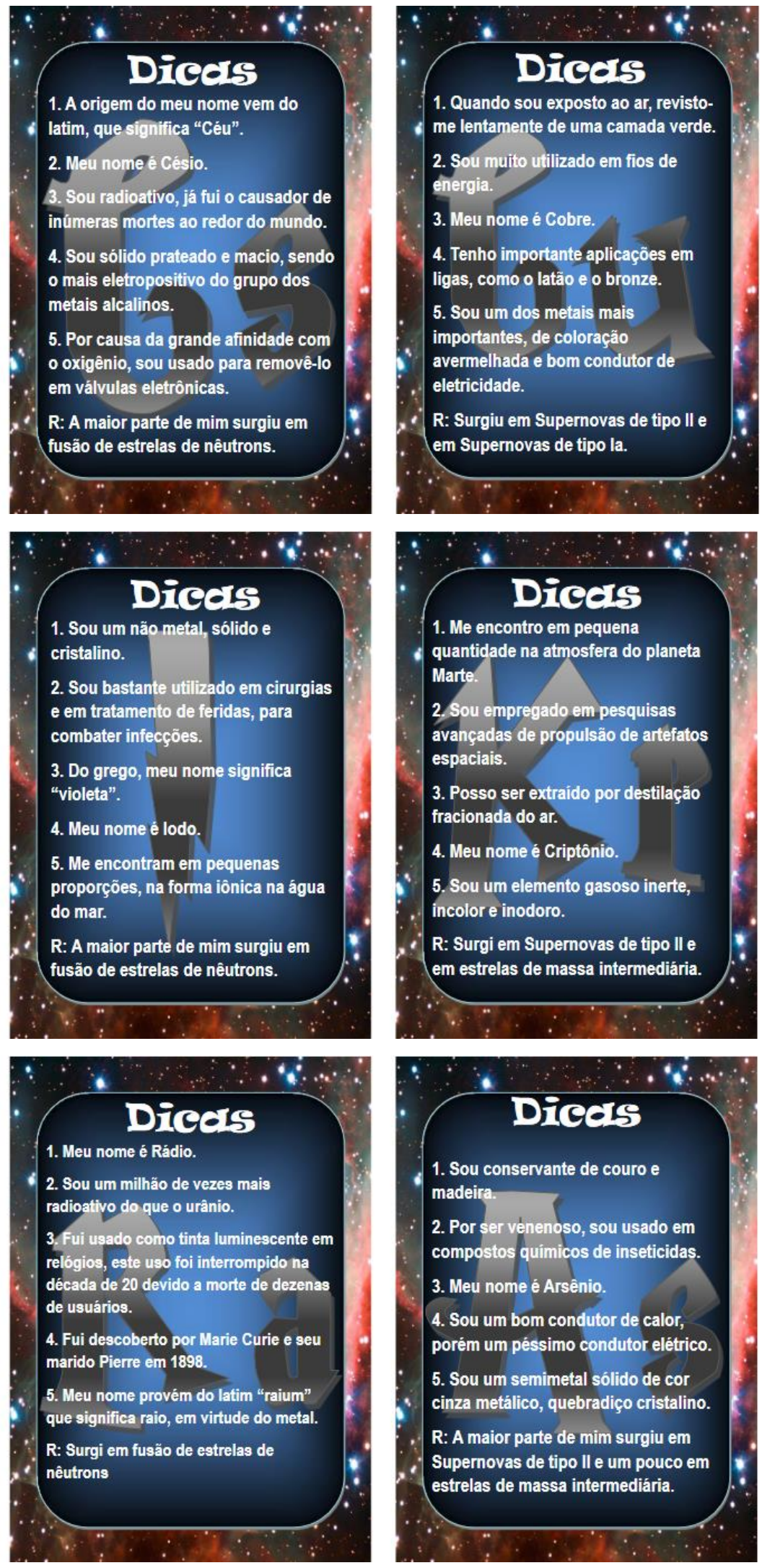

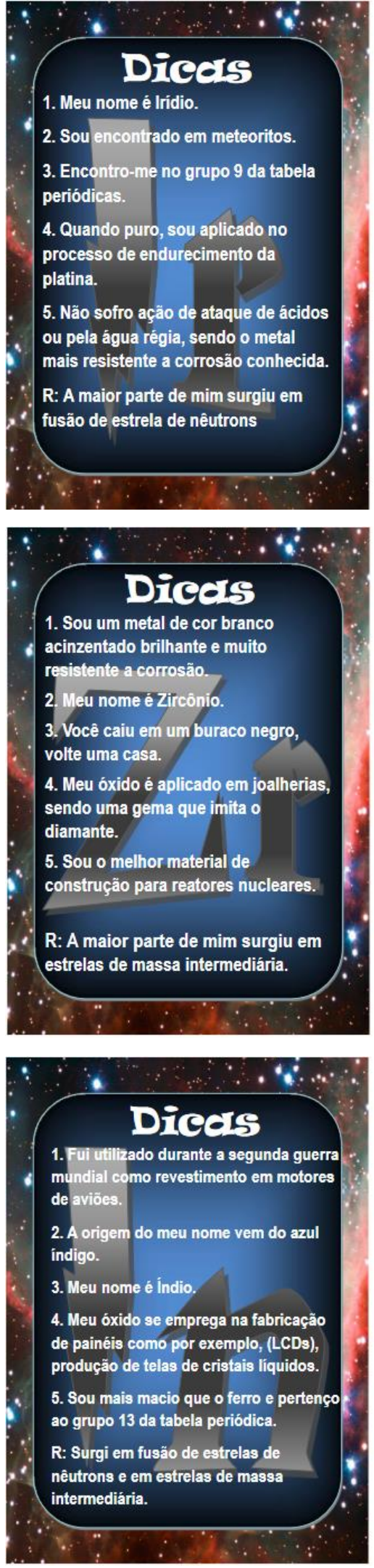
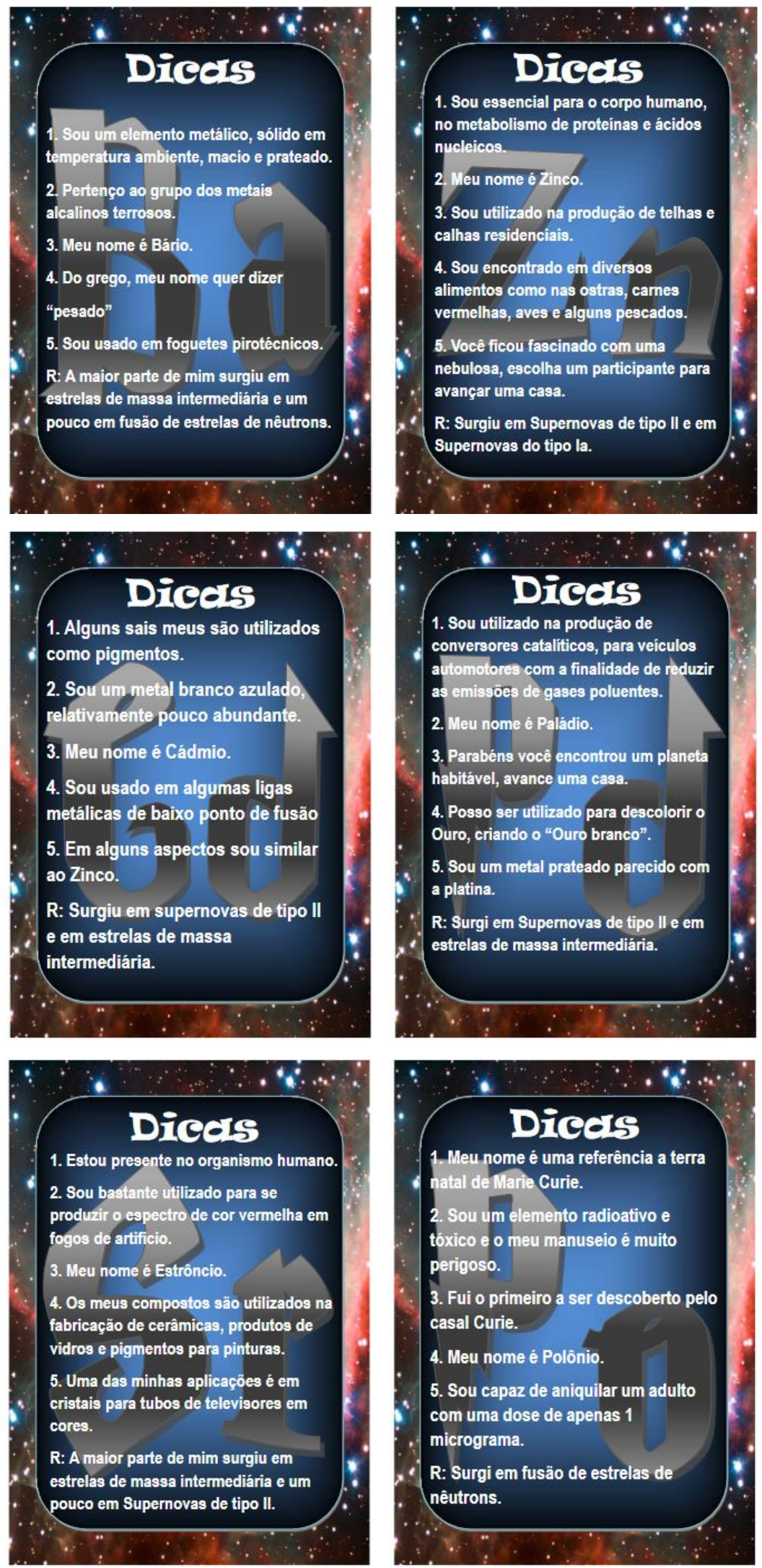

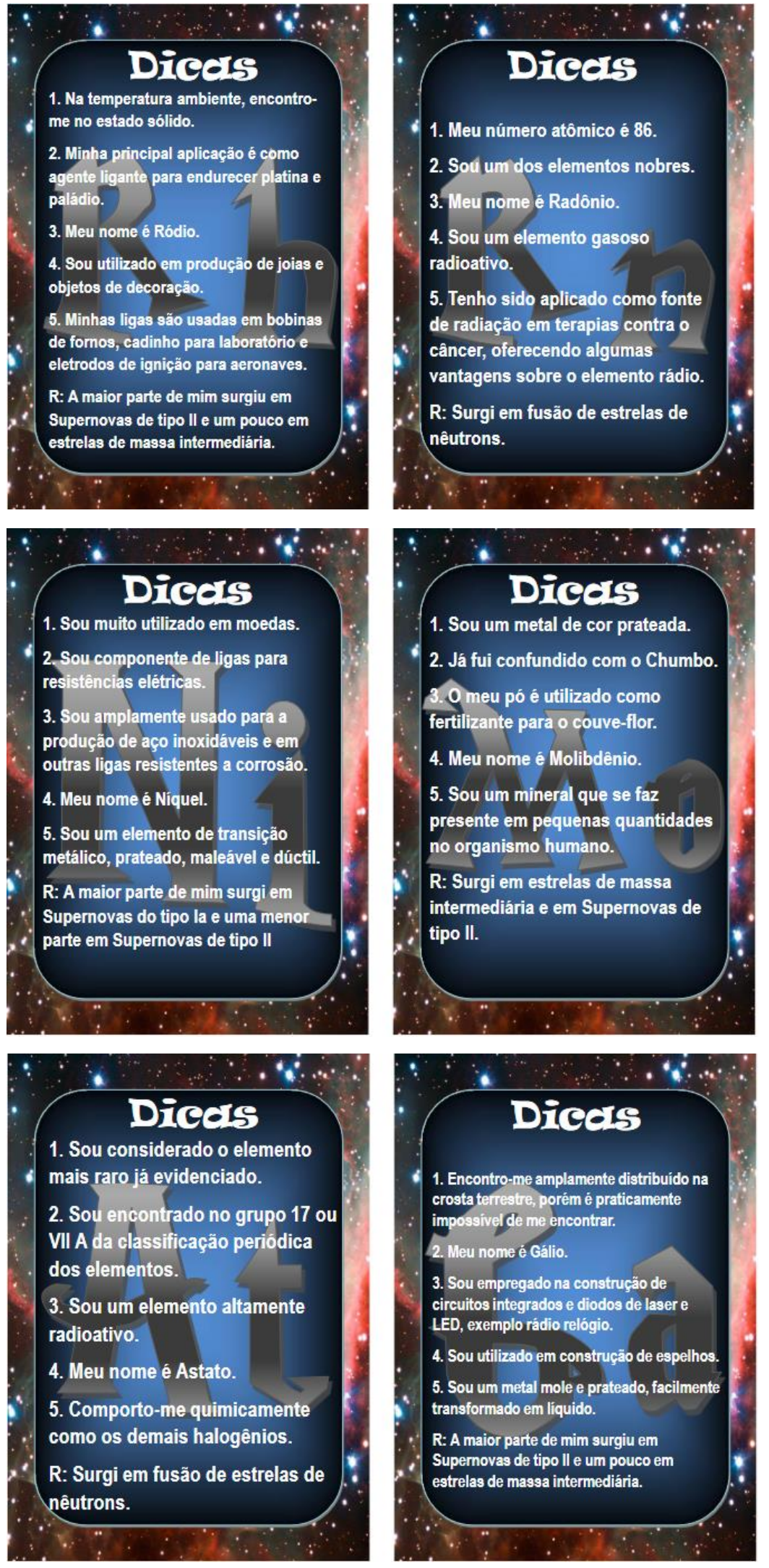
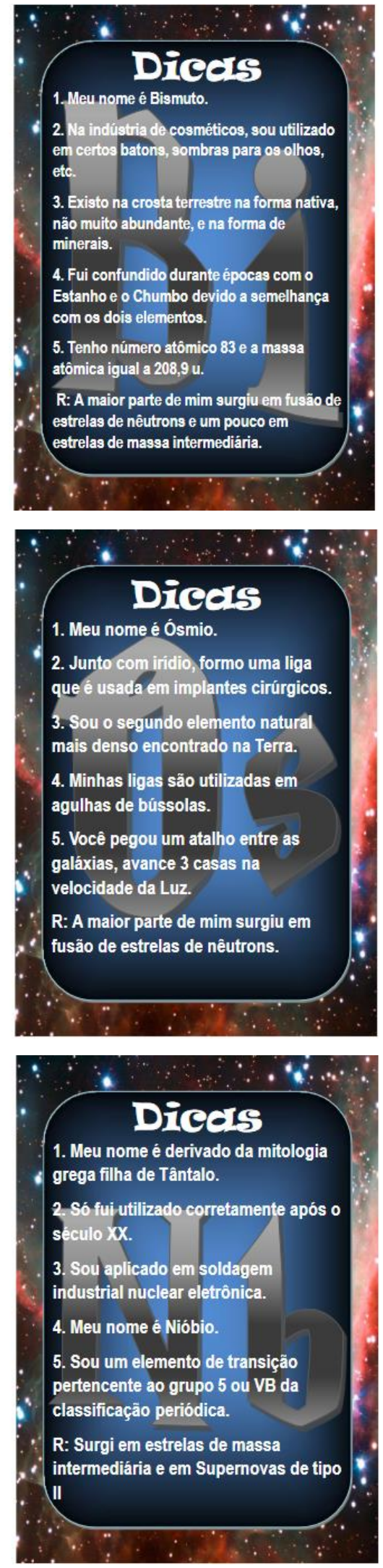

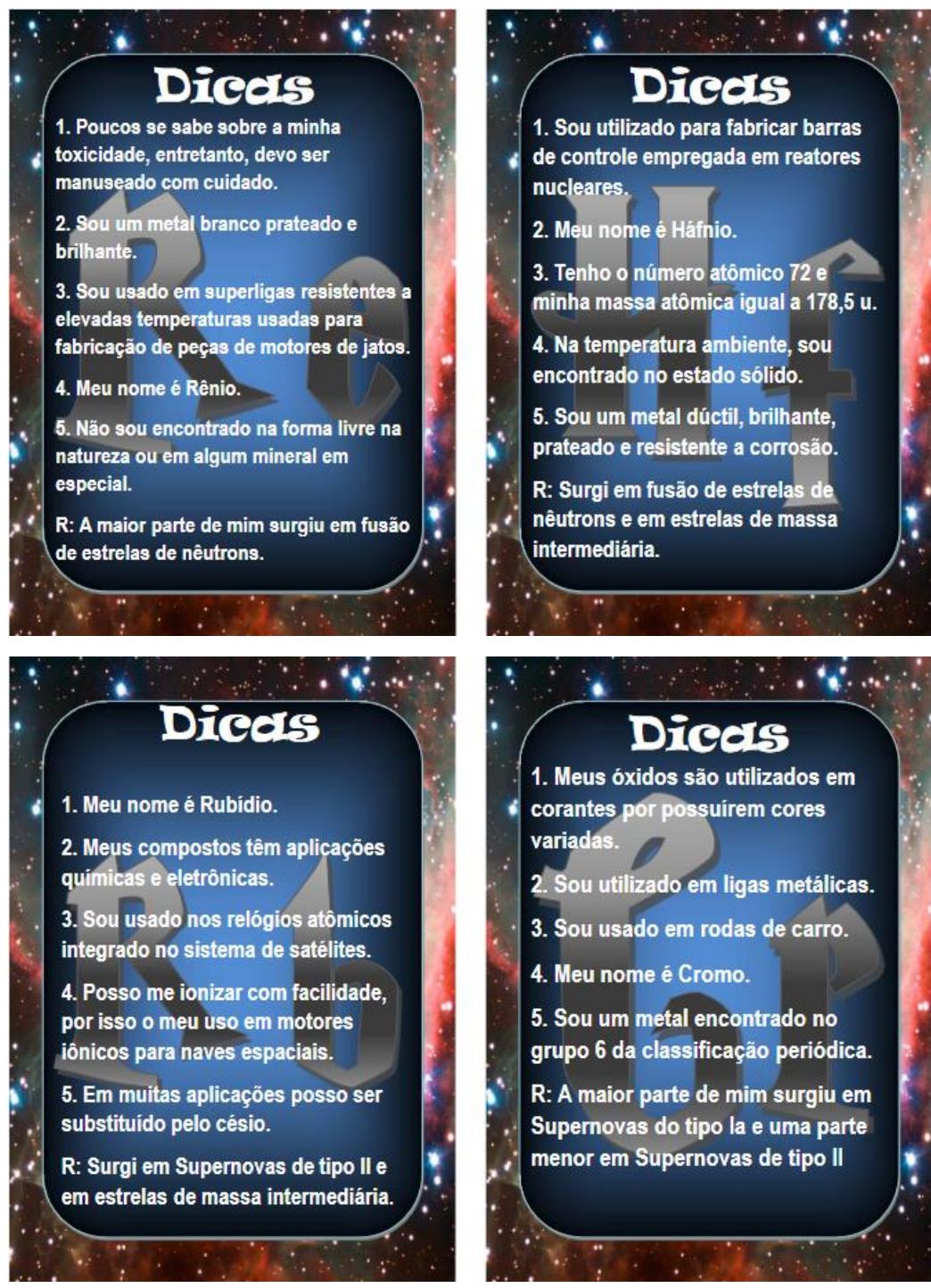
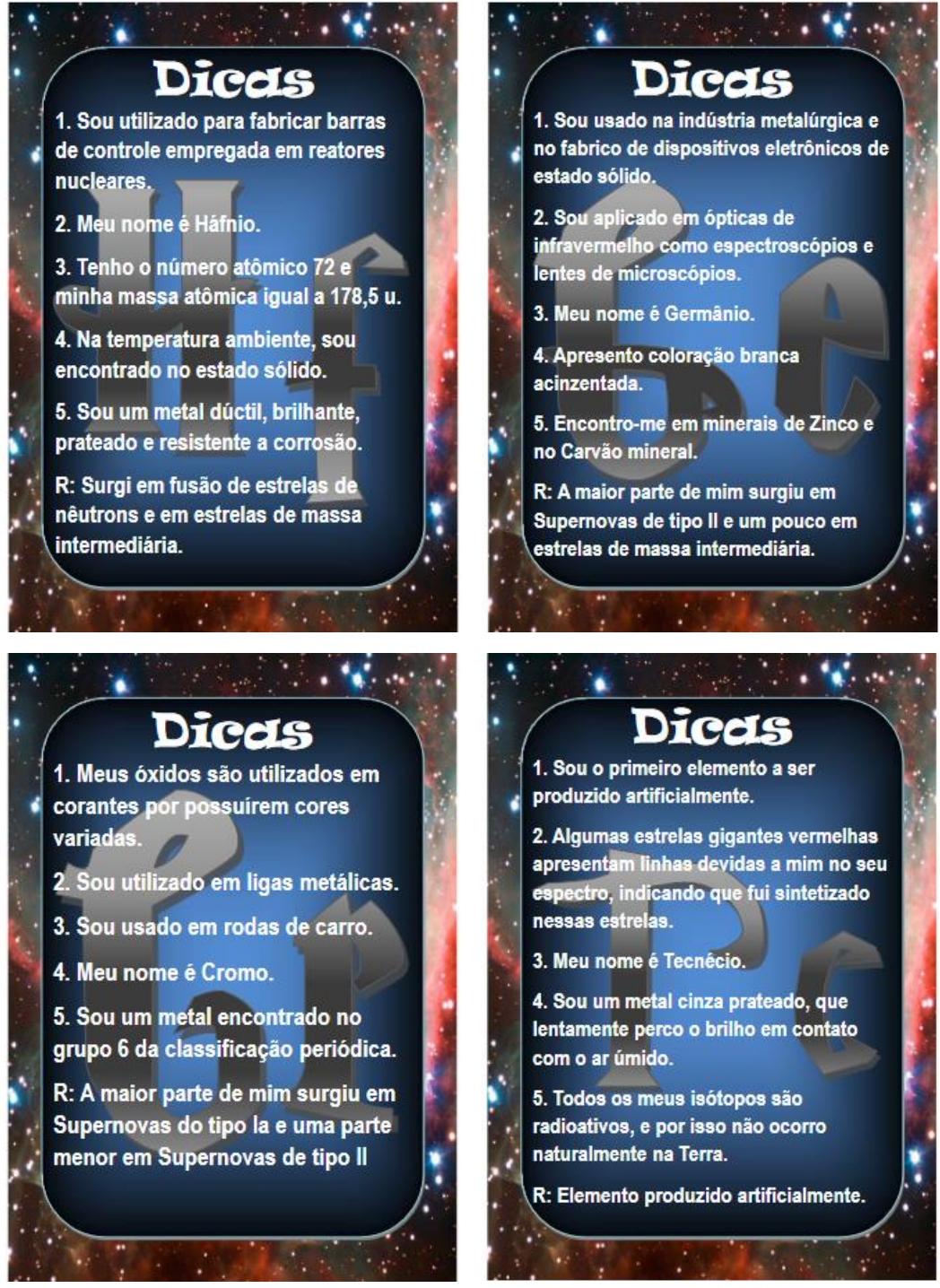


\section{CARTAS}

Verso
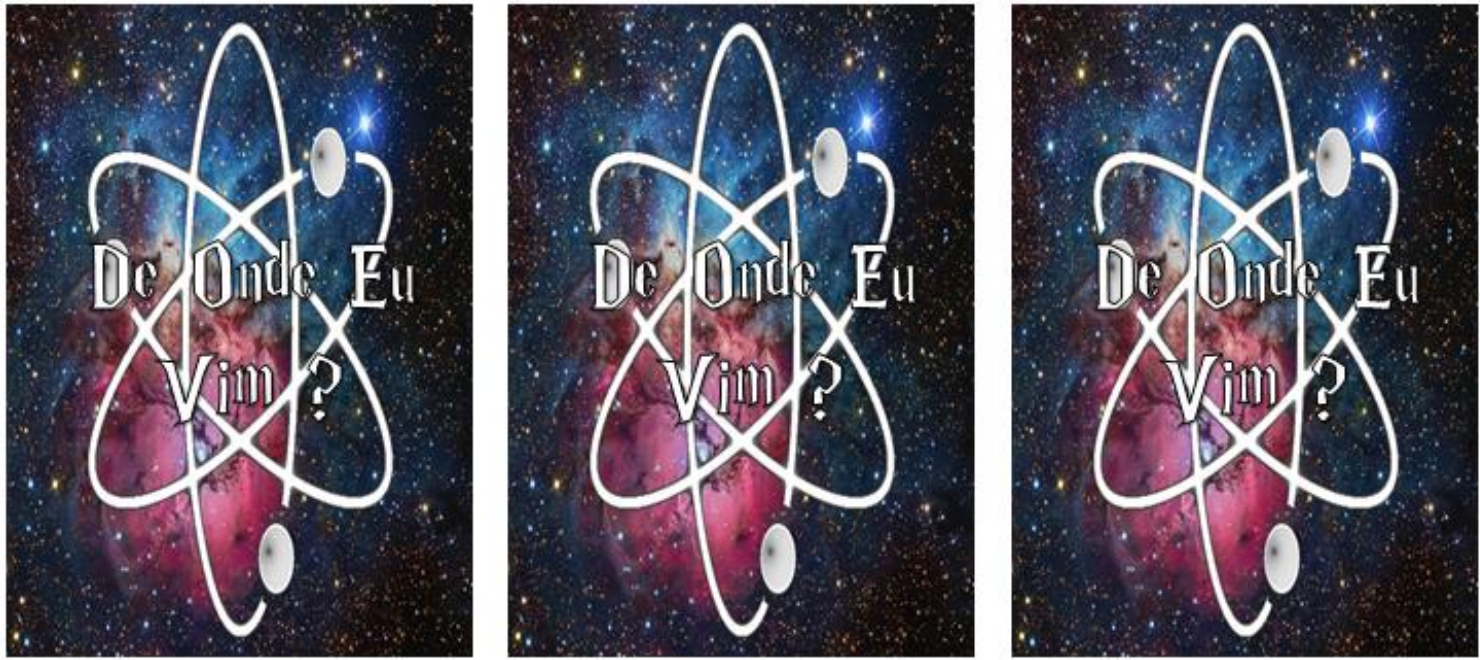

FICHA PARA AS DICAS

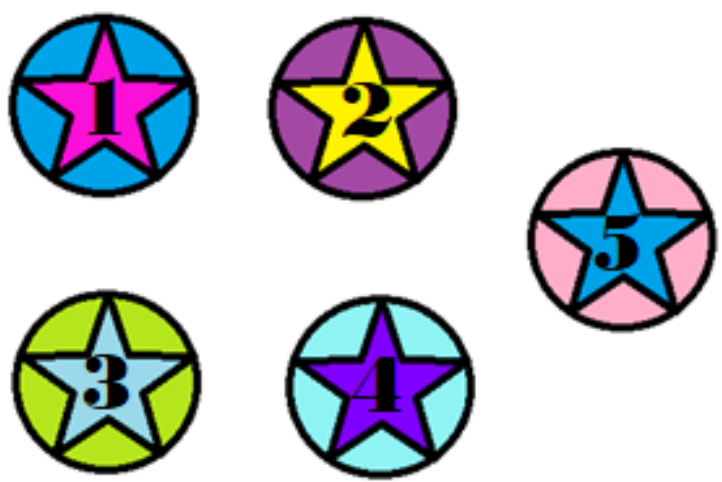




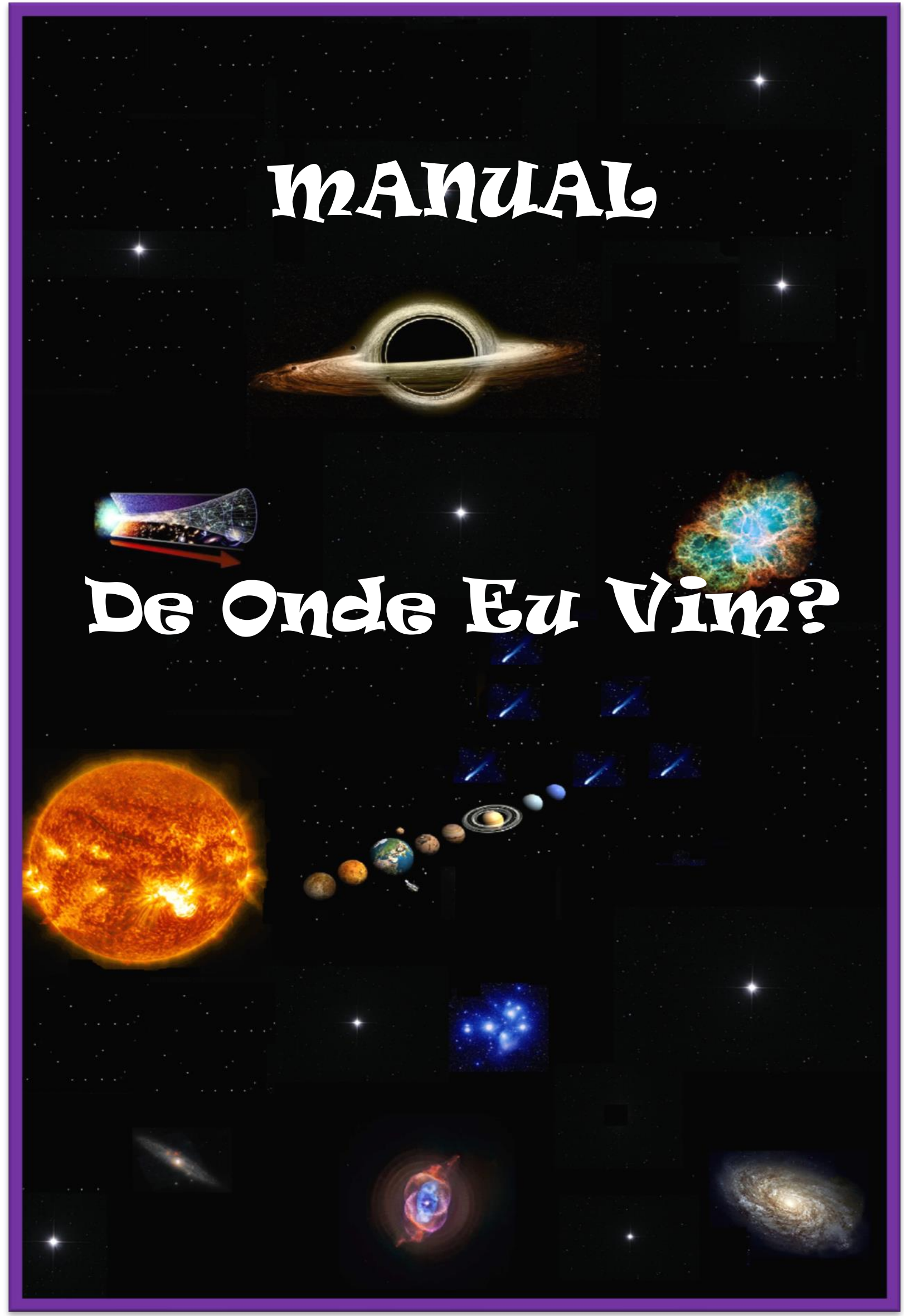




\section{Manual do Jogo - De Onde Eu Vim?}

"De Onde Eu Vim?" é um jogo inicialmente para alunos do $1^{\circ}$ ano do Ensino Médio, pois tem a intenção de apresentar a classificação periódica de uma maneira diferente. Além de conhecer as características, curiosidades e propriedades dos elementos, ainda mostra suas aplicações e como foram formados, fazendo assim com que os alunos já comecem a associar os elementos ao seu dia-a-dia, facilitando seu entendimento tanto de Química como de Astronomia.

\section{Jogadores:}

$>\quad 1$ líder para ler as dicas

$>2$ ou mais jogadores disputam a chegada.

\section{Componentes:}

$>4$ dados numéricos.

$>\quad 4$ peões coloridos.

$>5$ fichas numeradas para as dicas.

> 60 cartas com 5 dicas e respostas.

> 1 tabela da classificação periódica, com a aplicação dos elementos químicos no cotidiano e indicando como foram formados, para consulta.

$>\quad 1$ tabela periódica comum.

> 1 ampulheta de 30 segundos ou cronômetro. 


\section{Regras do jogo:}

O primeiro jogador escolhe uma dica de (1 a 5) da carta que o líder está na mão.

O líder lê a dica, e depois o primeiro jogador terá que adivinhar onde 0 elemento da carta foi formado.

Caso o jogador acerte, ele jogará o dado e o número que cair será o quanto ele avançará nas casas do tabuleiro.

O líder pega outra carta para continuar o jogo com o próximo jogador, caso não saiba ou erre passa-se a vez para o próximo.

O jogo ocorre em sentido horário entre os participantes.

Ganha o primeiro jogador que chegar ao planeta Terra.

\section{$\underline{\text { Tabela: }}$}

Uso livre para consulta. 


\section{Material para consulta}

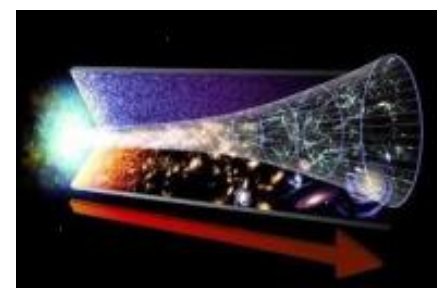

\section{Big Bang}

Um dos temas mais apaixonantes do conhecimento é o estudo da evolução do Universo e de tudo que ele contém. Estima-se que a idade do Universo seja, aproximadamente, 13,7 bilhões de anos. O momento zero do Universo marca o início de sua expansão, o Big Bang.

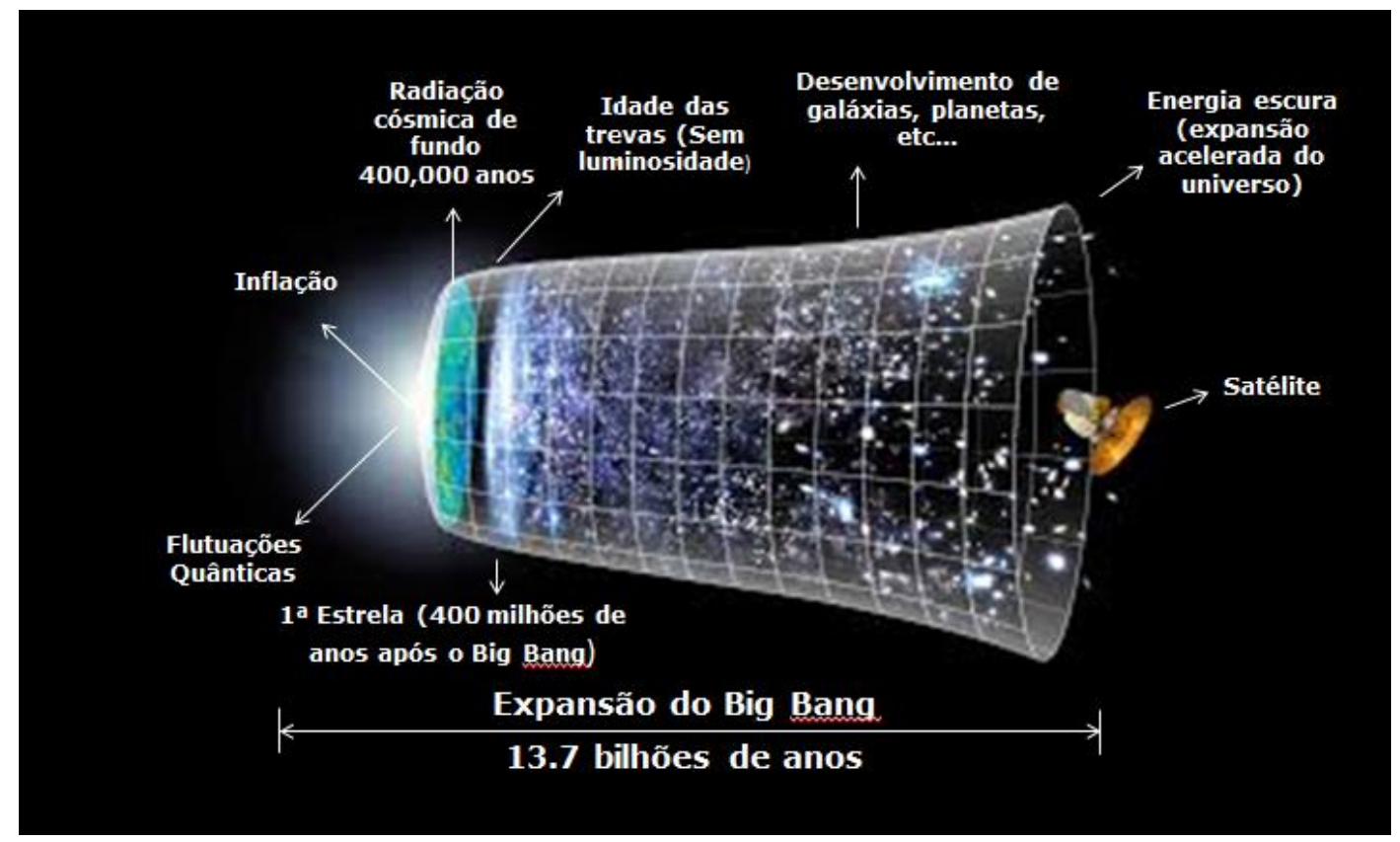

Em 1929, Edwin Hubble e Milton Humason, com base em suas observações no telescópio de Monte Wilson, verificaram que suas medidas de velocidades radiais das galáxias implicavam que elas estavam se afastando com uma velocidade de recessão proporcional à distância até nós. Isso foi posteriormente interpretado como indicando que o universo está se expandindo. 
Os elementos químicos mais leves como o Hidrogênio, Hélio e uma pequena quantidade de outros elementos leves foram fabricados durante 0 Big Bang.

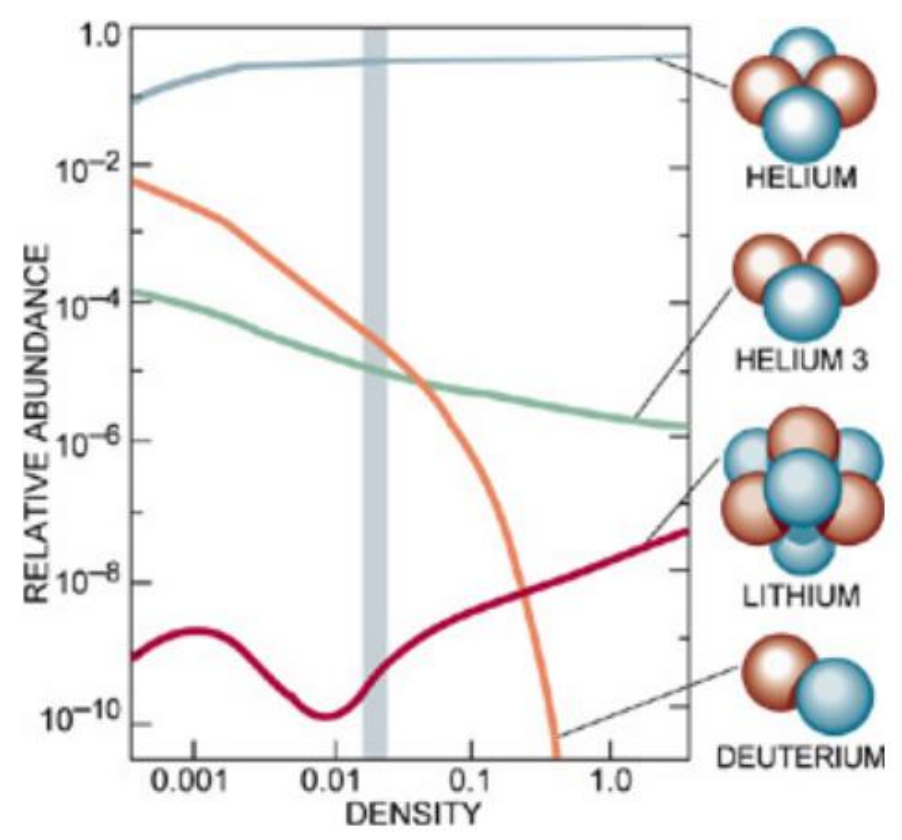

Quando o Universo tinha entre 1 e 100 segundos de idade foram sintetizados elementos até o número de massa $7:{ }^{1} \mathrm{H}$ (hidrogênio), ${ }^{2} \mathrm{H}$ (deutério, ou hidrogênio pesado, também indicado pelo símbolo D), ${ }^{4} \mathrm{He}$ (0 isótopo mais abundante do hélio), ${ }^{3} \mathrm{He}$ (o isótopo mais leve do hélio) e ${ }^{7} \mathrm{Li}$ (o isótopo mais pesado do lítio). 


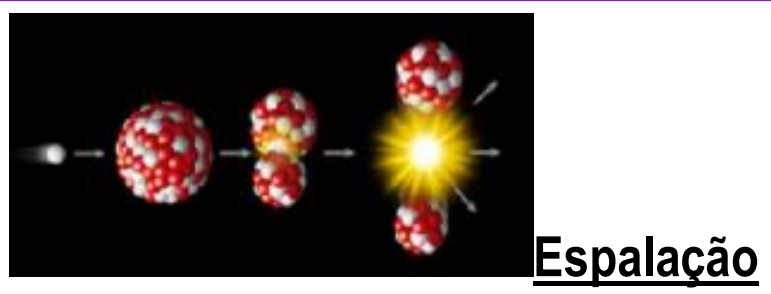

Espalação é um processo em que um núcleo atômico se fragmenta em núcleos atômicos menores devido ao impacto de uma partícula de alta energia. No ambiente astronômico, esse processo ocorre entre raios cósmicos (partículas de alta energia, principalmente prótons) e núcleos atômicos do meio interestelar (principalmente carbono, nitrogênio e oxigênio). A Espalação dá origem ao ${ }^{6} \mathrm{Li}$ (o isótopo mais leve do lítio), Be (berílio) e B (boro). 


\section{Evolução Estelar}
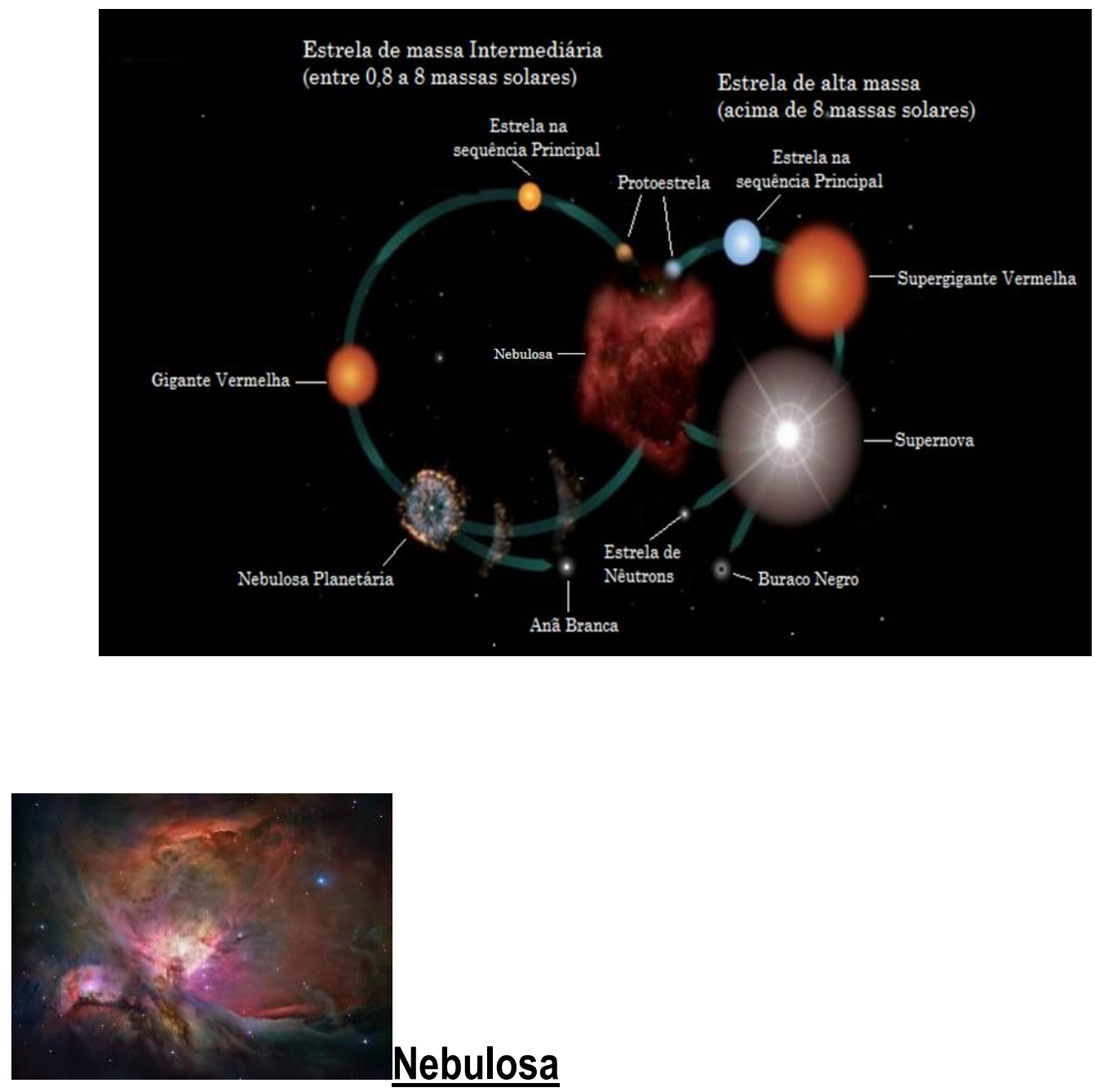

As nebulosas são nuvens interestelares formadas por gás e poeira. Algumas nebulosas estão associadas ao nascimento de estrelas ou a estrelas jovens, outras ao fim de sua vida. Podem ser classificadas em: nebulosas de emissão ou difusas, nebulosas de reflexão, nebulosas de absorção ou escuras, nebulosas planetárias e remanescentes de supernovas. 


\section{Estrelas}

As estrelas são corpos aproximadamente esféricos de plasma, que apresentam reações de fusão nuclear em alguma fase de sua evolução. Elas têm uma massa mínima de cerca de 0,08 massa solar para que para que realizem ao menos a fusão de hidrogênio em hélio. Brilham na luz visível e são classificadas em classe espectrais que são relacionadas com a sua cor e a temperatura da superfície.

\begin{tabular}{|c|c|c|c|c|c|c|c|}
\hline $\begin{array}{l}\text { Classe } \\
\text { Espectral }\end{array}$ & 0 & B & A & $\mathbf{F}$ & $\mathbf{G}$ & $\mathbf{K}$ & M \\
\hline Temperatura & $\begin{array}{l}\text { Mais De } \\
25000 K\end{array}$ & $\begin{array}{l}11000 \mathrm{~K} \\
\mathrm{a} \\
25000 \mathrm{~K}\end{array}$ & $\begin{array}{l}7500 \mathrm{~K} \\
\mathrm{a} \\
11000 \mathrm{~K}\end{array}$ & $\begin{array}{l}6000 K \\
a \\
7500 K\end{array}$ & $\begin{array}{l}5000 K \\
a \\
6000 K\end{array}$ & $\begin{array}{l}3500 \mathrm{~K} \\
\mathrm{a} \\
5000 \mathrm{~K}\end{array}$ & $\begin{array}{l}\text { Menos } \\
\text { de } \\
3500 \mathrm{~K}\end{array}$ \\
\hline Cor & Azul & $\begin{array}{l}\text { Branca } \\
\text { Azul }\end{array}$ & Branca & Amarelada & Amarela & Laranja & Vermelha \\
\hline
\end{tabular}

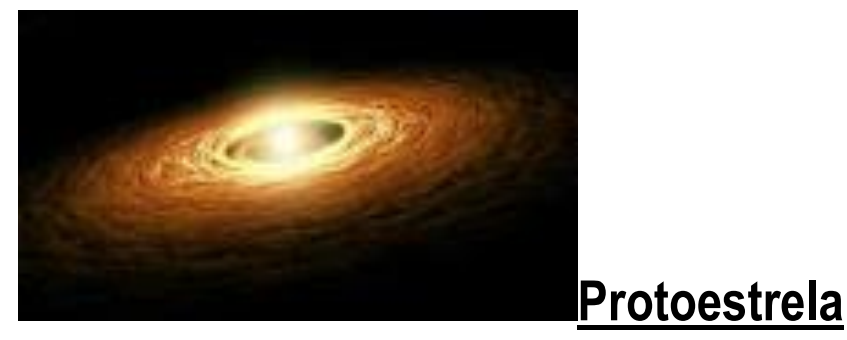

A protoestrela é a primeira fase da evolução de uma estrela. A formação estelar inicia-se em uma nuvem molecular gigante que se colapsa sob a ação da própria gravidade. À medida que se colapsa, ela se fragmenta. Esses fragmentos dão origem a protoestrelas. A escala de tempo envolvida em todo esse processo é de milhões de anos. 


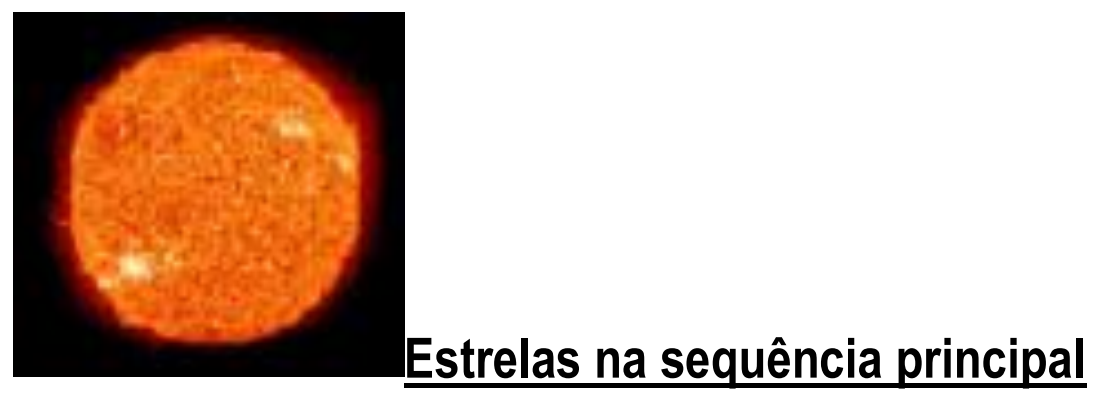

Quando a estrela adquire um equilíbrio hidrostático, após alguns milhões de anos a temperatura da estrela atinge um valor alto o suficiente para ocorrer reações nucleares transformando o hidrogênio em hélio. Quando isso ocorre, a estrela entra na fase da Sequência Principal. Durante esta etapa de sua evolução, o interior da estrela ocorre um processo de autorregulação que mantém a estrela estável.

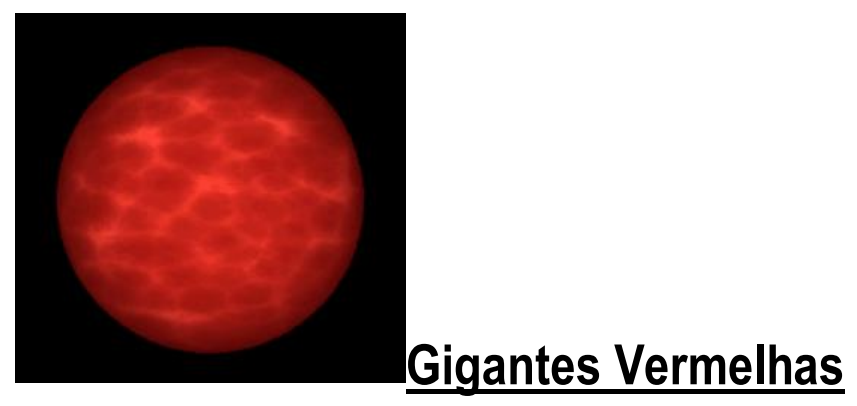

À medida que o hélio do núcleo da estrela vai se esgotando, ocorre uma queda de temperatura e pressão que faz com que a mesma sofra uma contração e volte se estabilizar. A partir desse momento, surge um envoltório ainda rico em hidrogênio que continua a converter hidrogênio em hélio e seu envelope mais exterior se expande, aumentando a luminosidade da estrela. 


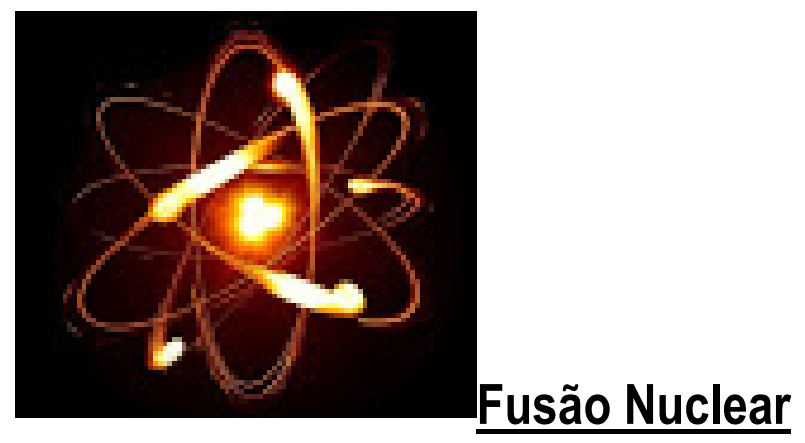

Fusão Nuclear é a união de núcleos atômicos, que formarão um núcleo maior. Na sequência principal, a estrela irá realizar fusão nuclear tranformando hidrogênio em hélio. 0 processo de fusão pode se dar por dois mecanismos, a cadeia próton-próton ( $p-p)$ e o ciclo CarbonoNitrogênio-Oxigênio (CNO). A cadeia p-p é a que atua no interior do Sol.

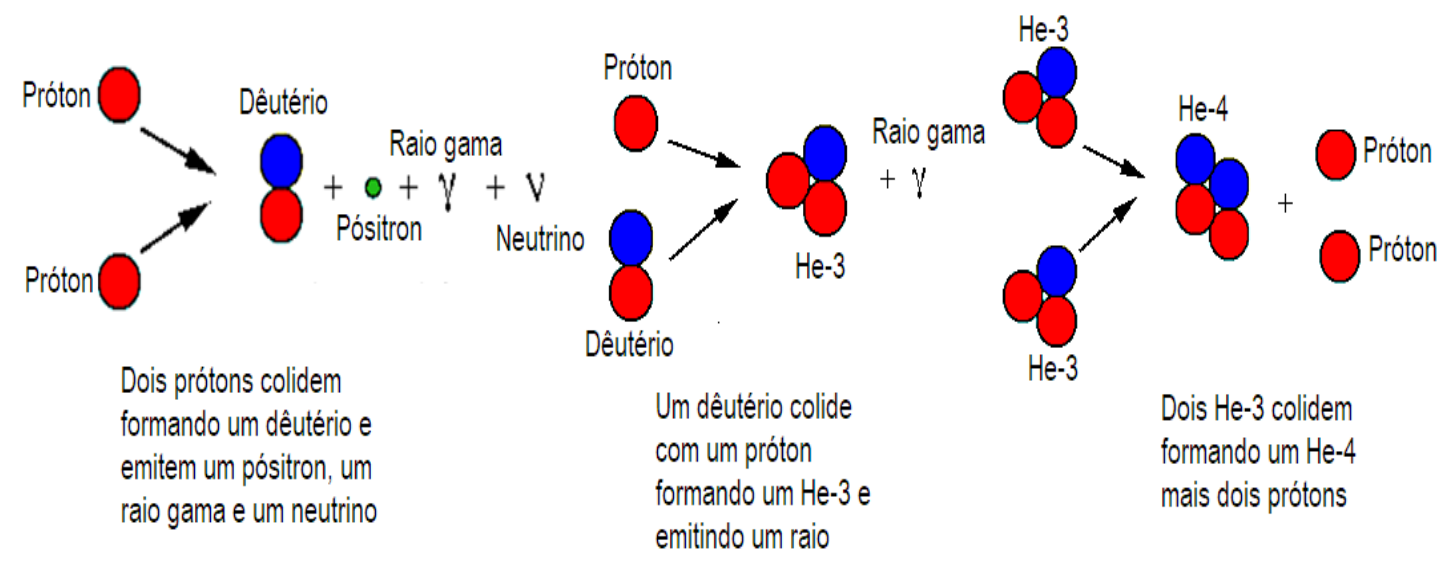


Ciclo Carbono-Nitrogênio-Oxigênio (CNO).

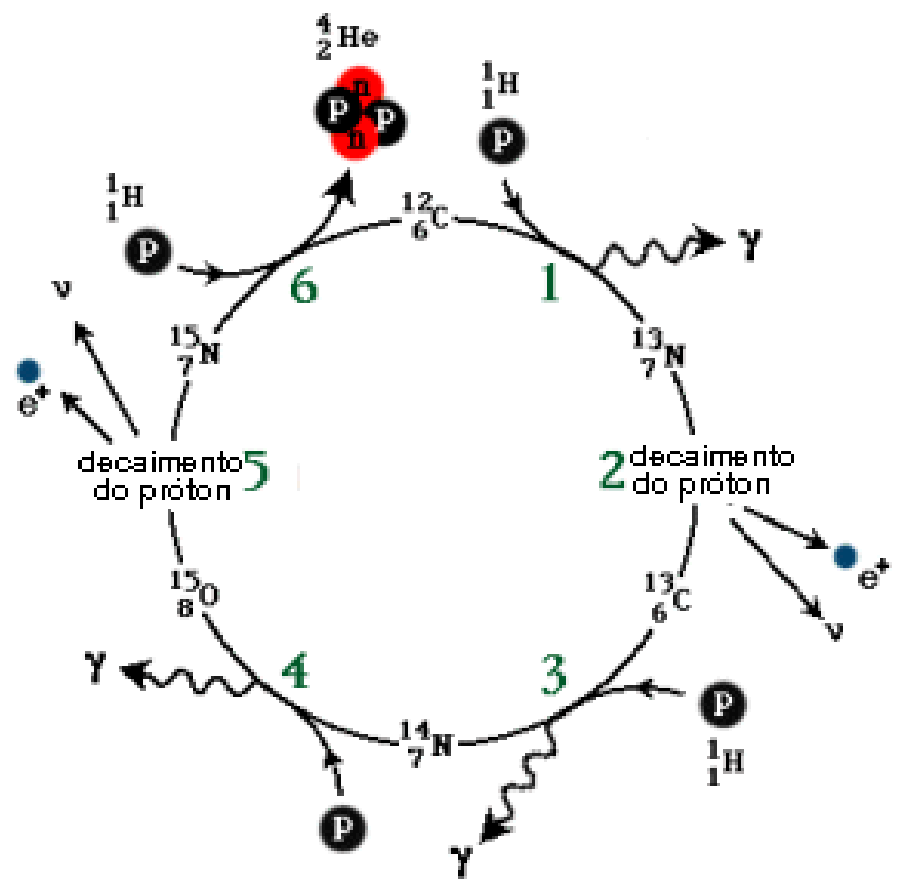

O ciclo CNO é mais eficiente em estrelas mais massivas que o Sol. Seu início é a fusão de um próton com um núcleo de carbono, o que gera raios gama e um núcleo de ${ }^{13} \mathrm{~N}$. O ${ }^{13} \mathrm{~N}$ é instável e decai em ${ }^{13} \mathrm{C}$ liberando um pósitron e um neutrino. $O$ pósitron encontrará um elétron e se destruirão gerando raios gama. $\mathrm{O}^{13} \mathrm{C}$ se funde com outro próton liberando ${ }^{14} \mathrm{~N}$ e raios gama. $\mathrm{O}^{14} \mathrm{~N}$ se funde com um próton liberando ${ }^{15} \mathrm{O}$ e raios gama. $\mathrm{O}{ }^{15} \mathrm{O}$ é instável e decai em ${ }^{15} \mathrm{~N}$ liberando um pósitron e um neutrino. $\mathrm{O}$ pósitron encontrará um elétron e se aniquilarão gerando raios gama. $0{ }^{15} \mathrm{~N}$ se funde com um próton formando o ${ }^{4} \mathrm{He}$ e ${ }^{12} \mathrm{C}$. E por fim, $0{ }^{12} \mathrm{C}$ dará início a um novo processo de fusão. 


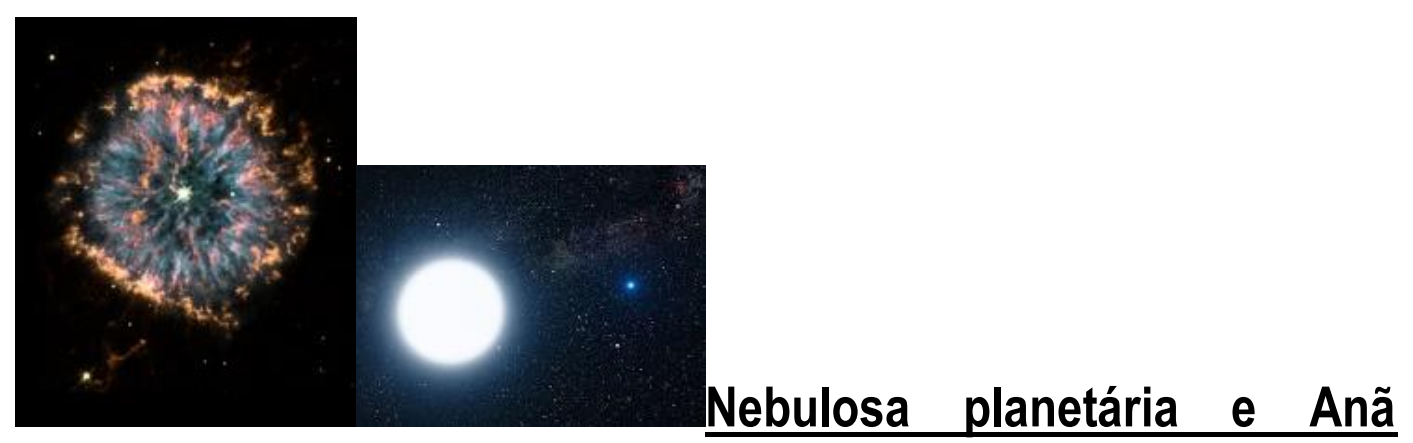

\section{Branca}

Estrelas de massa intermediária, (entre 0.8 a 8 massas solares), nos estágios avançados de sua evolução, sofrem oscilações violentas em seu envelope que não consegue manter e se destaca, gerando uma Nebulosa Planetária e deixando como resto uma anã branca. Esse será o tipo de fim do Sol. Essas estrelas são as principais contribuidoras ao Carbono e Nitrogênio do Universo.

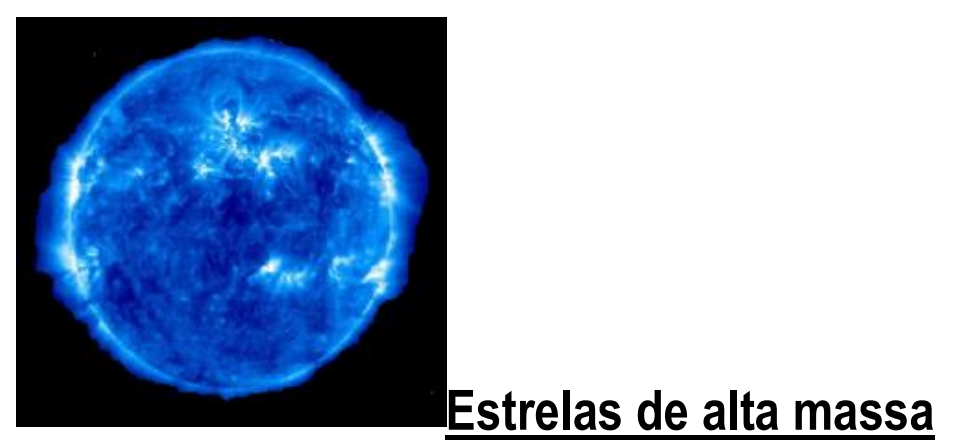

Uma estrela de alta massa (mais de 8 massas solares) termina sua vida como Supernova de tipo II, quando ejeta grandes quantidades de elementos como o Oxigênio, Neônio, Magnésio e Silício. Deixa como resto ou uma estrela de nêutrons ou um buraco negro. 


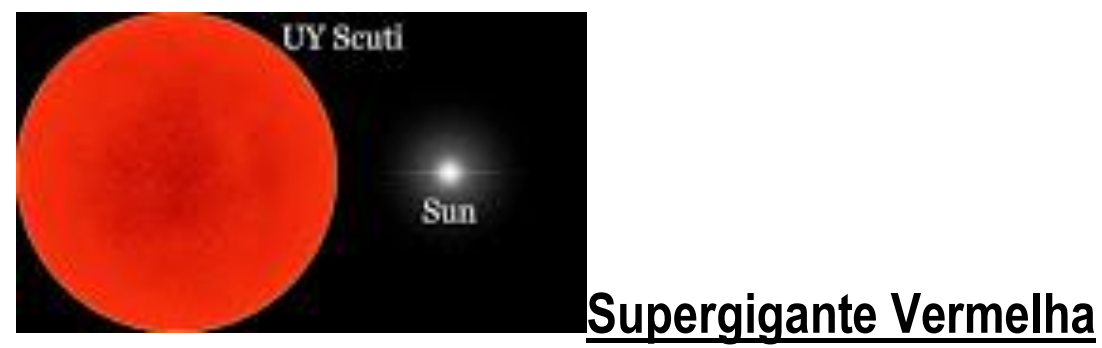

Se a estrela iniciar sua vida com massa entre 10 e 25 massas solares, após a sequência principal ela se tornará uma supergigante vermelha, ocorrerá uma explosão de supernova e deixará como resto uma Estrela de Nêutrons. Se a estrela iniciar sua vida com massa entre 25 e 100 massas solares, também passará pelo estágio de supergigante vermelha, ocorrerá uma explosão de supernova, mas no final o resto será um Buraco Negro.

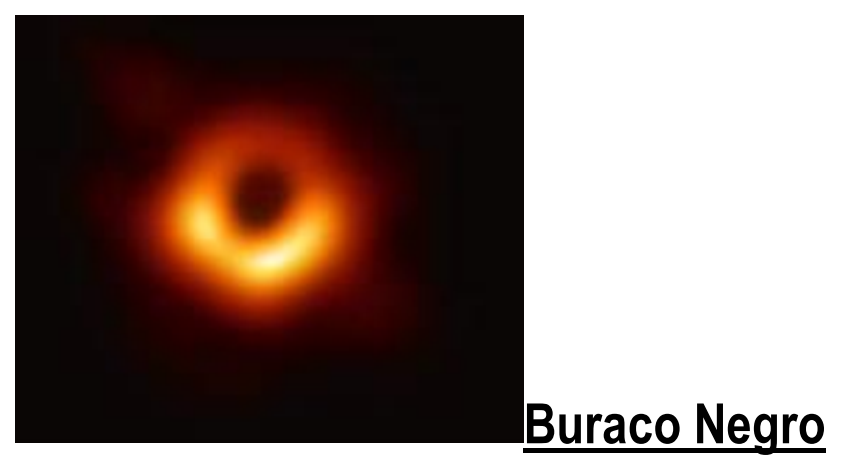

Buracos negros são concentrações de massas tão extremas que a força da gravidade é tão forte que nem a luz consegue escapar. A região que delimita o buraco negro é chamada de horizonte de eventos e sua dimensão é dada pelo Raio de Schwarzschild. 
No contexto astrofísico, existem dois tipos de buracos negros:

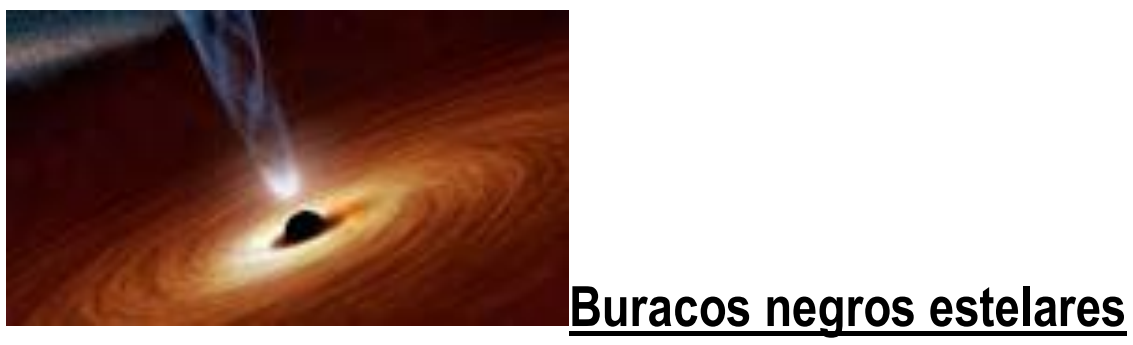

Os buracos negros estelares são o resultado da morte de uma estrela. Têm no máximo poucas dezenas de massas solares e são 0 resultado do final de uma estrela massiva, que explode em supernova.

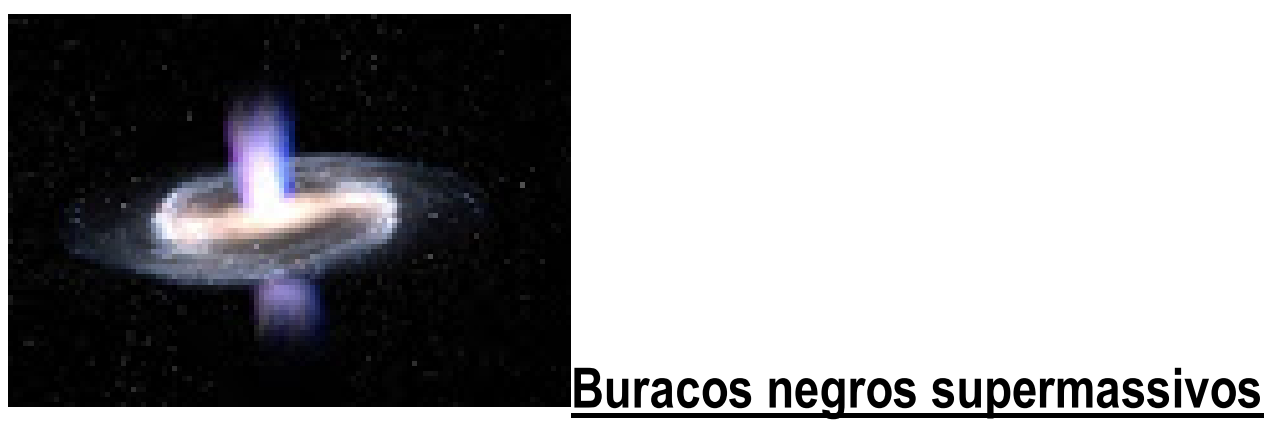

Buracos negros supermassivos são buracos negros com massas entre milhões e bilhões de massas solares que se localizam no centro de grandes galáxias. 


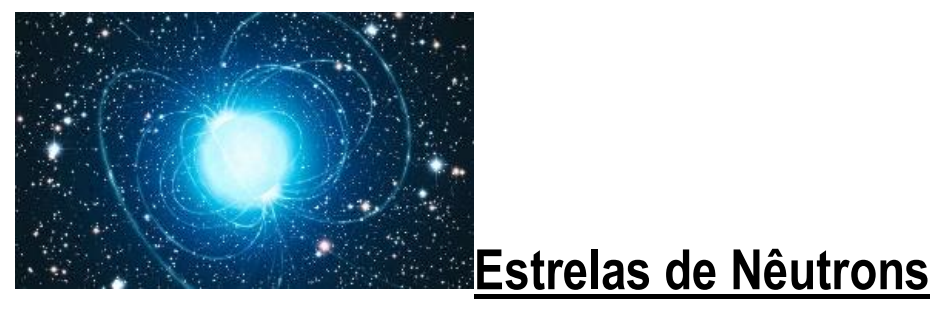

As estrelas de nêutrons são objetos extremamente densos, com densidade entre cerca de 1 bilhão e 10 bilhões de toneladas por centímetro cúbico. Elas são formadas quando estrelas massivas, com cerca de 10 a 25 vezes a massa do Sol, no final de sua vida explodem como supernova.

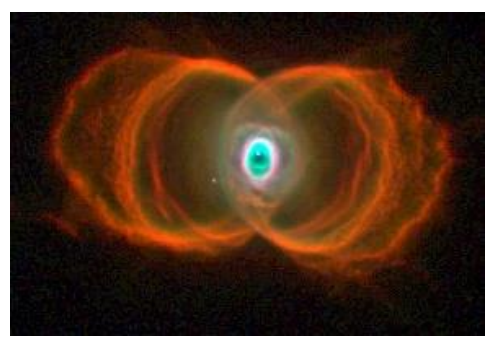

\section{Supernova tipo II}

Supernova tipo II, também conhecidas como supernovas de colapso do núcleo, são o resultado de uma violenta explosão de uma estrela massiva. A presença de hidrogênio, identificado através de seu espectro eletromagnético, é o que diferencia as supernovas tipo II de outras classes de supernova. Uma estrela deve ter pelo menos oito massas solares para que sofra este tipo de colapso. A estrela gera energia através da fusão nuclear de elementos químicos cada vez mais pesados até chegar ao ferro. Quando o ferro no núcleo chega a 1,38 massas solares acontece uma implosão, porque além do ferro as reações de fusão passam de exotérmicas para endotérmicas, o que sequestra energia, diminuindo a pressão que evitava o colapso gravitacional. 
O núcleo aquece e o colapso é interrompido, revertendo a implosão para uma explosão de supernova. As supernovas de tipo II deixam como resto ou uma estrela de nêutrons ou, se a massa da progenitora for acima de 25 massas solares, um buraco negro.

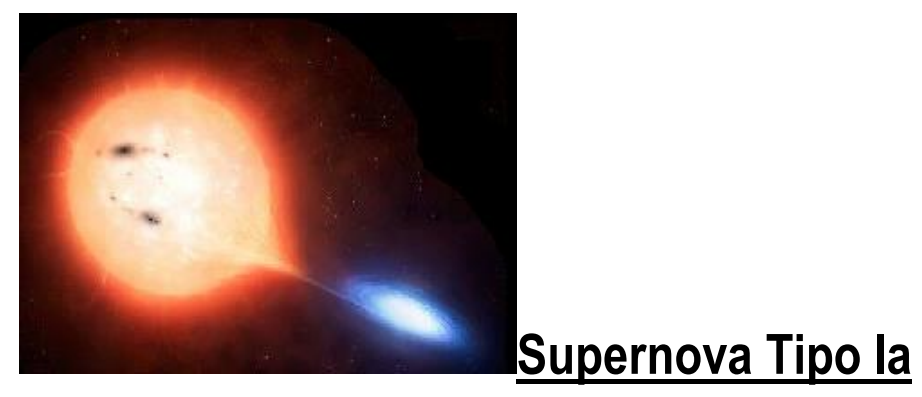

Esse tipo de supernova é originário de um sistema binário de estrelas, cada uma de massa intermediária (entre 0.8 que 8 massas solares) que, se estivessem isoladas, cada uma morreria como nebulosa planetária, deixando como resto uma anã branca. No sistema que produz uma supernova de tipo la, as coisas acontecem de um modo diferente.

A estrela mais massiva do par chega ao final da sua vida e deixa como produto uma anã branca. Após, a estrela menor deixa a sequência principal e se expande, tornando-se uma gigante vermelha. Se as duas estrelas estiverem próximas o suficiente, o envelope da estrela inicialmente menor preenche 0 lobo de Roche comum a ambas estrelas e a anã branca começa a capturar sua massa. 
A massa é transferida da companheira na fase de gigante vermelha até a anã branca formando um disco de acresção ao seu redor. A matéria capturada pode então sair sobre a anã branca que irá começar a aumentar de massa. Caso a anã branca ultrapasse o limite de Chandrasekhar (por volta de 1,4 massa solar), o que ocasionará um colapso da anã branca, produzindo uma explosão de supernova do tipo la. As supernovas de tipo la não deixam resto. Elas são as principais contribuidoras às abundâncias cósmicas dos elementos do grupo do ferro.

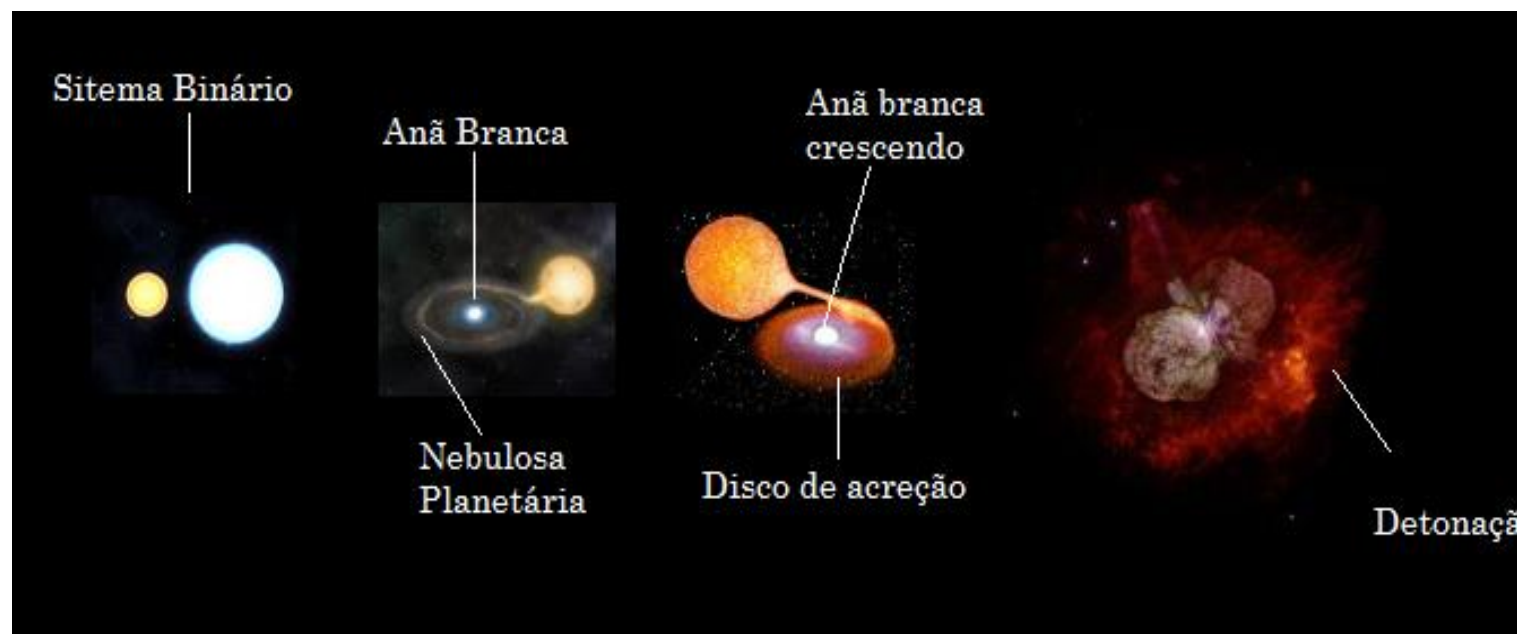




\section{Referências Bibliográficas}

\section{Sites:}

OBSERVATÓRIO NACIONAL. EAD Astrofísica Geral. 2013. Disponível em: http://www.on.br/ead_2013/

UNIVERSIDADE DE COIMBRA. A fonte de energia das estrelas-fusão e nucleossíntese. 2017. Disponível em:

http://fisica.uc.pt/fa/discs/wc.show_doc.php?id_disc=30\&id_turma=\&id_typ $=19 \&$ id_typdoc $=2 \& i d \_d o c=22331 \&$ anolect $=20092010$

UNIVERSIDADE FEDERAL DO RIO GRANDE DO SUL. Astronomia e Astrofísica. . Disponível em: http://astro.if.ufrgs.br/

UNIVERSIDADE DE SÃO PAULO. Astronomia ao Meio Dia. Disponível em: https://www.youtube.com/user/astro12h/videos

UNIVESPTV. Curso: Astronomia Geral 1. Disponível em:

https://www.youtube.com/watch?v=YF7D9IVsKcE\&list=PLxl8Can9yAHd7kUPviB Hxr-49QEI7PRXR\&index=26 


\section{Artigos e Livros:}

BRASIL. Ministério da Educação. PCN Ensino Médio + Orientações Educacionais Complementares aos Parâmetros Curriculares Nacionais.

Ciência da Natureza, Matemática e suas Tecnologias. Brasília: MEC/SEF,1998.

Disponível em: http://portal.mec.gov.br/seb/arquivos/pdf/CienciasNatureza.pdf

DAMINELI, A. STEINER, J. O Fascínio do Universo. São Paulo: Odysseus, 2010.

FIALHO, N. N. Os jogos pedagógicos como ferramentas de ensino. Congresso nacional de educação, 2008. Disponível em:

https://www.editorarealize.com.br/revistas/conedu/trabalhos/TRABALHO_EV073_ MD1_SA16_ID552_06092017182851.pdf

FOGAÇA, J. R. V. Elemento químico, Brasil Escola. 2020. Disponível em: http://brasilescola.uol.com.br/quimica/elemento-quimico.htm

MACIEL, W. J. Formação dos elementos. Revista USP, n. 62, p. 66-73, jun/ago 2004. Disponível em:

http://www.astro.iag.usp.br/ maciel/teaching/artigos/elementos/elementos.html 


\section{APÊNDICE B}

Questionário diagnóstico para professores

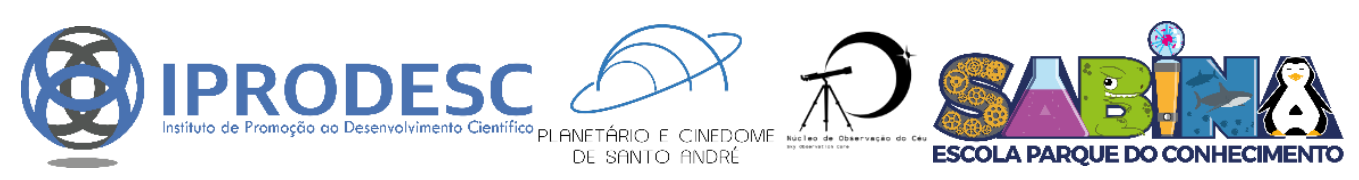

Prefeitura de

Santo André

\section{PLANETÁRIO JOHANNES KEPLER E NÚCLEO DE OBSERVAÇÃO DO CÉU}

\section{QUESTÕES:}

1. Você considera os jogos um método de aprendizagem?
( ) Sim
( ) Não

2. Alguma vez você utilizou jogos em sala de aula?
( ) Sim
( ) Não

Se sim em que ano (s) escolar (es)?

\begin{tabular}{|l|l|l|l|l|l|l|l|l|l|l|l|l|}
\hline ENSINO & \multicolumn{9}{|l|}{ FUNDAMENTAL } \\
\hline $\begin{array}{l}\text { ANO } \\
\text { ESCOLAR }\end{array}$ & $1^{\circ}$ & $2^{\circ}$ & $3^{\circ}$ & $4^{\circ}$ & $5^{\circ}$ & $6^{\circ}$ & $7^{\circ}$ & $8^{\circ}$ & $9^{\circ}$ & $1^{\circ}$ & $2^{\circ}$ & $3^{\circ}$ \\
\hline & & & & & & & & & & & & \\
\hline
\end{tabular}


3. O método foi satisfatório?

( ) Sim ( ) Não
( ) Não apliquei nenhum jogo

4. Você teve alguma dificuldade em aplicar o jogo?

( ) Sim ( ) Não

( ) Não apliquei nenhum jogo

Qual (is)?

5. Aplicaria novamente o jogo como ferramenta didática?

( ) Sim ( ) Não

( ) Não apliquei nenhum jogo

Página 145 de 147

SABINA ESCOLA PARQUE DO CONHECIMENTO

PLANETÁRIO E CINEDOME DE SANTO ANDRÉ - JOHANNES KEPLER

NÚCLEO DE OBSERVAÇÃO DO CÉU - NOC

Travessa Juquiá, s/no. Vila Eldízia. Santo André - SP/BRASIL

Nova entrada pelo Parque Central: R. José Bonifácio, s/no. Vila Assunção.

Santo André - SP/BRASIL 
Fone: (11) 4422-2000

\section{APÊNDICE C}

Questionário diagnóstico para alunos do $9^{\circ}$ ano do fundamental e $1^{\circ}$ ano do ensino médio

\section{Questionário diagnóstico (Pré jogo)}

Data:

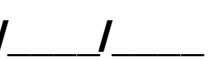

1. O que é astronomia?
(a) Estudo do zodíaco
(b) Estudos dos astros
(c) Estudos dos astronautas

2. Onde surgiu a maioria dos elementos químicos?
(a) Tabela periódica
(b) Laboratório
(c) Morte de estrelas

3. O que é uma Nebulosa?
(a) Gás e poeira suja
(b) Nuvem de matéria interestelar
(c) Nuvem de fumaça preta

4. Você já teve aula com jogos?

( ) Sim, qual ano escolar?

( ) Não.

( ) Não lembro

5. O que você acha de jogos como meio de aprendizado?

( ) Legal, consigo aprender jogando.

( ) Ruim, não consigo aprender jogando.

( ) Não sei, nunca joguei na aula. 
Questionário diagnóstico para alunos do $9^{\circ}$ ano do fundamental e $1^{\circ}$ ano do ensino médio

\section{Questionário diagnóstico (Pós jogo)}

Data:

1. O que é astronomia?

(d) Estudo do zodíaco

(e) Estudos dos astros

(f) Estudos dos astronautas

2. Onde surgiu a maioria dos elementos químicos?

(d) Tabela periódica

(e) Laboratório

(f) Morte de estrelas

3. O que é uma Nebulosa?

(d) Gás e poeira suja

(e) Nuvem de matéria interestelar

(f) Nuvem de fumaça preta

4. Você gostou do jogo "De Onde Eu Vim"?

( ) Sim.

( ) Não.

( ) Não sei.

5. O que você achou do jogo como meio de aprendizado?

( ) Gostei, consegui aprender jogando.

( ) Não gostei, não consegui aprender jogando.

( ) Não sei.

6. Em uma breve frase me conte o que você aprendeu. 
Alunos aprendendo com o Jogo "De Onde Eu Vim?
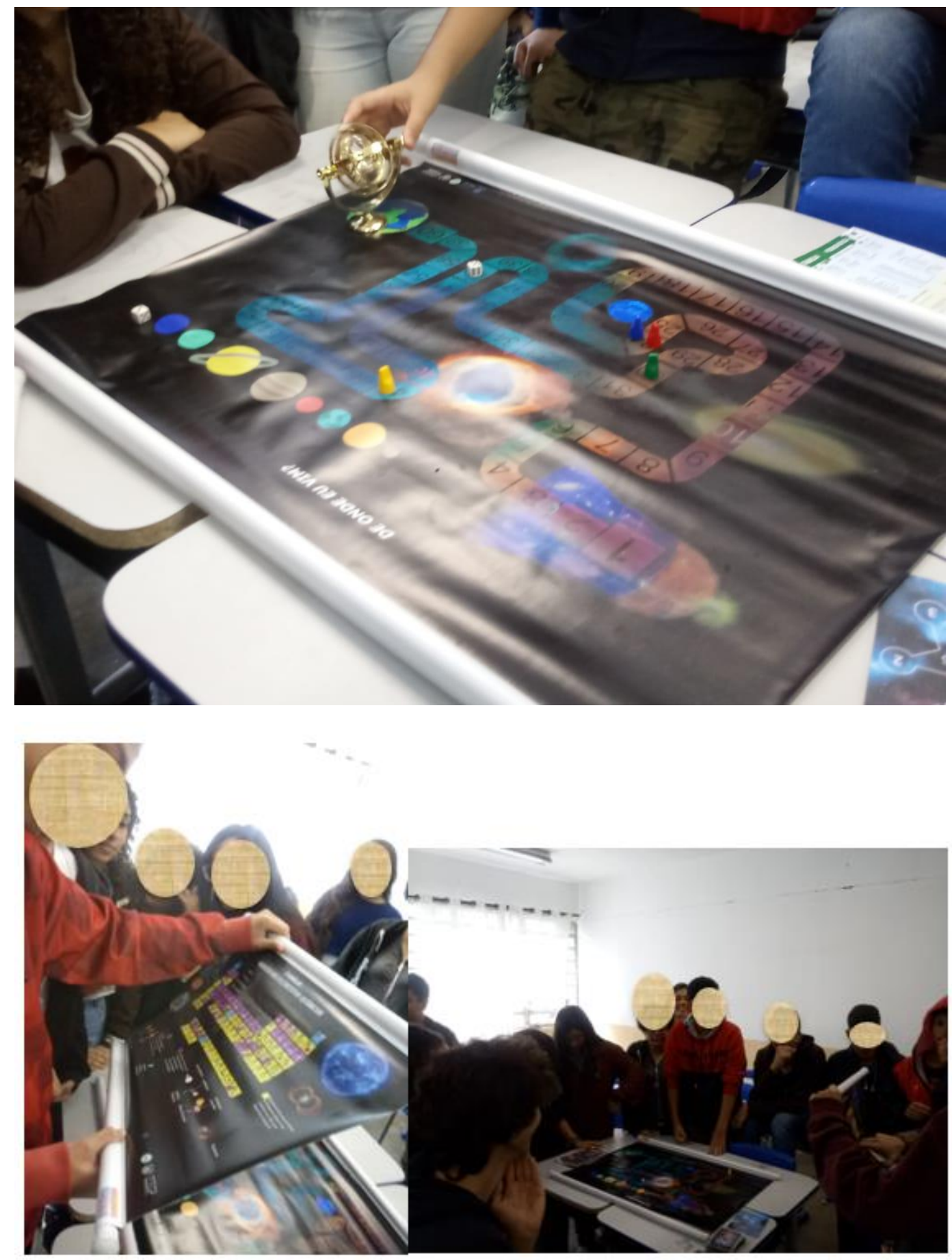

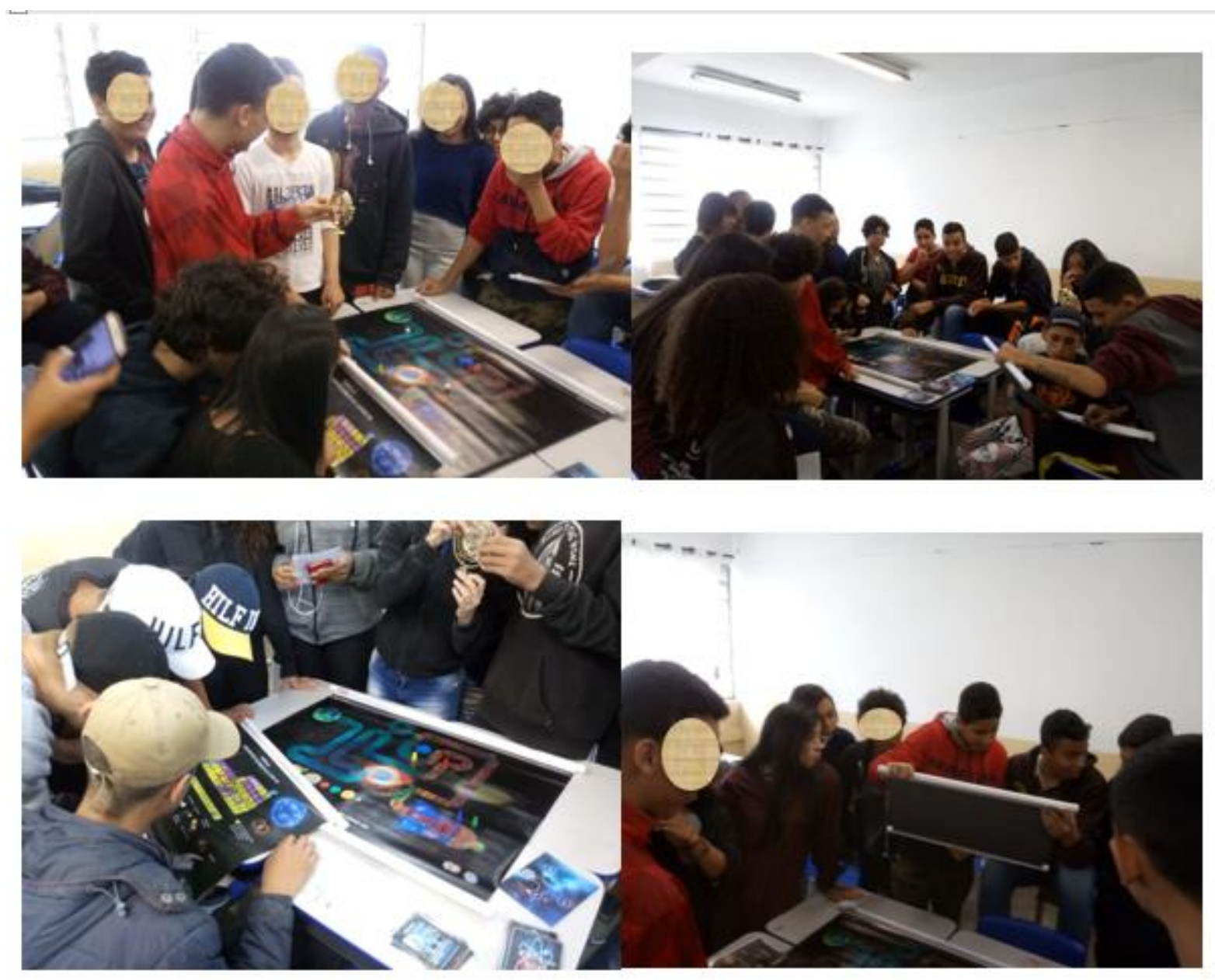